A Journal on Research

in Vascular Diseases

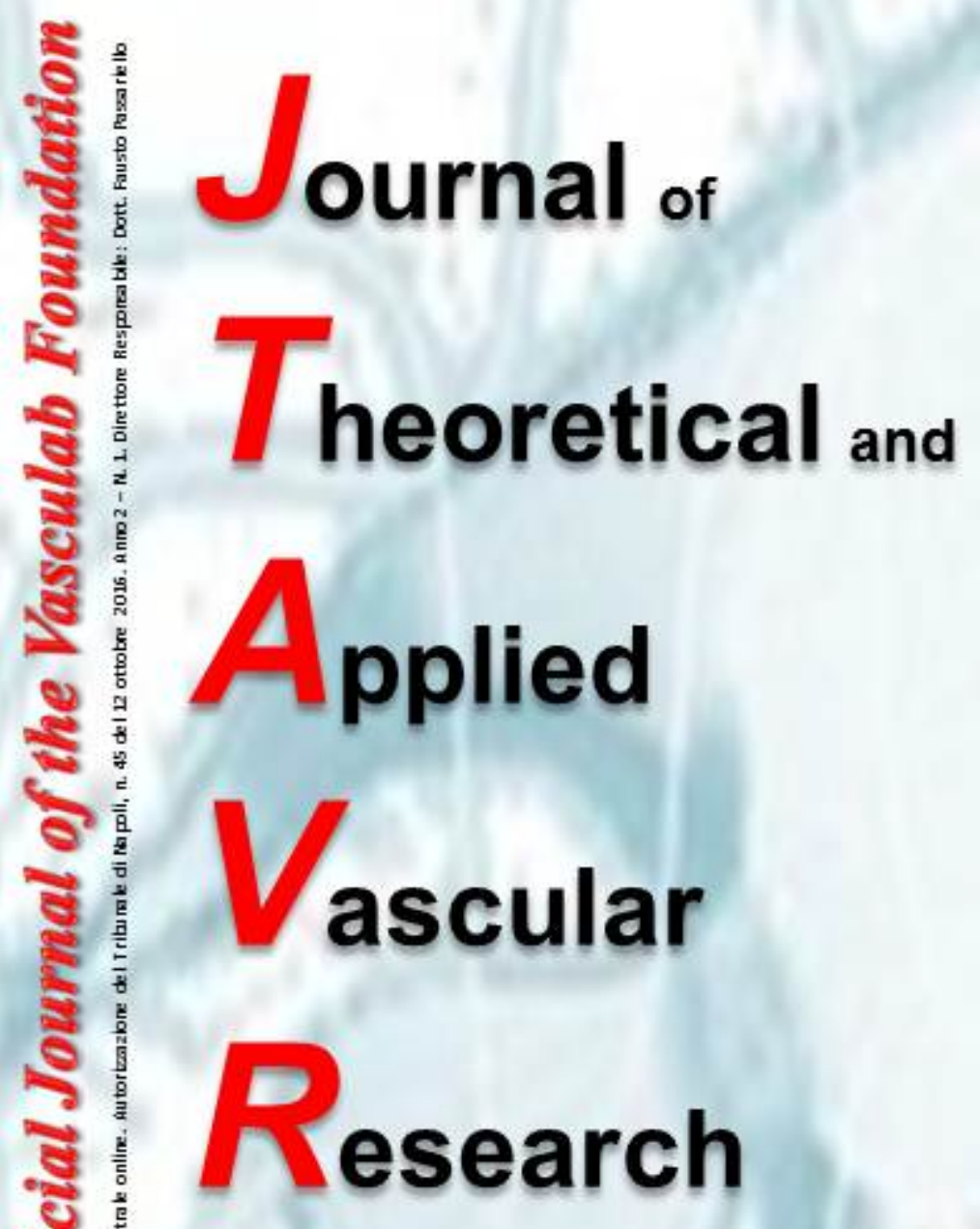

Fondazione Vasculab 
Fondazione Vasculab impresa sociale ontus

\section{www.vasculab.eu}

\section{DONA IL TUO 5 PER MILLE}

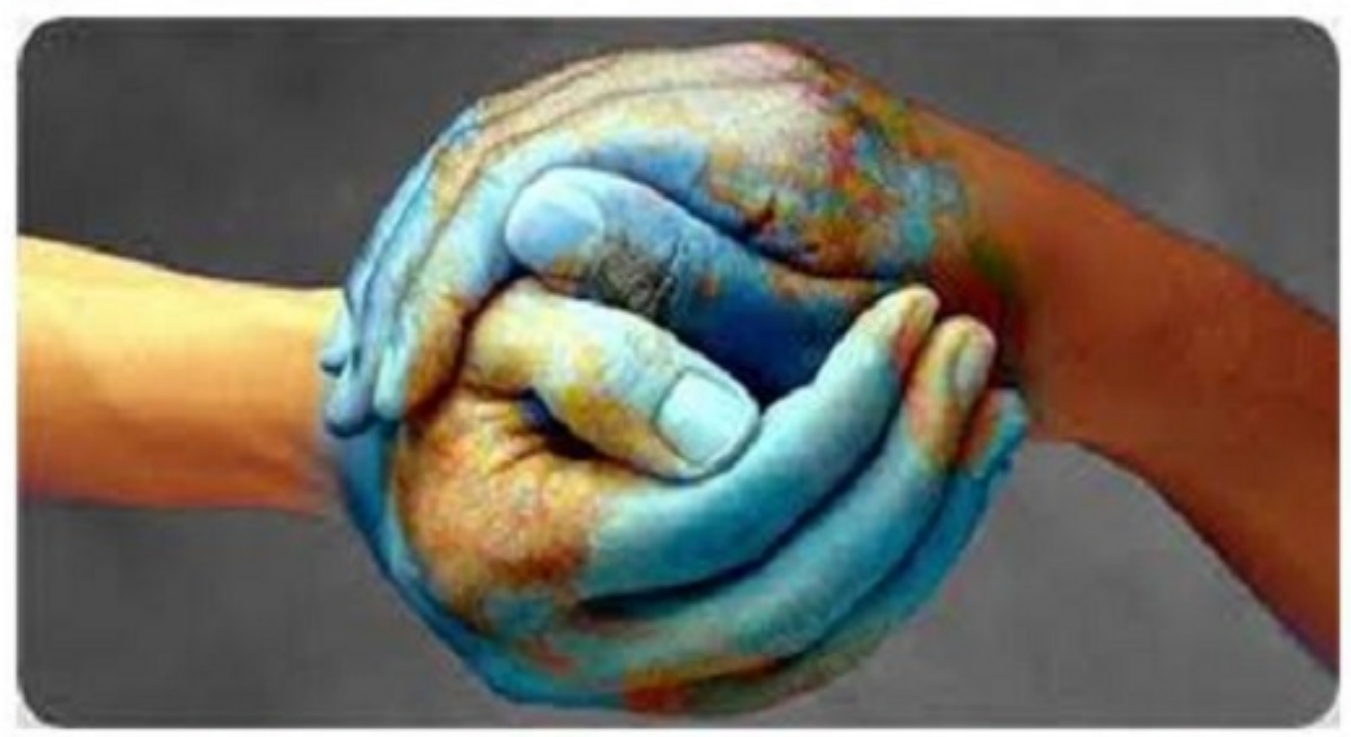

Sostieni le iniziative della Fondazione Vasculab ONLUS

- Ricerca scientifica e divulgazione in Medicina

- Metodi alternativi alla sperimentazione animale

- Missioni mediche umanitarie all'estero

Inserisci il Codice Fiscale della Fondazione

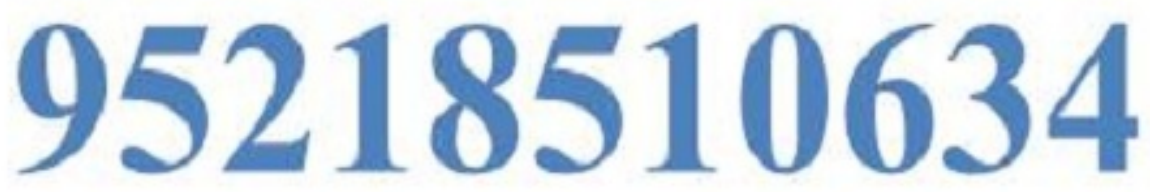

nella dichiarazione dei redditi (Unico o 730)

nella sezione del 5 per mille

Fondazione Vasculab impresa sociale (ONLUS)

Email fondazione@vasculab.it

tel/fax: +390817144110 cell +393356250756

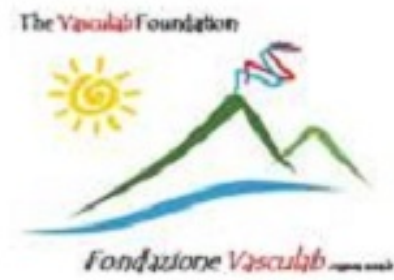




\section{N. 03-2017 Nov, year 2}

\section{Journal of Theoretical and Applied Vascular Research}

Online ISSN 2532-0831 DOI: 10.24019/issn.2532-0831

A Journal on Research in Vascular Diseases, published three times a year

The Official Journal of the Vasculab Foundation

\section{Editor-in-Chief}

Fausto Passariello

\section{Editorial Board}

Editor Biology and Medicine

Fausto Passariello

Giovanni Agus, Francesco Albergati, Claudio Allegra, Pier Luigi Antignani, Malika Boucelma, Alberto Caggiati, Massimo Cappelli, Mariella Catalano, Domenico Corda, Stefano Ermini, Andrea Fontanella, Claude Franceschi, Giorgio Guarnera, Arkadiusz Jawien, Mark Malouf, Ferdinando Mannello, Sandro Michelini, Waldemar Lech Olszewski, Fausto Passariello, Malay Patel, Neil Piller, Angelo Scuderi, Massimo Vaghi, Carolina Weller

Editor Basic Sciences, History and Philosophy of Science

Alessandra Passariello

\section{Editorial office, imagine and communication}

Iolanda Palma - jtavr@vasculab.eu

\section{Operative Executive Board}

Iolanda Palma, Alessandra Passariello, Fausto Passariello

\section{Web Authoring}

HTML, XML, XSLT, XSL-FO, Javascript, PHP, MySql, LATEX programming by Fausto Passariello

\section{Online editing, graphics and advertisement, marketing}

Aquarius s.r.1.

\section{Cover}

"VNet cover", digital image by Fausto Passariello, editing by Iolanda Palma.

Editor

Fondazione Vasculab impresa sociale ONLUS, Via Francesco Cilea, 280 - 80127 Napoli - Tel/Fax +39 0817144110 jtavr@vasculab.eu - www.vasculab.eu/jtavr.xml

Pubblicazione quadrimestrale online. Autorizzazione del Tribunale di Napoli, n. 45 del 12 ottobre 2016. Anno 2 - N. 2.

Direttore responsabile: Dott. Fausto Passariello 


\section{Vascular News}

(C) 2017 Fondazione Vasculab impresa sociale ONLUS. All rights reserved.

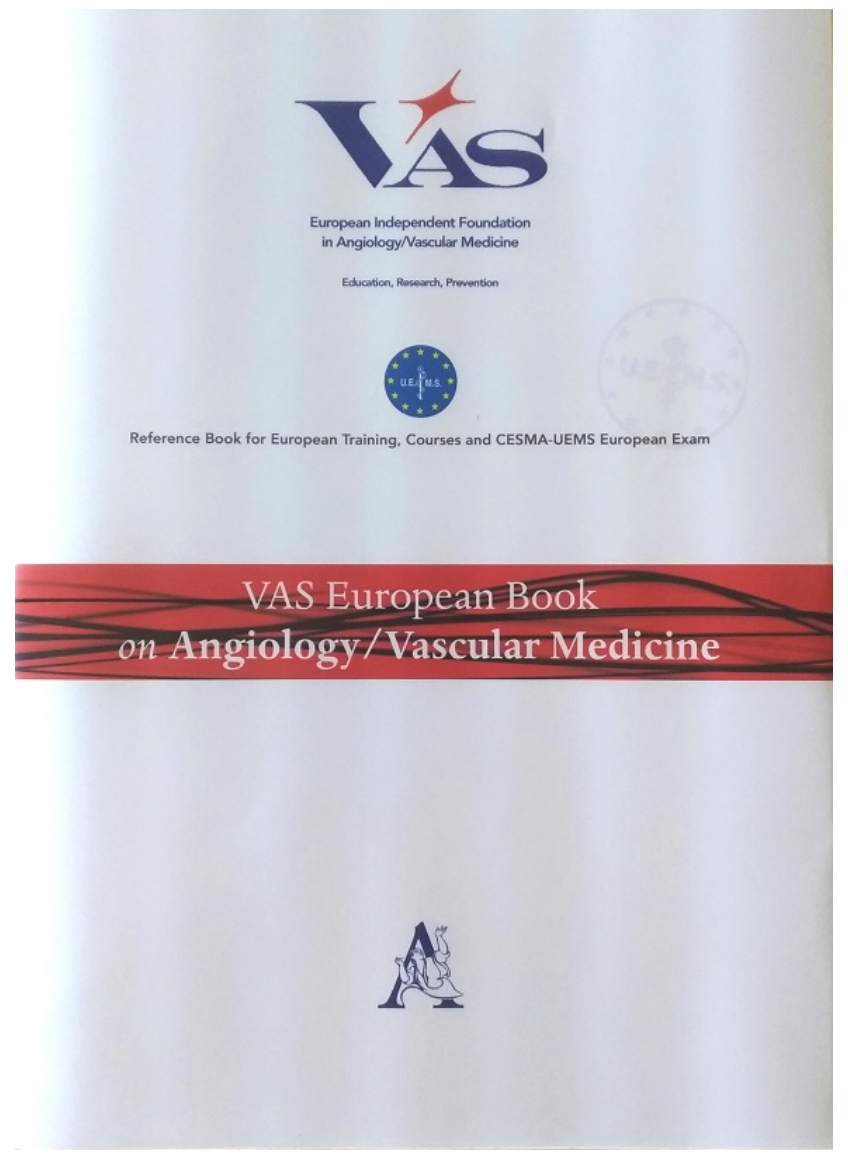

VAS European Book

VAS European Book on Angiology/Vascular Medicine is a relevant educational tool:

- $\quad$ European harmonization of training, quality and health offer

- Development of Vascular Medicine/ Angiology

- An updated training instrument

- Everyday help in medical practice

- $\quad$ Stimulus for research

- Reinforcing active European collaboration.
The Book helps and strengthens the joint efforts for Certification/Accreditation by VAS and UEMS Division of Angiology/Vascular Medicine:

\section{For Centres}

- $\quad$ UEMS Accreditation as European Training Centres

- VAS Recognition as VAS Regional

Reference Center or VAS Regional

Cooperative Center

\section{For individual Specialists}

- UEMS European Diploma (CESMA-

UEMS European Exam)

- $\quad$ European Fellowship of Excellence (EFE-

VAS)

- $\quad$ European Training Fellowship (ETF-VAS)

\section{It is the recognised Textbook for}

- $\quad$ Academic and EACCME Credited Courses ( European Master, European Postgraduate Course, Courses on sub-specialistic topics)

- $\quad$ CESMA-UEMS European Exam in Angiology/Vascular Medicine (EBEAVM)

\section{Editors}

Mariella Catalano (IT), Zsolt Pecsvarady(HU), JeanClaude Wautrecht (BE), Dan Mircea Olinic (RO), Grigoris T. Gerotziafas(FR), Francesco Boccardo (IT), BeatriceAmann-Vesti (CH), Debora Karetova (CZ),Bengt Fagrell (SE), Curt Diehm (DE), MatijaKozak (SL), Michael E. Edmonds (UK).

www.vas-int.net 
The Journal of Theoretical and Applied Vascular Research (JTAVR) publishes scientific papers on vascular diseases, biological research, history and philosophy of science.

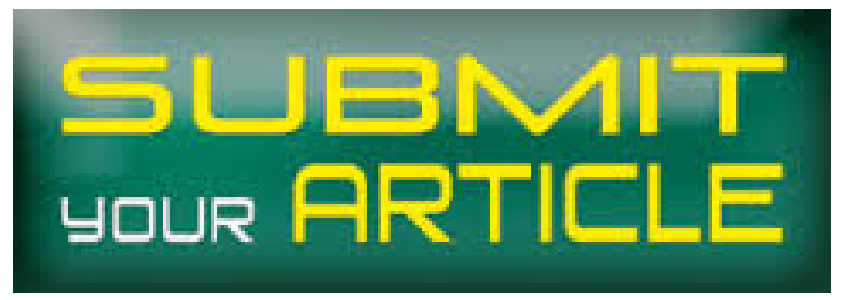

Manuscripts are expected to comply with the instructions to authors which conform to the Uniform Requirements for Manuscripts Submitted to Biomedical Editors by the International Committee of Medical Journal Editors (www.icmje.org/).

\section{Submission of manuscripts}

Papers should be submitted directly online to the Editorial Office at the Fondazione Vasculab ONLUS website: www.vasculab.eu/jtavr/submissions.htm

The journal adheres to the principles of the Helsinki Declaration (http://history.nih.gov/research/downloads/ helsinki.pdf) about research concerning human beings and to the International Guiding Principles for Biomedical Research Involving Animals (http://cioms.ch/publications/ guidelines/1985_texts_of_guidelines.htm) recommended by the WHO. In addition, the journal strongly supports alternative non-animal experiments, in order to Replace, Reduce and Refine (3Rs) animal experimental designs.

For complete information about publication terms please contact the Editorial Office of JTAVR, Fondazione Vasculab impresa sociale ONLUS, via Francesco Cilea 280 Italy - Phone +39-081-7144110 - E-mail: jtavr@vasculab.eu.

\section{Open Access Publication}

All manuscripts submitted to JTAVR are assumed to be submitted under the Open Access publishing model. In this publishing model, papers are peer-reviewed in the normal way under editorial control. Submission and reviewing process are not charged. When a paper is accepted for publication the author is issued with an invoice for payment of a publication processing fee (see www.vasculab.eu/ jtavr.xml). Payment of this charge allows JTAVR to recover its editorial and production costs and create a pool of funds that can be used to provide fee waivers for selected authors, for instance for invited authors, authors of papers on history and philosophy of science and for authors from lesser developed countries (see below).

\section{Free download}

Published papers appear electronically and are freely available from our website. Authors may also use their published .pdf's for any non-commercial use on their personal or non-commercial institution's website.

\section{Commercial use}

No articles from the JTAVR website may be reproduced, in any media or format, or linked to for any commercial purpose (eg. product support, etc) without the prior written consent of JTAVR and payment to JTAVR of an appropriate fee.

\section{Publication fees}

Initial publications of JTAVR (up to presumably one year) are free of charge for invited Authors and for the members or supporters of the Vasculab Foundation. For the Vasculab Foundation membership see www.vasculab.eu.

\section{Article types}

Editorials, original articles, review articles, systematic reviews and meta-analyses, randomised controlled trials, research protocols, original case reports, case series, therapeutical notes, clinical images, clinical videos, letters to the Editor, guidelines, special articles (like history and philosophy of science), invited sessions, reprints of historical papers of actual interest.

In order to submit an article online, follow the step by step instructions at www.vasculab.eu/jtavr/submissions.htm

\section{Preparation of manuscripts}

\section{Footnotes or endnotes}

JTAVR does not encourage the use of footnotes. Generally, they are not used in medical journals, but they are tolerated, especially in articles in the field of history and philosophy. Footnotes or endnotes must be quoted in Low Caps Romans in rectangular brackets (example: [iv] and cited as ${ }^{[i v]}$.

\section{References}

- Only cited references can be included in the bibliography. They must be numbered in Arabic numerals, in the exact sequence as they are firstly cited (example: "1)").

- Bibliographical entries in the text should be quoted using superscripted Arabic numerals (cited as ${ }^{1}$ ).

- References must be set out in the standard format approved by the International Committee of Medical Journal Editors (ICMJE), as described in the document Recommendations for the Conduct, Reporting, Editing, and Publication of Scholarly work in Medical Journals http://www.icmje.org/icmje-recommendations.pdf.

A simplified but comprehensive list is given in www.nlm.nih.gov/bsd/uniform requirements.html.

\section{Citation examples}

\section{Standard journal article}

List the first six authors followed by et al.

Halpern SD, Ubel PA, Caplan AL. Solid-organ transplantation in HIVinfected patients. N Engl J Med. 2002 Jul 25;347(4):284-7.

As an option, if a journal carries continuous pagination throughout a volume (as many medical journals do) the month and issue number may be omitted. 
Halpern SD, Ubel PA, Caplan AL. Solid-organ transplantation in HIVinfected patients. N Engl J Med. 2002;347:284-7.

\section{Books and Monographs}

Author(s) and editor(s)

Breedlove GK, Schorfheide AM. Adolescent pregnancy. 2nd ed. Wieczore RR, editor. White Plains (NY): March of Dimes Education Services; 2001.

\section{Chapter in a book}

Meltzer PS, Kallioniemi A, Trent JM. Chromosome alterations in huma solid tumors. In: Vogelstein B, Kinzler KW, editors. The genetic basis of human cancer. New York: McGraw-Hill; 2002. p. 93-113.

\section{Electronic materials}

\section{Homepage/Web site}

Cancer-Pain.org [Internet]. New York: Association of Cancer Online Resources, Inc.; c2000-01 [updated 2002 May 16; cited 2002 Jul 9]. Available from: http://www.cancer-pain.org/.

\section{Vasculab mailing list}

Provided you know the number '\#' of the message, the format of the citation here follows, where the date of the last access is required (following the Vancouver style) and the symbol '\#' must be replaced with the effective number of the message:

Author(s) name(s). Vasculab Yahoo Groups. The Vascular List. Message '\#'. https://it.groups.yahoo.com/neo/groups/vasculab/conversations/ messages/\# Accessed on line on 'date of last access'. A (free) subscription to Vasculab is required.

\section{Historical monographs}

The format will be specified in next future.

\section{File of tables}

Each table should be submitted as a separate file. Formats accepted are doc and .rtf. Each table must be numbered in Roman numerals and accompanied by the relevant title. Notes should be inserted at the foot of the table and not in the title. Tables should be referenced in the text sequentially.

\section{File of figures}

Each figure should be submitted as a separate file. Formats accepted: JPEG set at 300 dpi resolution preferred; other formats accepted are TIFF and PNG. Figure should be numbered in Arabic numerals and accompanied by the relevant title. Figures should be referenced in the text sequentially.

Histological photographs should always be accompanied by the magnification ratio and the staining method.

\section{Color illustrations}

Open Access papers appear electronically. As no printed issues of JTAVR are produced there are $\mathrm{NO}$ additional charges for color illustrations.

However consider that many people will print them in black and white. Thus for a better result in communicating your data, test also the black and white printing when choosing colors. 


\section{Chronic venous disorders: from macrocirculation to microcirculation}

\section{PL Antignani ${ }^{1}$}

${ }^{1}$ Director, Vascular Center, Nuova Villa Claudia, Rome, Italy

submitted: Jun 25, 2018, accepted: Jun 25, 2018, EPub Ahead of Print: Jun 26, 2018, published: Jun 30, 2018 Conflict of interest: None

DOI: 10.24019/jtavr.49 - Corresponding author: Prof. Pier Luigi Antignani, antignanipl@ gmail.com

C 2017 Fondazione Vasculab impresa sociale ONLUS. All rights reserved.

Recent findings suggest that inflammatory processes are involved in the structural remodelling in venous valves and in the vein wall, leading to valve incompetence and the development of varicose veins. This has been shown by several authors who found infiltration of valve leaflets and the venous wall by leukocytes (monocytes and tissue macrophages) in all valve specimens from patients with chronic venous disease (CVD) and in none from controls ${ }^{1,2}$.

Vein wall remodelling is likely to involve the complex interplay of a range of factors, including an altered ratio between metalloproteinases (MMPs), particularly MMP9, and their tissue inhibitors (TIMPs), and elevated levels of cytokines and growth factors favour an alteration of the extracellular matrix. Neutrophils and mast cells and their interaction with the venous endothelium are believed to play an important role in the initiation of the inflammatory response in $\mathrm{CVD}^{3,4}$.

The transmission of high venous pressures to the dermal microcirculation results in the stimulation of an inflammatory process in which cytokine and growth factor release leads to leukocyte migration into the interstitium and the initiation of further inflammatory events. This process is associated with the intense dermal fibrosis and tissue remodelling seen in chronic venous insufficiency ${ }^{5}$.

The many manifestations of the disease are frequently associated with symptoms usually ascribed to CVD. The proportion of patients with symptoms increases with increasing CEAP clinical classes, but the mechanisms underlying symptom appearance have not been elucidated. It has been postulated that it is related to the inflammatory cascade of events seen at all stages of CVD and in which the leukocyte and its interaction with the endothelium play a key role. It is increasingly believed that the emerging twin themes of disturbed venous flow patterns and chronic inflammation underlie and link all the manifestations of the disease $^{6}$.

A potentially confusing aspect in clinical practice which still needs to be clarified concerns the patient's perception of symptoms (such as heaviness and pain) which according to some studies, could be confined to the superficial venous circulation, where it is estimated that over $90 \%$ of the $\mathrm{C}$ nociceptive fibers of the entire venous system is concentrated ${ }^{6}$.

Some genetic, environmental and behavioral risk factors (family history, seasonality and orthostatism) cause an increase in hydrostatic pressure, leading to valve dysfunction and the resulting venous reflux.

The increase in venous pressure also increases the tension of the endothelial wall, which stimulates the production and activity of MMPs. Increased venous pressure also causes loss of endoluminal glycosaminoglycans (GAGs glycocalyx), endothelial cell lesions, resulting in increased vascular permeability, leukocyte infiltration and increased adhesion molecules (ICAM-1, VCAM-1, L- selectin, P-selectin) inflammatory cytokines and reactive oxygen species (ROS) with the end result of a further increase in MMPs ${ }^{7,8}$.

Venous wall distension may also result in the increase of other MMPs inducers, such as EMMPRIN (extracellular matrix metalloproteinase inducer), hormones and NGAL (neutrophil gelatinase-associated lipocalin $)^{4}$. High levels 
of MMPs activate specific protease receptors on endothelial cells, leading to a reduced endothelial production of Nitric Oxide (NO), which inhibits VSM contraction and stimulates venous dilatation. MMPs also stimulate endothelial cells to produce EDHF (the hyperpolarizing factor of endothelial derivation), which hyperpolarizes cell membranes, with further loss of VSM's contractile function and the consequent amplification of the venous relaxation. The activity of the MMPs further supports venous dilatation through the release of growth factors (such as TGF beta, VGF, FGF), which stimulate VSM hypertrophy. The hyperactivity of the MMPs finally degrades the ECM, triggering a mechanism of migration of the SMC, with further dilation of the venous wall and the consequent establishment of varicose veins ${ }^{3,4}$.

Increase in MMPs can also cause hyperpolarization and relaxation of the smooth muscle cells (VSM) and ECM degradation, leading to dilatation of the venous wall, valve dysfunction and to the progressive increase of venous hydrostatic pressure, thus establishing, an actual vicious circle of hemodynamic and inflammatory self-feeding. The formation of varicose veins and their tortuosity is also favored by the action of MMPs, which degrade the extracellular matrix in particular in the atrophic regions ${ }^{5-8}$.

The structure and function of the venous wall are regulated by a series of metabolic activities involving ions, molecules and enzymes. Matrix metalloproteinases (MMPs) are Zinc (Zn) dependent endopeptidases, widely known for their ability to degrade various extracellular matrix (ECM) proteins. For this reason, MMPs play a central role in remodelling the venous tissue, degrading various components of the matrix.

MMPs can interact with bioactive molecules on the cell membrane and regulate cellular receptors and signaling, influencing cell proliferation, migration and differentiation, thus being directly involved also in cell apoptosis, immune response, tissue repair and in angiogenesis 6,7 .

\section{References}

1) Saharay M, Shields DA, Porter JB, Scurr JH, Coleridge-Smith PD. Leucocyte activity in the microcirculation in patients with chronic venous disease. J Vasc Surg 1997;26:265-273.

2) Antignani PL. News in inflammatory and microcirculatory mechanisms in venous ulcers. Allegra C, Antignani PL, Kalodiki E, editors. In: News in Phlebology. Minerva Medica. 2013; 211-214.

3) Kucukguven A, Khalil RA. Matrix metalloproteinases as potential targets in the venous dilation associated with varicose veins. Curr Drug Targets. 2013;14(3):287-324.

4) Chen Y, Peng W, Raffetto JD, Khalil RA. Matrix Metalloproteinases in Remodeling of Lower Extremity Veins and Chronic Venous Disease. Prog Mol Biol Transl Sci. 2017;147:267-299.
The venous smooth muscle cells (SMC) appear disorganized in the media and the adjacent intima tunica, with abundant unstructured and undefined material. Furthermore, collagen fibers appear disorganized, making it difficult to distinguish the media tunica from the external one, and the elastic fibers appear thick and fragmented. The VV show an imbalance in the ECM protein components mainly due to changes in the collagen and/or elastin content in the venous walls. Experiments on SMC in VV culture and fibroblasts cultured from patients with CVD showed an increase in the synthesis of type I collagen and a decrease in the synthesis of type III collagen. Type III collagen is a critical factor in determining the elasticity and distensibility of blood vessels and the alterations in the collagen synthesis and the type I / type III relationship could cause alterations in the integrity of the venous wall, resulting in structural weakness, dilatation and formation of $\mathrm{VVs}^{5,6}$.

This pathological process can be physiologically counterbalanced by a compensatory anti-inflammatory response system which involves prostaglandins and their receptors leading to decreased MMPs and therefore to an accumulation of ECM, particularly in the hypertrophic regions of varicose veins ${ }^{6}$.

Among the many pathophysiologic mechanisms at work, the leukocyte-endothelium interactions seem to be important in many aspects of the disease and have been identified as a possible target for pharmacologic intervention. Pharmacologic agents that could attenuate various elements of the inflammatory cascade and inhibit the inflammatory process might offer a greater opportunity to prevent future morbidity 6,7 . It seems reasonable to speculate that such treatment could reduce the risk of CVD progression if applied as soon as the first symptoms appear.

\section{Pier Luigi Antignani}

Rome

5) Shoab SS, Scurr JH, Coleridge-Smith PD. Increased plasma vascular endothelial growth factor among patients with chronic venous disease. J Vasc Surg 1998;28:535-540.

6) Antignani PL. Medical Treatment of Chronic Venous Disease. SM J Pharmac Ther. 2017;3(1):1015.

7) Castro-Ferreira R, Cardoso R, Leite-Moreira A, Mansilha A. The role of endothelial dysfunction and inflammation in chronic venous disease. Ann Vasc Surg. 2018;46:380-393.

8) Apollonio A, Antignani PL, Di Salvo M, Failla G, Guarnera G, Mosti G, Ricci E; SUV Study Group. A large Italian observational multicentre study on vascular ulcers of the lower limbs. Int Wound J. 2016;13(1):27-34. 


\section{Non-animal ultrasound phantoms for device testing and training}

\section{F Passariello ${ }^{1}$}

${ }^{1}$ Fondazione Vasculab ONLUS, via Francesco Cilea 280 - 80127 Naples, Italy

presented to: Contribute to the Conference 'Sperimentazione non-animale. Un'alternativa possibile.' [Non animal experiments. A possible alternative.] Fondazione Humaniter. Napoli, Nov 29, 2017. submitted: Jun 27, 2018, accepted: Jun 29, 2018, EPub Ahead of Print: Jun 29, 2018, published: Jun 30, 2018 Conflict of interest: None

DOI: 10.24019/jtavr.26 - Corresponding author: Dr. Fausto Passariello, afunzionale@ tiscalinet.it

C 2017 Fondazione Vasculab impresa sociale ONLUS. All rights reserved.

\begin{abstract}
A phantom is a physical object to simplify device testing and clinical training. An industrial device is more reliable for device testing in quality control procedures, though it is expensive. When precision requirements are not so strict as it occurs in training, people prefer to use home-made phantoms, though many of these artisanal methods use animal products. The current paper illustrates a few alternative vegetal phantoms. Agar is a widely used material in laboratory investigations and can be used to contain ultrasound targets. Another quick and effective alternative is given by tofu. Target sizes and flow ultrasound measurements can be easily effected using a phantom and training can be planned and repeated as much as required. The current paper shows how low-cost animal phantoms can be perfectly replaced by low-cost vegetal ones for clinical and training purposes. Vegetal phantoms can be classified as possible realizations of the Replace, the 1 st of the 3 Rs pre-requisites for non-animal experiments.
\end{abstract}

Keywords Ultrasound phantoms; agar phantoms; tofu phantoms; ultrasound training; 3Rs.

\section{Introduction}

Ultrasound imaging devices must be calibrated to be reliable measuring devices. For instance, the ultrasound probes and the internal procedures are projected to get the maximal resolution in the axial (depth) and transverse (lateral) directions.

Testing of imaging devices is accomplished using simplified models (phantoms), which contain several geometric objects of known size, to check the device capability of capturing the correct values. According to the use of the phantom, structures can be also traversed by a fluid, in order to simulate the behavior of a more complex but dynamic real condition.

Device testing requires a great precision in measurements as well as in the manufacturing of the phantoms, thus an industrial device is more reliable and preferable, because the aim is to perform a quality control test.

Several professional phantoms are on the market, generally provided by device manufacturers and made of synthetic materials. However, these phantoms are generally expensive and most people, especially in training, prefer to build their phantoms manually, for their personal and clinical environments as well as for an educational classcourse.

Many low-cost alternatives can be home-made, especially for training in diagnostic procedures or in ultrasound-guided surgical procedures. There is quite a lot of home-made instructions and movies on the web, which show how to get an easy and low-cost phantom. However, many of these artisanal methods use animal products like gelatin as medium to include geometrical ultrasound targets.

As an extreme case example, a simple method to train the emergency personnel in vascular access procedures, even without any ultrasound guide, uses a rubber tourniquet and a slice of turkey meat to simulate a vessel to get people 
acquainted with the needle puncture for vascular access ${ }^{1}$. Thus the usefulness of reviewing the already available methods to build a home-made vegetal phantom.

nothing new is here presented, everything being already known, though generally not sufficiently well-known;

- $\quad$ the vegetal phantom shows similar properties in comparison with the other ones of animal origin;

- as regards precision and reliability, a homemade vegetal phantom cannot be compared at all to the synthetic industrial devices;

- $\quad$ the ready-made available devices are much more expensive.

\section{Vegetal phantoms}

\section{Agar phantoms}

Agar or agar-agar is a mixture of agarose and agaropectin. Agarose is a linear polysaccharide made by a linear sequence of two disaccharides ${ }^{2}$. Widely used in microbiology as a culture medium (Petri dish) and in general chemistry as a support for electrophoresis, its origin dates to the XVII century in Japan ${ }^{3}$.

Agar is insoluble in cold water, but it hydrates in boiling water, returning to a gel phase as soon as temperature is held below $35-45^{\circ} \mathrm{C}$. This property makes it easy and quick to get a support for an ultrasound phantom $^{4,5}$. Placing several ultrasound targets (an orange, a nut, a straw or a tourniquet) into a plastic container and adding a warm solution of agar, it suffices to wait a while for its spontaneous cooling to get a stable gel phantom. The targets can be filled with still water or extraneous materials, which can generate acoustic shadows, according to their echogenicity, for instance simulating gallstones.

\section{Tofu phantoms}

Tofu, called also vegetal meat or bean curd, is the result of the coagulation of soy milk. Its origin dates to more than 2000 years ago in China, while the first use of the term in English dates to the XIX century in the USA6.

Tofu can be stored in different consistencies, but here an application is shown using an extra-firm tofu to build a phantom.

Take an extra-firm tofu slab and, profiting of its consistency, push inside it as many straws you want to simulate a vascular access. A tourniquet can be inserted in the straw and then the straw can be removed, to simulate a compressible vessel. Place all in a container and add cold water to cover the straws, but not the tofu surface. In such a way, water will fill the straws, leaving the surface dry instead.

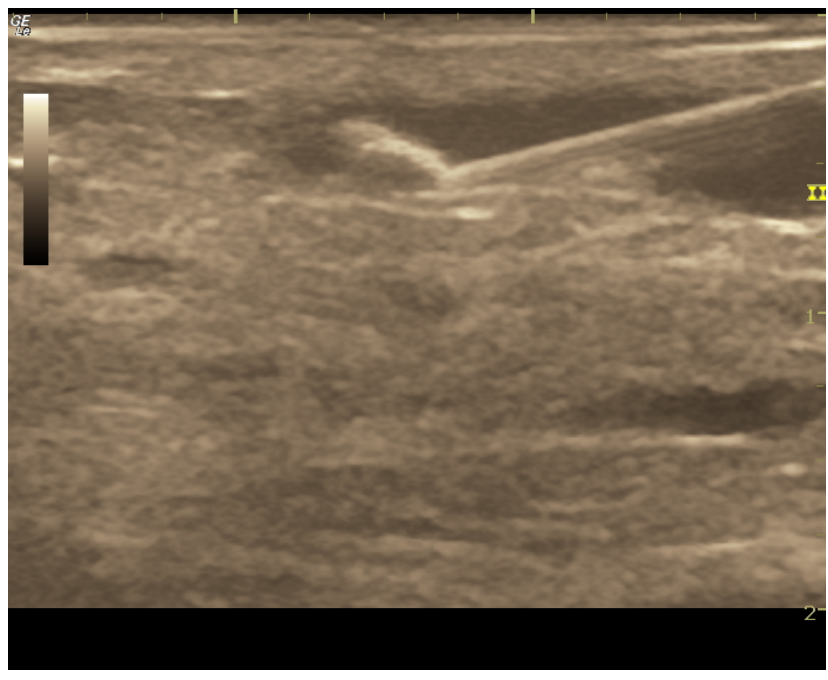

Figure 1 - A true vascular access for venous sclerotherapy in a human tributary vein of a lower limb. A thick jet of hyper-echogenic sclerosing foam exits the tip of the needle. Note the ultrasound artifact with repeated thin and light parallel images of the needle, is a general effect which can be also detectable with a phantom.

The described procedure is efficiently shown on a web movie ${ }^{7}$, where it is well emphasized how negligible is the required time to prepare the phantom. As the simulated vessels connect to the external container, any injection of material during the training procedure can exit to the outer container and the phantom is practically regenerated by simple washing and emptying of the container.

\section{Measurements and training}

Measuring the size of the ultrasound targets before including them into the container gives the possibility of training the ultrasound operators in the collection of reliable measures.

In addition, using a particle fluid and connecting the straws or tourniquets to a calibrated volumetric pump or reservoir allows the comparison of the flow measurements (change of levels in the reservoir or automatic pump calibration) with the ones made by ultrasound (Doppler velocity multiplied by the B-Mode ultrasound area).

As regards the vascular access, targets can be positioned at different depths in the phantom, in order to simulate difficulties which arise in deeper vessels, when the needle must be longer and the angle between the needle and the skin or the vessel is less acute.

Figure 1 show a true vascular access in the human, while figure 2 shows instead a simulated access on a tofu phantom. Having a phantom, you can bite as many times you want to learn the tricks of the chosen procedure. 


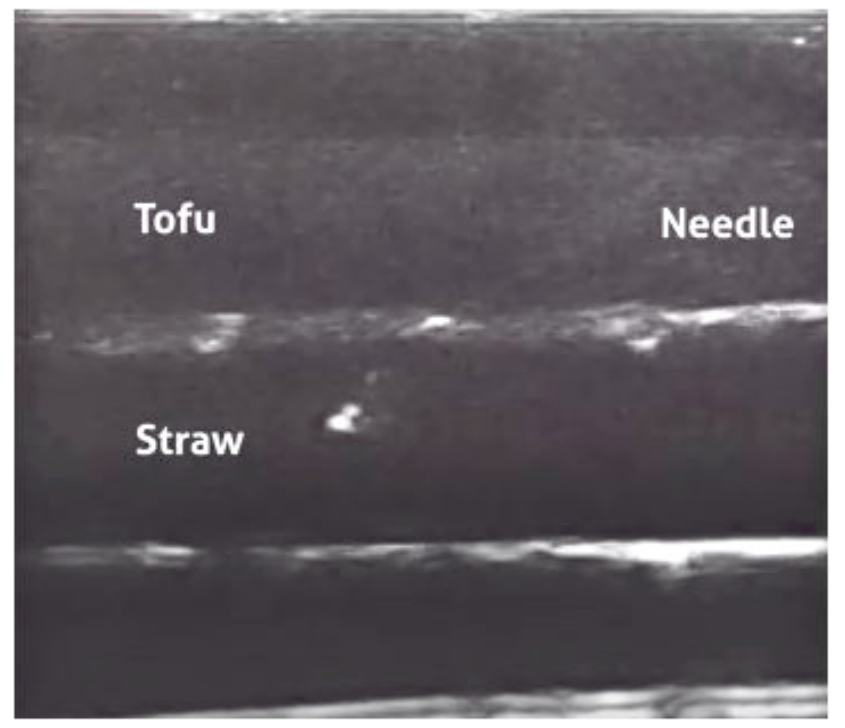

Figure 2 - A simulated vascular access on a tofu phantom. Taken from a Youtube educational movie (Eddie)

\section{References}

1) Passariello F. Sperimentazione non-animale. Un'alternativa possibile. [Non animal experi-ments. A possible alternative.] Conference at Fondazione Humaniter. Napoli, 2017, Nov 29.

2) Bin Luo, Ronghua Yang, Peng Ying, Awad M, Choti M, Taylor R. Elasticity and Echo-genicity Analysis of Agarose Phantoms Mimicking Liver Tumors. Proceedings of the IEEE 32nd Annual Northeast Bioengineering Conference [Internet]. IEEE; Available from: http://dx.doi.org/10.1109/nebc.2006.1629762

3) Zucca P, Fernandez-Lafuente R, Sanjust E. Agarose and Its Derivatives as Supports for En-zyme Immobilization. Molecules [Internet]. MDPI AG; 2016 Nov 19;21(11):1577. Available from http://dx.doi.org/10.3390/molecules 21111577

4) Mitchell MD, Kundel HL, Axel L, Joseph PM. Agarose as a tissue equivalent phantom ma-terial for NMR imaging. Magnetic Resonance Imaging [Internet]. Elsevier BV; 1986 Jan;4(3):263-6. Available from: http://dx.doi.org/10.1016/0730-725x(86)91068-4

\section{Conclusion}

For device testing, synthetic but expensive phantoms are already available to achieve reliable industrial laboratory results for quality control.

The current paper shows instead how low-cost animal phantoms can be perfectly replaced by low-cost vegetal ones for clinical and training purposes.

In addition, agar and tofu phantoms are of easy home-made manufacture from materials, which are widely available on the market. Their use is in agreement with the $1^{\text {st }}$ of the 3 Rs pre-requisites for non-animal experiments, i.e. Replace, Reduce, Refine, which are nowadays generally accepted $^{8}$.

5) Earle M, Portu GD, DeVos E. Agar ultrasound phantoms for low-cost training without re-frigeration. African Journal of Emergency Medicine [Internet]. Elsevier BV; 2016 Mar;6(1):18-23. Available from: http://dx.doi.org/10.1016/j.afjem.2015.09.003

6) Anonymous. Tofu. [Internet]. Last edited on 30 June 2018 [Accessed on Jun 30, 2018]. Available from: https://en.wikipedia.org/ wiki/Tofu

7) Eddie C. Easy DIY Tofu ultrasound phantom. YouTube movie. Available from:https://www.youtube.com/watch? $\mathrm{v}=\mathrm{utWZHA7gp-4}$.

8) European society for alternatives to animal testing. Available at the address http://www.eusaat-congress.eu/ at the date of Jun 30, 2018 



\title{
Dimensional analysis in the venous system
}

\author{
F Passariello \\ ${ }^{1}$ Fondazione Vasculab ONLUS, via Francesco Cilea 280 - 80127 Naples, Italy
}

presented to: Masterclass in Fluid Mechanics in the XVIII World Congress of the International Union of Phlebology (UIP), Melbourne (AUS), Feb 4-8, 2018

submitted: Jun 7, 2018, accepted: Jun 26, 2018, EPub Ahead of Print: Jun 29, 2018, published: Jun 30, 2018

Conflict of interest: None

DOI: 10.24019/jtavr.25 - Corresponding author: Dr. Fausto Passariello, afunzionale@tiscalinet.it

(C) 2017 Fondazione Vasculab impresa sociale ONLUS. All rights reserved.

Abstract Dimensional analysis, a standard method of Fluid Mechanics, was applied to the field of venous hemodynamics. Three independent physical quantities, velocity, length and pressure, were chosen and seven other ones were used to derive the non-dimensional terms. The mathematical burden was reduced to the minimum and the attention was focused on the results. Among them, a new formulation of an already known non-dimensional term, recalled the flow-length (FL), was identified and selected for a deeper experimental study.

Keywords Buckingham $\mathrm{Pi}$ theorem, Fluid mechanics, Venous hemodynamics, Non-dimensional numbers, Flow-length.

\section{Introduction and aim}

The paper resumes the content of a Masterclass held recently in an international phlebology meeting ${ }^{1}$. Dimensional analysis (DA) is a standard method in Physics and Engineering, especially in Fluid Mechanics ${ }^{2,3,4}$, and it is used to clarify, to check and to foresee the mathematical relationship between physical quantities. As a practical consequence, non-dimensional terms detected by DA are used in modelling, when comparing a prototype to a different size scaled model, i.e. bigger or smaller.

DA can be practically used:

- 1) trivially to remind the structure of wellknown physical laws;

- 2) to check the consistency of a new theoretical relationship;
- 3) to search for new possible laws

- a) in a brute force extensive analysis;

- b) in a selected set of quantities under study.

The results can be:

- 1) trivial, i.e. clear and simply obtained by inspection;

- 2) already known, i.e. a different way to represent well-assessed laws;

- 3) new previously unexplored connections

- a) with a clear physical interpretation;

- b) without a ready physical interpretation.

The main procedure in DA is the $\Pi_{i}$ theorem or Buckingham theorem ${ }^{5-10}$, which provides practical hints for the computation of useful non-dimensional terms. Each term is a non-dimensional product $\Pi_{i}$ of physical quantities, their sum being non-dimensional too. Therefore, the words "terms" and "products" are used in this paper in an interchangeable way.

The aim of this paper was to apply the $\Pi_{i}$ theorem to the field of venous hemodynamics, with the strong hope to find a practical relationship between easy measurable physical quantities, collected during a widely available diagnostic investigation. Venous hemodynamics was never extensively studied with DA. Its theoretical results will be then investigated in future experimental works, in order to capture the coefficients of the terms, applied to the venous system. 


\section{Main physical entities}

$\begin{array}{cccc}\# & \text { dimensions } & \text { name } & \text { symbol } \\ 1 & & \\ 2 & {[\mathrm{~L}][\mathrm{T}]^{-1}} & \text { Velocity } & \mathrm{V} \\ 3 & {[\mathrm{~L}]} & \text { Length } & \mathrm{D} \\ & {[\mathrm{M}][\mathrm{L}]^{-1}[\mathrm{~T}]^{-2}} & \text { Pressure } & \mathrm{P}\end{array}$

Table I - The selected main physical entities, their name, symbol and dimensions, pertaining to the current dimensional analysis. They allowed the formulation of a starting core of equations, which was then minimally changed to derive

each $\Pi_{i}$ term.

\section{Method}

The international system of units (SI, from the French "Système International d'unités") was chosen ${ }^{11, \text { i }}$

The next step consisted then in writing the list (Table I and II) of the potentially involved $\mathrm{N}$ physical quantities, together with their dimensions.

An arbitrarily choice of $\mathrm{Q}$ main quantities from the previous list of $\mathrm{N}$ was performed, provided they contained all the $\mathrm{Q}$ fundamental physical quantities of the chosen measuring system (e.g. $\mathrm{M}, \mathrm{L}$ and $\mathrm{T}$ in $\mathrm{SI}$ and $\mathrm{Q}=3$ ) ${ }^{\mathrm{ii}}$.

$\mathrm{N}=10$ physical quantities were selected $\mathrm{d}^{\mathrm{iii}}$, choosing as the main group $\mathrm{Q}=3$ quantities, the velocity $\mathrm{V}$, the length $\mathrm{D}$ and the pressure $\mathrm{P}$, their dimensions being shown in Table I.

Their independence was checked, showing that except for the trivial solution $(0,0,0)$ no combination of their exponent values $(\mathrm{a}, \mathrm{b}, \mathrm{c})$ existed $^{12}$, to provide a nondimensional product ${ }^{\text {iv }}$.

Indeed, raising the three main physical quantities to the unknown exponents a b c

$$
\begin{aligned}
& {[\mathrm{V}]^{\mathrm{a}}[\mathrm{D}]^{\mathrm{b}}[\mathrm{P}]^{\mathrm{c}}=} \\
& =[\mathrm{L}]^{\mathrm{a}}[\mathrm{T}]^{-\mathrm{a}}[\mathrm{L}]^{\mathrm{b}}[\mathrm{M}]^{\mathrm{c}}[\mathrm{L}]^{-\mathrm{c}}[\mathrm{T}]^{-2 \mathrm{c}}= \\
& =[\mathrm{M}]^{\mathrm{c}}[\mathrm{L}]^{\mathrm{a}+\mathrm{b}-\mathrm{c}}[\mathrm{T}]^{-\mathrm{a}-2 \mathrm{c}}
\end{aligned}
$$

and equating to 0 each exponent in the SI base units, the following system of equations could be laid down

$$
0=a+b-c ;(\text { for }[L])
$$

$$
\begin{aligned}
& 0=\mathrm{c} ;(\text { for }[\mathrm{M}]) \\
& 0=-\mathrm{a}-2 \mathrm{c} ;(\text { for }[\mathrm{T}])
\end{aligned}
$$

The unique solution of the system was $\mathrm{a}=\mathrm{b}=\mathrm{c}=0$, i.e. the three chosen quantities were independent on each other and could constitute a base of the measuring system. The above described procedure provided a core equation set for all the other subsequent computation.

Any of the examples shown in Table III could be chosen to represent practically the corresponding main quantities, i.e. velocity, length and pressure. For instance, the diastolic velocity, the calibre and the intravascular pressure in any vein could constitute a valid triad and were effectively used in almost all practical implementations of the method.

A quicker notation for dimensions, omitting the square brackets, was adopted in the text below. $\mathbf{N}$ $Q=7(10-3) \Pi_{\mathbf{i}}$ products (Table II) were found and for each of them the equations were written and solved.

The computing procedure essentially consisted in taking each representative quantity from table II and adding it separately to the main quantities $\mathrm{V}^{\mathrm{a}} \mathrm{D}^{\mathrm{b}} \mathrm{P}^{\mathrm{c}}$. For each additional quantity, a new computational procedure was performed, producing new coefficients for a modified core of linear equations.

The system was then solved, following in each case the same computational scheme. Finally, the computed coefficients were applied to get each corresponding nondimensional term ${ }^{13,14}$. 


\section{$\Pi_{\mathrm{i}}$ terms}

$\begin{array}{lccccc}\Pi & \text { dimensions } & \text { name } & \text { symbol } & \Pi \text { formula } & \text { Interpretation } \\ \Pi_{1} & {[\mathrm{~T}]} & \text { time } & \mathrm{t} & \mathrm{VD}^{-1} \mathrm{t} & \text { Stokes number, FL } \\ \Pi_{2} & {[\mathrm{M}][\mathrm{L}]^{-1}[\mathrm{~T}]^{-1}} & \text { absolute viscosity } & \mu & \mathrm{VD}^{-1} \mathrm{P}^{-1} \mu & \text { Reynolds number } \\ \Pi_{3} & {[\mathrm{~L}]^{3}[\mathrm{~T}]^{-1}} & \text { flow } & \Phi & \mathrm{V}^{-1} \mathrm{D}^{-2} \Phi & \text { Leonardo continuity law } \\ \Pi_{4} & {[\mathrm{M}][\mathrm{L}]^{-3}} & \text { density } & \rho & \mathrm{V}^{2} \mathrm{P}^{-1} \rho & \text { Bernouilli kinetic term } \\ \Pi_{5} & {[\mathrm{~L}][\mathrm{T}]^{-2}} & \text { acceleration } & \mathrm{ac} & \mathrm{V}^{-2} \mathrm{D} \text { ac } & \text { Froude number } \\ \Pi_{6} & {[\mathrm{M}][\mathrm{T}]^{-2}} & \text { superficial tension } & \sigma & \mathrm{D}^{-1} \mathrm{P}^{-1} \sigma & \text { Young-Laplace law } \\ \Pi_{7} & {[\mathrm{~T}]^{-1}} & \text { angular velocity } & \omega & \mathrm{V}^{-1} \mathrm{D} \omega & \text { Strouhal number }\end{array}$

Table II - The $\Pi_{i}$ terms of the current dimensional analysis, each one derived by adding a physical quantity (name) to the set of the main physical quantities (velocity, length, pressure). A brief interpretation is given in the right column. For a detailed description see the text.

\section{Results}

\section{Trivial results}

A trivial immediate non-dimensional result is given by the ratio between two physical quantities of the same dimension, both taken from the same example group. For instance, transmural pressure divided by the intravascular pressure is non-dimensional. The same applies separately to length and velocity, thus having for instance the nondimensional ratios given by the vein diameter (D) divided by the height at the groin $(\mathrm{H})(\mathrm{D} / \mathrm{H})$ and the mean velocity ratio between the great saphenous vein (GSV) and the common femoral vein (CFV) $\left(\mathrm{V}_{\mathrm{GSV}} / \mathrm{V}_{\mathrm{CFV}}\right)$. In addition, the same property holds for the powers of the main physical entities, for instance:

- $\quad$ for the surface $\left([\mathrm{L}]^{2}\right)$, the GSV terminal valve area (ATV) divided by the GSV cross-section ( $\mathrm{AGSV}_{\mathrm{GS}}$ ) at $2 \mathrm{~cm}$ from the junction $\left(\mathrm{A}_{\mathrm{TV}} / \mathrm{A}_{\mathrm{GSV}}\right.$ );

- for the volume $\left([\mathrm{L}]^{3}\right)$, the ratio between the blood volume ejected by the calf pump (EV) and the volume of the lower limb (LV), computed by the frustum method ${ }^{15}(\mathrm{EV} / \mathrm{LV})$.

These obvious results were not treated extensively, because they can be derived by simple inspection and do not require any computation.

\section{Examples of main physical quantities in the venous system}

Velocity Max or mean, systolic or diastolic velocity in any vein and anatomical site Length Max or min calibre of a vessel, height of the body or at the Lewis angle or at $\begin{array}{ll}\text { Pressure } & \text { the groin, vein wall thickness, length of a venous shunt, etc. } \\ \text { Systolic or diastolic pressure in the aortic arch, difference of pressure, }\end{array}$ transmural pressure, intravascular pressure

Table III - Physical instances of the main physical quantities in veins. Quantities marked in bold were practically used for the real computation of the non-dimensional terms. 


\section{Dimensional analysis}

The text below describes the computation details for each $\Pi_{i}$ term. The computation of the first term was outlined in a detailed and plain way, while for all the other terms the details were omitted.

\section{Time}

The term $\Pi_{1}$ was computed adding the time (t) quantity $\left(1^{\text {st }}\right.$ line in Table II) to the core equations. Using for the dimensions the unknown coefficients $\mathbf{a}, \mathbf{b}, \mathbf{c}$ the following relationship could be laid down

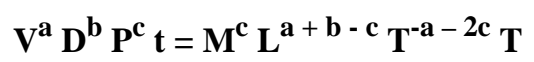

leading then to the algebraic equation system

$$
\begin{aligned}
& \mathbf{0}=\mathbf{a}+\mathbf{b}-\mathbf{c}(\text { for }[\mathrm{L}]) \\
& \mathbf{0}=\mathbf{c}(\text { for }[\mathrm{M}]) \\
& \mathbf{0}=-\mathbf{a}-\mathbf{2 c + 1}(\text { for }[\mathrm{T}])
\end{aligned}
$$

$$
\text { and solving } \mathbf{a}=\mathbf{1} ; \mathbf{b}=\mathbf{- 1} ; \mathbf{c}=\mathbf{0} \text {. }
$$

Finally, substituting with the computed values, the non-dimensional term $\mathbf{V D}^{\mathbf{- 1}} \mathbf{t}$ was obtained.

\section{Viscosity}

The term $\Pi_{2}$ was computed adding the viscosity $(\mu)$ quantity $\left(2^{\text {nd }}\right.$ line in Table II) to the core equations.

$$
V^{a} D^{b} P^{c} \mu=M^{c} L^{a+b-c} T^{-a-2 c} M^{-1} T^{-1}
$$

and then

$$
\begin{aligned}
& 0=a+b-c-1(\text { for }[\mathrm{L}]) \\
& 0=\mathbf{c}+\mathbf{1}(\text { for }[\mathrm{M}]) \\
& 0=-\mathbf{a}-\mathbf{2 c - 1}(\text { for }[\mathrm{T}])
\end{aligned}
$$

and solving $\mathbf{a}=\mathbf{1} ; \mathbf{b}=\mathbf{- 1} ; \mathbf{c}=\mathbf{- 1}$. obtained.

Finally, the non-dimensional term $\mathbf{V} \mathbf{D}^{-\mathbf{1}} \mathbf{P}^{\mathbf{- 1}} \mu$ was

\section{Flow}

The term $\Pi_{3}$ was computed adding the flow $(\Phi)$ quantity ( $3^{\text {rd }}$ line in Table II) to the core equations.

$$
\mathbf{V}^{\mathbf{a}} \mathbf{D}^{\mathbf{b}} \mathbf{P}^{\mathrm{c}} \Phi=\mathbf{M}^{\mathrm{c}} \mathbf{L}^{\mathrm{a}+\mathbf{b}-\mathbf{c}} \mathbf{T}^{-\mathbf{a}-2 \mathrm{c}} \mathbf{L}^{3} \mathbf{T}^{-1}
$$

and then

$\mathbf{0}=\mathbf{a}+\mathbf{b}-\mathbf{c}+\mathbf{3}($ for $[\mathrm{L}])$

$$
\begin{aligned}
& 0=\mathbf{c}(\text { for }[M]) \\
& 0=-\mathbf{a}-2 c-1(\text { for }[T])
\end{aligned}
$$

and solving $\mathbf{a}=\mathbf{- 1} ; \mathbf{b}=\mathbf{- 2} ; \mathbf{c}=\mathbf{0}$. obtained.

Finally, the non-dimensional term $\mathbf{V}^{-\mathbf{1}} \mathbf{D}^{-\mathbf{2}} \Phi$ was

\section{Density}

The term $\Pi_{4}$ was computed adding the density $(\rho)$ quantity $\left(4^{\text {th }}\right.$ line in Table II) to the core equations.

$$
V^{a} D^{b} P^{c} \rho=M^{c} L^{a+b-c} T^{-a-2 c} M L^{-3}
$$

and then

$$
\begin{aligned}
& \mathbf{0}=\mathbf{a}+\mathbf{b}-\mathbf{c}-\mathbf{3}(\text { for }[\mathrm{L}]) \\
& \mathbf{0}=\mathbf{c}+\mathbf{1}(\text { for }[\mathrm{M}]) \\
& \mathbf{0}=\mathbf{- a - 2 c}(\text { for }[\mathrm{T}])
\end{aligned}
$$

and solving $\mathbf{a}=\mathbf{2} ; \mathbf{b}=\mathbf{0} ; \mathbf{c}=\mathbf{- 1}$. obtained.

Finally, the non-dimensional term $\mathbf{V}^{\mathbf{2}} \mathbf{P}^{\mathbf{- 1}} \rho$ was

\section{Acceleration}

The term $\Pi_{\mathbf{5}}$ was computed adding the acceleration (ac) quantity ( $5^{\text {th }}$ line in Table II) to the core equations.

$$
V^{a} D^{b} P^{c} a c=M^{c} L^{a+b-c} T^{-a-2 c} L_{T}^{-2}
$$

and then

$$
\begin{aligned}
& \mathbf{0}=\mathbf{a}+\mathbf{b}-\mathbf{c}+\mathbf{1}(\text { for }[\mathrm{L}]) \\
& 0=\mathbf{c}(\text { for }[\mathrm{M}]) \\
& 0=-\mathbf{a}-2 \mathrm{c}-2(\text { for }[\mathrm{T}])
\end{aligned}
$$

and solving $\mathbf{a}=\mathbf{- 2} ; \mathbf{b}=\mathbf{1} ; \mathbf{c}=\mathbf{0}$. obtained.

Finally, the non-dimensional term $\mathbf{V}^{-\mathbf{2}} \mathbf{D}$ ac was

\section{Superficial tension}

The term $\Pi_{6}$ was computed adding the superficial tension $(\sigma)$ quantity $\left(6^{\text {th }}\right.$ line in Table II) to the core equations.

$$
V^{a} D^{b} P^{c} \sigma=M^{c} L^{a+b-c} T^{-a-2 c} M T^{-2}
$$

and then

$$
0=\mathbf{a}+\mathbf{b}-\mathbf{c}(\text { for }[\mathbf{L}])
$$


$\mathbf{0}=\mathbf{c}+\mathbf{1}($ for $[\mathrm{M}])$

$0=-\mathbf{a}-2 \mathrm{c}-2($ for $[\mathrm{T}])$

and solving $\mathbf{a}=\mathbf{0} ; \mathbf{b}=\mathbf{- 1} ; \mathbf{c}=\mathbf{- 1}$. obtained.

Finally, the non-dimensional term $\mathbf{D}^{\mathbf{- 1}} \mathbf{P}^{-\mathbf{1}} \sigma$ was

\section{Angular velocity}

The term $\Pi_{\mathbf{7}}$ was computed adding the angular velocity $(\omega)$ quantity $\left(7^{\text {th }}\right.$ line in Table II) to the core equations.

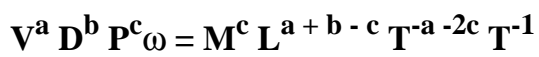

and then

$$
\begin{aligned}
& 0=\mathbf{a}+\mathbf{b}-\mathbf{c}(\text { for }[\mathrm{L}]) \\
& 0=\mathbf{c}(\text { for }[\mathrm{M}]) \\
& 0=-\mathbf{a}-2 \mathrm{c}-1(\text { for }[\mathrm{T}])
\end{aligned}
$$

and solving $\mathbf{a}=\mathbf{- 1} ; \mathbf{b}=\mathbf{1} ; \mathbf{c}=\mathbf{0}$. obtained

Finally, the non-dimensional term $\mathbf{V}^{-\mathbf{1}} \mathbf{D} \omega$ was

\section{Main non-dimensional numbers in fluid mechanics}

\section{Name}

Stokes (Stk)

Reynolds (Re)

Froude (Fr)

Euler $(\mathrm{Eu})$

Weber (We)

Womersley $(\alpha)$

Strouhal (St)

\section{Formula}

$$
\mathrm{Stk}=\tau \mathrm{V} / \mathrm{D}
$$$$
\operatorname{Re}=\mathrm{VD} \rho / \mu
$$$$
\mathrm{Fr}=\mathrm{V} /(\mathrm{gD})^{1 / 2}
$$$$
\mathrm{Eu}=\Delta \mathrm{p} / \rho \mathrm{V}^{2}
$$$$
\mathrm{We}=\rho \mathrm{V}^{2} \mathrm{D} / \sigma
$$$$
\alpha=\mathrm{R}(\omega \mathrm{R} / \mu)^{1 / 2}
$$$$
\mathrm{St}=\omega \mathrm{D} / \mathrm{V}
$$

\section{Main phenomenon}

Dispersion

Viscous

Gravity

Pressure

Surface

Pulsatility

Vortices

Table IV - The most used non-dimensional numbers in modelling. Symbols: $\tau$ relaxation time, $V$ velocity, $D$ length, $\rho$ density, $\mu$ viscosity, $g$ gravitational acceleration, $p$ pressure, $\sigma$ superficial tension, $R$ radius, $\omega$ angular velocity. For additional information see the text. 


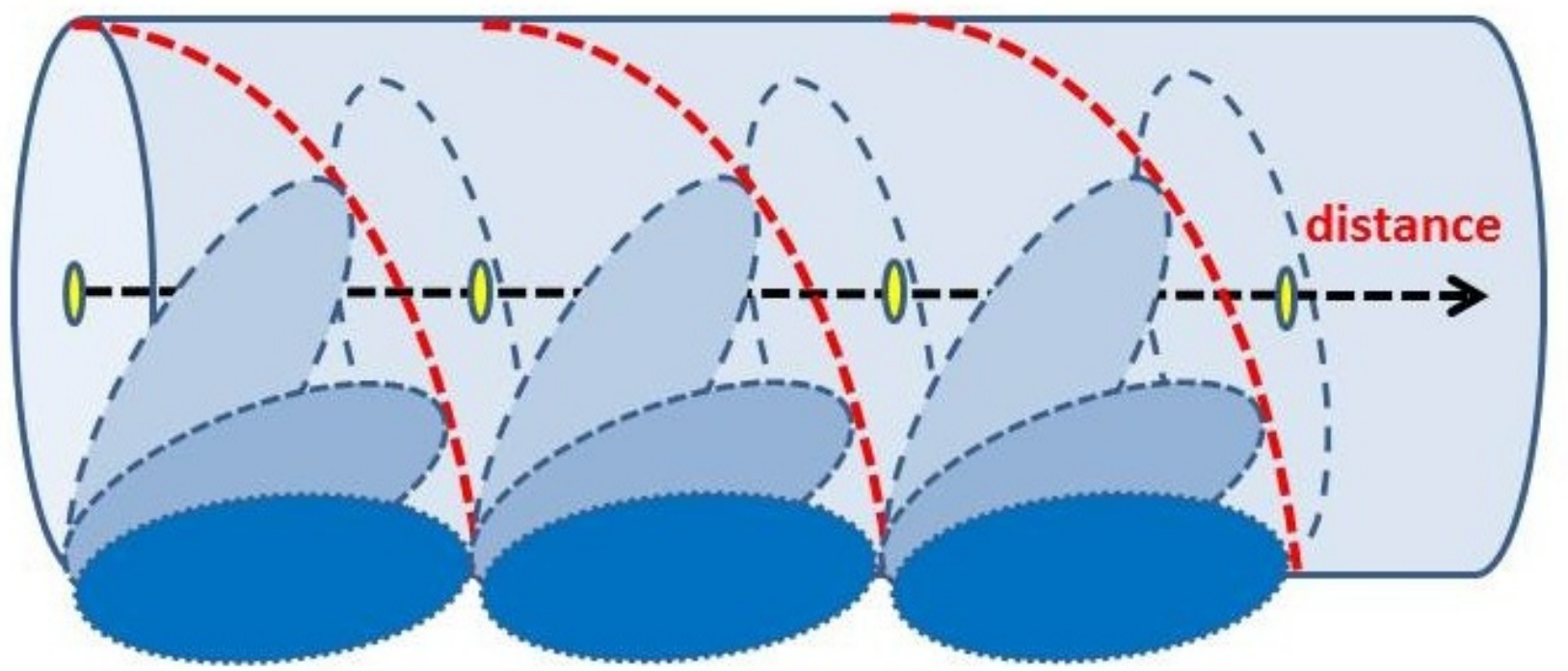

Figure 1 - Using the diameter as Length Unit. The flow-length $(F L)$ counts how many diameters are covered by the fluid in the time length of flow. Imagine the cross-section like a rolling coin, covering the distance given by the mean velocity $\boldsymbol{V}$ multiplied by the time length $\mathrm{t}$ of flow.

FL counts indeed how many diameters are covered by the flow, in any pathophysiologic conditions, like the spontaneous breath for forward flow or the Valsalva for the reflux. FL was selected for a deeper experimental study, as it can be measured in a very simple way by echocolordoppler, so that it could be part of any vascular ultrasound investigation and report. Being applied to a different context, FL is therefore a reformulation of the Stokes formula for venous (or arterial) macro-circulation.

As regards the time length, FL can be easily applied when there is a well recognizable cycle (and thus an identifiable time), while for a continuous flow with a steady velocity value the Froude number seems a better choice.

The $\Pi_{2}$ term $\mathbf{V D}^{\mathbf{- 1}} \mathbf{P}^{\mathbf{- 1}} \boldsymbol{\mu}$ has a non-dimensional property which holds also for its reciprocal $\mathbf{P} / \mathbf{V} * \mathbf{D} / \mu$, where $\mathrm{P}$ is the pressure, $\mathrm{V}$ the mean velocity, $\mathrm{D}$ the diameter and $\mu$ the absolute viscosity. As the dimension of the energy density is $\left[\rho \mathrm{V}^{2}\right]=[\mathrm{P}]$ and consequently $[\rho \mathrm{V}]=[\mathrm{P} / \mathrm{V}]$, where $\rho$ is the density, substituting in the formula for the reciprocal of the $\Pi_{2}$ term the following relationship is obtained

$$
\mathbf{P} / \mathbf{V} * \mathrm{D} / \mu=\rho \mathbf{V} * \mathrm{D} / \mu=\operatorname{Re}
$$

where Re is the Reynolds number.
Thus, the $\Pi_{2}$ term is the reciprocal of the Reynolds number, which is commonly used in fluid mechanics. In the same way Re needs the value of blood viscosity, the $\Pi_{2}$ term is of difficult computation too, being the intravascular pressure generally unknown.

The $\Pi_{3}$ term $\mathbf{V}^{-1} \mathbf{D}^{-\mathbf{2}} \Phi$ could be related to the wellknown Leonardo law (equation of continuity), while the $\Pi_{4}$ term $\mathbf{V}^{\mathbf{2}} \mathbf{P}^{-\mathbf{1}} \rho$ could be referred to the kinetic term of the Bernouilli equation $\left(\mathbf{P}=\rho \mathbf{V}^{\mathbf{2}}\right)$.

The $\Pi_{\mathbf{5}}$ term $\mathbf{V}^{-\mathbf{2}} \mathbf{D}$ ac is the reciprocal of the squared Froude number (Fr). Generally Fr is applied to open channels, where the symbol $\mathrm{g}$ in the formula is the gravity acceleration constant. In venous hemodynamics the interest is in pipes, where the flow acceleration can be used. As all the quantities are easily measurable in a common echocolordoppler investigation, Fr can be computed too in an easy way.

The $\Pi_{\mathbf{6}}$ term $\mathbf{D}^{\mathbf{- 1}} \mathbf{P}^{\mathbf{- 1}} \boldsymbol{\sigma}$ reflects the Young-Laplace formula $\mathbf{P}=\sigma / \mathbf{D}$, experimentally discovered by Young in 1804 and then reformulated theoretically one year later by Laplace $^{17}$ (Fung 1981, p.19). Alternatively, substituting P with the kinetic term of the Bernouilli equation, it becomes the reciprocal of the Weber number (We). 
The $\Pi_{7}$ term $\mathbf{V}^{-\mathbf{1}} \mathbf{D} \boldsymbol{\omega}$ is the Strouhal number $(\mathrm{St})$, where $\omega$ is the pulsatility of flow (like the heart rate) and deals with the generation of vortices downstream of an obstacle to flow, as in a pulsatile flow in a carotid stenosis ${ }^{18}$ (Fung 1984, p.46). In the $\Pi_{7}$ term instead, it is possible to consider $\omega$ as the angular velocity of flow (there is an additional angular dimension), inside the cross section of the pipe. This interpretation involves flow velocities in other directions than the commonly used axial ones and suggests a deeper theoretical investigation.

\section{Conclusion}

DA is an easy method to get interesting theoretically relationship, without any experimental data collection. Apart from the huge work in describing the theoretical method and the ordered results, the practical application of DA for the current paper required almost 1 hour of work, sitting down at a desk and computing all the values manually. Using a program would have substantially reduced the computation time to a few minutes. The collected results cover a great part of fluid mechanics of

\section{Endnotes}

[i] A reduced set of the SI units Mass [M] Kilogram (Kg), Length [L] meter (m) and Time [T] second (s) was used, as the remaining SI units (Ampère, Candela, Kelvin, Mole) were considered of minor importance in venous hemodynamics.

[ii] DA does not depend on the choice of the main physical quantities, thus just the quantities which fit better to computation or measurement were used

\section{References}

1) Passariello F. Dimensional analysis in venous hemodynamics. Masterclass to the XVIII UIP Meeting, Feb 4-8, 2018, Melbourne (AUS).

2) Munro BR, Young DF, Okishi TH. Fundamentals of Fluid Mechanics. John Wiley \& Sons, Inc. 2006.

3) Leroux J-P, Bauduin Ph. Mécanique des fluides. Paris, Dunod, 1972.

4) Giles RV. Fluid mechanics and hydraulics. Schaum. New York, McGraw-Hill, 1962.

5) Hanche-Olsen H. Buckingham's pi-theorem. TMA4195 Mathematical modelling. 2004-08-16. [Accessed on Jun 7, 2018]. Available from: https://folk.ntnu.no/hanche/notes/buckingham/ buckingham-a4.pdf 1922.

6) Bridgman PW. Dimensional Analysis, Yale University Press,

7) Buckingham E. On Physically Similar Systems: Illustrations of the Use of Dimensional Analysis. Phys. Rev., vol. 4, 1914, p. 345. the past 150 years, undoubtedly showing the power of the method.

However, DA provides reliable formulas apart from the non-dimensional coefficients, which require instead a separate experimental investigation, in order to assess their value and behaviour.

Accordingly, an experimental work to assess the reliability and the clinical meaning of FL (or the modified Stokes non-dimensional number) is currently underway in chronic venous diseases ${ }^{16}$, comparing FL to the Froude and Reynolds numbers.

In the same way, interesting non-dimensional relationship like the $\Pi_{6-7}$ terms were considered for a deeper theoretical approach, in order to provide an application more near to the venous system as well as to draw a future experimental design. Indeed, the main aim of the current paper was to find an useful relationship, adopting typical measurements of venous hemodynamics. Finally, the results show the possibility in the human of a non-invasive measurement by a simple echocolordoppler of most fluid mechanics non-dimensional numbers, generally considered just a theoretical and academic subject, thus never clinically reported.

[iii] Although the choice was arbitrary, the biophysical and clinical experience was a useful help in the selection of these physical quantities.

[iv] Intentionally, the matrix notation was not used in this paper. However, it's worth noting that the rank of the dimensional matrix of all the considered physical quantities is $\mathrm{M}=3$.

8) Sterret SG. Physically similar systems: A history of the concept. Wichita State University Thesis. Chapter 18 in "Magnani L, Bertolotti T (Eds). Springer Handbook of Model-Based Science. 2017. Springer International Publishing.

9) Anonymous. Dimensional analysis. [Internet]. Last edited on 26 May 2018 [Accessed on Jun 7, 2018]. Available from: https:// en.wikipedia.org/wiki/Dimensional analysis

10) Anonymous. Buckingham $\pi$ theorem. [Internet]. Last edited on March 31, 2018 [Accessed on Jun 7, 2018]. Available from: https:// en.wikipedia.org/wiki/Buckingham_ $\pi$ _theorem

11) Le Système International d'unités [The International System of Units]. Bureau international des poids et mesures. Organisation intergouvernementale de la Convention du Mètre. [Internet]. [Accessed on Jun 7, 2018]. Available at the address https://www.bipm.org/utils/ common/pdf/si brochure 8.pdf at the date of Jun 7, 2018.

12). Chen W. Algebraic theory of dimensional analysis. Journal of the Franklin Institute [Internet]. Elsevier BV; 1971 Dec;292(6):403-22. [Accessed on Jun 7, 2018]. Available from: http:// dx.doi.org/10.1016/0016-0032(71)90161-x 
13) Delattre N, Moretto P. A new dimensionless number highlighted from mechanical energy exchange during running. Journal of Biomechanics [Internet]. Elsevier BV; 2008 Sep;41(13):2895-8. [Accessed on Jun 7, 2018]. Available from: http://dx.doi.org/10.1016/ j.jbiomech.2008.06.034

14) Dixit RK, Mandal JN. Dimensional analysis and modelling laws for bearing capacity of reinforced and unreinforced soil. Construction and Building Materials. 1993;7(4): 203-5.

15) Kaulesar Sukul DMKS, den Hoed PT, Johannes EJ, van Dolder R, Benda E. Direct and indirect methods for the quantification of leg volume: comparison between water displacement volumetry, the disk model method and the frustum sign model method, using the correlation coefficient and the limits of agreement. Journal of Biomedical Engineering [Internet]. Elsevier BV; 1993 Nov;15(6):477-80. [Accessed on Jun 7, 2018]. Available from: http:// dx.doi.org/10.1016/0141-5425(93)90062-4

16) Passariello F. The non-dimensional flow-length number in ultrasound venous hemodynamics. Presented to the XVIII UIP Meeting, Feb 4-8, 2018, Melbourne (AUS). International Angiology 2018 Feb;37(1 Suppl 1):42-3.

17) Fung YC. Biomechanics, Mechanical properties of living tissues. New York Springer Verlag, Inc.; 1981.

18) Fung YC. Biodynamics, Circulation. New York, Springer Verlag, Inc.; 1984. 


\section{Contribution of the calf pump and foot pump to the return of venous blood from the lower extremity}

\section{Recek ${ }^{1}$}

${ }^{1}$ Retired, formerly Department of Surgery, University Hospital, Hradec Kralove, Czech Republic. Address: Cestmir Recek, Mantlergasse 24, 1130 Vienna, Austria.

submitted: Jan 4, 2018, accepted: Jan 11, 2018, EPub Ahead of Print: Jan 14, 2018, published: Jun 30, 2018

Conflict of interest: None

DOI: 10.24019/jtavr.43 - Corresponding author: Dr. Cestmir Recek, cestmir@ recek.at

(C) 2017 Fondazione Vasculab impresa sociale ONLUS. All rights reserved.

\begin{abstract}
The anatomy and function of the calf pump and the foot pump as well as the interplay of their activity are described. The calf muscle pump constitutes an effective mechanism enhancing efficiently the return of venous blood toward the heart. During calf muscle contractions, the venous blood is ejected mainly into the popliteal vein, but a smaller part escapes through calf perforators into the saphenous system and streams further in the centripetal, i.e. physiological direction toward the heart. Calf muscle contractions induce marked increase in systolic pressure and calf muscle relaxations entail decrease of diastolic pressure both in deep and superficial veins of the lower leg. The systolic and diastolic pressure changes are produced in deep veins and are transmitted through calf perforators into the saphenous system, as documented by simultaneous pressure recordings in the posterior tibial and great saphenous veins. The systolic increase of pressure in
\end{abstract}

\section{Introduction}

The vis a tergo, the remainder of the cardiac energy propelling venous blood from the lower extremities against the gravitation toward the heart is not powerful enough to move the venous blood toward the heart effectively; the pressure difference between the venules and the right atrium amounts to about $20 \mathrm{~mm} \mathrm{Hg}$. In addition to this motive force, the calf muscle pump (CMP) constitutes an effective mechanism that promotes drainage of venous blood from the lower extremity, produces marked increase of systolic pressure and decrease of diastolic pressure both in deep and superficial veins of the lower leg, and entails a distinct physiological decrease of ambulatory venous pressure in the lower leg veins. The requirements for a proper action the great saphenous vein is caused by the outward flow within calf perforators; competent valves in calf perforators would preclude any relevant pressure increase. Calf pump activity entails a distinct decrease of ambulatory venous pressure in lower leg veins, whereas in the thigh veins the pressure does not decrease; in this way, the ambulatory pressure gradient of $37.4+-6.4 \mathrm{~mm} \mathrm{Hg}$ arises between thigh and lower leg veins and triggers the venous reflux in incompetent venous channels connecting both poles of the ambulatory pressure gradient. In contrast to the very efficient performance of the calf pump, the performance of the foot pump is hemodynamically unimportant. The ejection volume produced by the calf muscle pump comes at about $60 \mathrm{ml}$ or more, whereas the blood volume ejected by the foot pump reaches a negligible value of 3-4 $\mathrm{ml}$.

Keywords calf muscle pump; foot pump

of the CMP are patency and perfect competence of deep lower leg veins, no impediments in the venous outflow tract, and undisturbed contractility of the calf musculature. The physiological effectivity of the CMP is compromised by the venous reflux since the volume of the venous blood expelled by the CMP is more or less replaced by the refluxing volume. The contribution of the foot pump to the venous return from the lower extremity has not so far been cleared up.

The intention of this review article is to evaluate the physiological significance of the CMP and the foot pump, to assess the systolic and diastolic pressure behavior in deep and superficial veins of the lower leg during calf pump activity, as well as to evaluate the flow behavior in calf 
perforators resulting from systolic and diastolic pressure differences.

\section{Anatomy and function of the calf muscle pump}

Calf muscle pump is formed by the calf musculature and the deep lower leg veins. The calf musculature consists of

- $\quad$ 1. The posterior compartment inducing plantar flexion of the ankle joint and the toes as well as supination of the foot,

2. The anterior compartment inducing dorsal flexion of the ankle joint and the toes, and

3. The lateral compartment inducing plantar flexion of the ankle joint as well as pronation of the foot.

Deep lower leg veins consist of three paired conductive veins: the posterior tibial vein (PTV), anterior tibial vein, and peroneal vein, as well as of the muscular veins contained in the sural musculature (most important: gastrocnemius veins and soleus veins). Calf muscle pump is called "peripheral heart": contractions of the sural muscles eject the venous blood centripetally toward the heart and promote substantially the return of venous blood from the lower extremity against the gravitation force. During calf muscle contraction, the pressure rises considerably in deep lower leg veins (on average by $75 \mathrm{~mm} \mathrm{Hg}$ ) and a little less also in the great saphenous vein (GSV). The systolic pressure difference between the PTV and the GSV amounts in healthy people to about $40 \mathrm{~mm} \mathrm{Hg}$ and in varicose vein patients to merely $14 \mathrm{~mm} \mathrm{Hg}^{1-3}$; the different pressure gradient is apparently caused by the unequal flow rate capacity of the calf perforators in healthy people and in varicose vein patients. Thus, during calf muscle contractions the venous blood is ejected mainly into the popliteal vein, but a smaller part escapes through calf perforators into the GSV and streams further in the centripetal direction toward the heart. During calf muscle relaxation, the diastolic pressure decreases both in deep lower leg veins and in the GSV ${ }^{1,2}$, 4; the pressure gradient turns round, the diastolic pressure in the GSV is roughly $13 \mathrm{~mm} \mathrm{Hg}$ higher than in the $\mathrm{PTV}^{2,3}$. The systolic and diastolic pressure changes are produced in deep veins. Pressure transmissions between the PTV and the GSV take place through the connecting channels, through calf perforators, which was documented by simultaneous pressure recordings. The pressures transmissions could not take place without bidirectional streaming through calf perforators, i.e. without systolic outward and diastolic inward flow. The steep systolic increase in pressure in the GSV is produced by the outward flow through calf perforators. This flow is centripetal, i.e. physiological; it continues via GSV toward to heart and can be registered in the GSV by duplex ultrasonography. If calf perforators in healthy people were competent, the increase in systolic pressure in the GSV, moreover coincident with similar steep increase in the PTV could not occur. Similar conditions exist in the heart across the competent and incompetent mitral valve. Competent mitral valve precludes systolic increase in pressure in the left atrium. Regurgitation through incompetent mitral valve induces increase in pressure in the left atrium. Thus, with some benevolence, CMP can be compared with the left ventricle, the saphenous system with the left atrium. The pressure in the popliteal and femoral vein oscillates during the CMP activity but does not decrease below the value of the hydrostatic pressure during the diastolic phase ${ }^{1,2,4}$. The pressure difference arising in this way between the popliteal/femoral vein and deep lower leg veins has been called ambulatory pressure gradient; its value is $37.4+-6.4 \mathrm{~mm} \mathrm{Hg}^{5}$. Ambulatory pressure gradient triggers reflux in incompetent veins connecting both poles of the pressure gradient.

The performance of the CMP depends primarily on the patency and impeccable competence of the deep conductive veins of the lower leg (posterior and anterior tibial veins and peroneal veins). Incompetence of these veins disturbs the performance of the CMP. Further factors impairing CMP performance are obstacles in the outflow venous $\operatorname{tract}^{6}$ and reduced calf muscle strength due to muscle weakness, atrophy or palsy.

Plethysmographic findings enable quantification of the CMP performance. Ejection volume produced by the CMP is an important parameter indicating its effectivity; it is determined by air-plethysmography; the normal values are in the range of $60-90 \mathrm{ml}^{7}$. Ejection fraction is another parameter used for evaluating CMP performance; it is expressed in percentage and is calculated as the volume of blood ejected with one calf muscles contraction divided by the functional venous volume. Because this parameter depends on the value of the functional venous volume, it is not suitable for evaluating results after therapeutic procedures that reduce the venous volume contained in varicose veins. The ejection fraction, i.e. the quotient $\mathrm{EV} / \mathrm{VV}$ improves and simulates improvement of the calf muscle performance but the pumping effectivity remains actually unaffected. Other valuable plethysmographic parameters registered after a series of calf muscle contractions and relaxations, such as refill time $\mathrm{t}-50$ and $\mathrm{t}-90$, refill volume gained by strain gauge plethysmography, and residual volume gained by air plethysmography are influenced both by the CMP performance and by the venous reflux. Saphenous reflux simulates malfunction of the CMP because the ejection volume is devaluated by the refluxing volume. Therefore, the lastly mentioned parameters can be taken into consideration for evaluation of the CMP performance only after elimination of saphenous reflux. As a rule, in patients with primary varicose veins even the severest 
hemodynamic disorders in CEAP classes C4 - C6 are caused by the saphenous reflux, whereas the performance of the CMP remains unaffected. After elimination of saphenous reflux physiological ambulatory venous pressure conditions as well as normal plethysmographic values are restored, which would be impossible if impairment of CMP performance were present ${ }^{3,8-11}$;

\section{Anatomy and function of the foot pump}

The substantial part of venous reservoir of the foot pump is formed by the plantar venous plexus. According to Binns and Pho ${ }^{12}$ the plantar venous plexus consists, in addition to subtle veins, mainly of the large lateral plantar vein that is partly double-barreled, of a little smaller medial plantar vein, and of the deep plantar venous arch. The plantar veins are convoluted and fitted with valves directing the flow into the PTV. From the diameter and length of these veins it can be computed that the plantar venous plexus contains altogether about $6 \mathrm{ml}$ of blood. In another study, White et al. ${ }^{13}$ found on the average 2.7 large veins in the plantar venous plexus with a diameter of $4.0+-1.0 \mathrm{~mm}$. The entire length of these veins along the forefoot amounts to about $30 \mathrm{~cm}$; that means they contain about $5 \mathrm{ml}$ of blood. So, the total venous volume of the sole including the blood volume in the foot muscles might hardly reach $10 \mathrm{ml}$.

The contribution of the foot pump to the venous return is still disputable. Plantar veins empty due to compression exerted by weight bearing. Because of the anatomical configuration of the foot only the lateral part of the foot is involved in the pumping process. If taking into account the normal ejection fraction of $60 \%$, the estimated ejection volume of the foot pump would come at about $3-4 \mathrm{ml}$; the large part of this very small volume is ejected into deep lower leg veins, a petty part might be ejected into the GSV.

Broderick et al. ${ }^{14}$ researched venous emptying from the foot using several provoking maneuvers: weight bearing, toe curl, electrical stimulation of the tibial nerve at the medial malleolus, and passive compression. Flow measurements in the particular lower leg veins (posterior tibial veins, anterior tibial veins, and peroneal veins) as well as in the popliteal veins were performed using DUS; the flow in the GSV was not measured. Flow measurements in the deep lower leg veins were performed at the level between the lower and middle part of the lower leg. Values of the ejection volume were obtained by multiplying the cross-sectional area $\mathrm{X}$ mean velocity $\mathrm{X}$ total flow duration. Electrical stimulation of the foot muscles ejected just $1 \mathrm{ml}$ of venous blood into the lower leg veins altogether, which documents that the contraction of the metatarsal muscles exerts just a miniscule effect. Intermittent pneumatic compression of the foot produced venous outflow of $2.18 \mathrm{ml}$, which is likewise negligible. Weight bearing maneuver expelled $6.08 \mathrm{ml}$ and toe curls
$5.03 \mathrm{ml}$ of venous blood into deep lower leg veins. Oddly enough, weight bearing maneuver and toe curls induced in the popliteal vein a remarkable centripetal flow of 33.34 $\mathrm{ml}$ and $31.04 \mathrm{ml}$, respectively, which evidenced that weight bearing maneuvers and toe curls activated not only the foot pump but more effectively also the calf muscle pump. It is obviously quite difficult to provoke selectively the activity of the foot pump without evoking in the weigh-bearing limb involuntary contractions of the calf musculature that occur in order to ensure balance of the body. In addition, toe curls activate by itself the calf muscle pump (musculus flexor hallucis longus and musculus flexor digitorum longus). Because the flow measurements in the lower leg veins were performed at the level between the lower and middle third of the lower leg, it can be deduced that the upper section of the calf musculature where the substantial mass of calf musculature is concentrated might be the most important part of the CMP.

The findings documented that intermittent pneumatic compression of the sole and active contractions of the foot muscles were not capable of expelling a noteworthy volume of venous blood from the foot. The total volume ejected by these two maneuvers into deep lower leg veins amounted to $3.18 \mathrm{ml}(1 \mathrm{ml}$ due to electrical stimulation of the tibial nerve, $2.18 \mathrm{ml}$ due to intermittent pneumatic compression), which complies with the calculations of the venous capacity and ejection potential derived from the anatomical findings, as mentioned in the foregoing paragraph. In addition, the results of these measurements evidenced that the weight bearing maneuver that was primary intended to activate the foot pump was able to achieve only $20 \%$ of the ejection volume registered in the popliteal vein, whereas $80 \%$ of the ejection volume in the popliteal vein accrued from the upper two parts of the calf pump (proximal to the probes measuring the flow in deep lower leg veins). If we take into account that the foot ejected just $3 \mathrm{ml}$ of venous blood into deep lower leg veins but the weight bearing maneuver induced ejection of $6.08 \mathrm{ml}$ registered at the point of measurements in deep lower leg veins, it follows that the lower part of the calf muscles (below the probes) contributed about $3 \mathrm{ml}$ to the ejection volume. Considering the fact that the ejection volume produced by the CMP activity comes at not less than $60 \mathrm{ml}$, it is clear that 3 $\mathrm{ml}$ ejected by the foot pump are negligible and could be ignored.

\section{Interplay of the calf and foot pump activity}

The calf and foot pumps work probably in sequence during normal walking: calf pump (extensor muscles inducing dorsiflexion in the ankle joint) -> foot pump (foot in contact with the ground) -> calf pump (flexor muscles inducing plantar flexion in the ankle joint). When performing tip toe maneuvers, the toe stand represents the systole of the calf muscle pump; the return to the stand on the heel represents the diastole. However, treading fully 
on the heel activates simultaneously the foot pump. Thus, in contrast to the gait cycle, during the tip toe maneuvers the systolic phase of the foot pump occurs during the diastolic phase of the calf pump, i.e. it works de facto as an interference factor. The effect can be demonstrated on the pressure curves. Figure 1 depicts simultaneous pressure recordings in the PTV and GSV in a patient with a severe saphenous reflux; no decrease in pressure occurred during calf pump activity. On the descending arms of the pressure curves, i.e. during the diastole of the calf pump petty spikes were registered, which were apparently evoked by the systolic input of the foot pump. It is evident that the systolic phase of the foot pump does not affect the systolic/diastolic amplitudes produced by the calf pump; the recordings document that the hemodynamic effect of the foot pump is negligible in comparison with the calf pump. This is well comprehensible because the venous blood volume contained in the foot is irrelevant in comparison with the blood volume contained in the calf. In addition, the foot pump is not able to produce the pronounced diastolic decrease in pressure either in the PTV or in the GSV. The systolic and diastolic pressure amplitudes in the PTV and GSV appear synchronously and are very similar, which documents that they are produced by the calf pump, both in varicose vein patients and in healthy people.

\section{Conclusion}

Calf muscle pump is an effective mechanism propelling venous blood from the lower extremities against the gravitation force toward the heart; the contribution of the foot pump is in this regard negligible. The marked and synchronous increase in systolic and decrease in diastolic pressure in the PTV and the GSV both in varicose vein patients and in healthy people is caused by free pressure transmission and bidirectional flow through the calf perforators, which makes deep and superficial veins of the lower leg conjoined vessels.

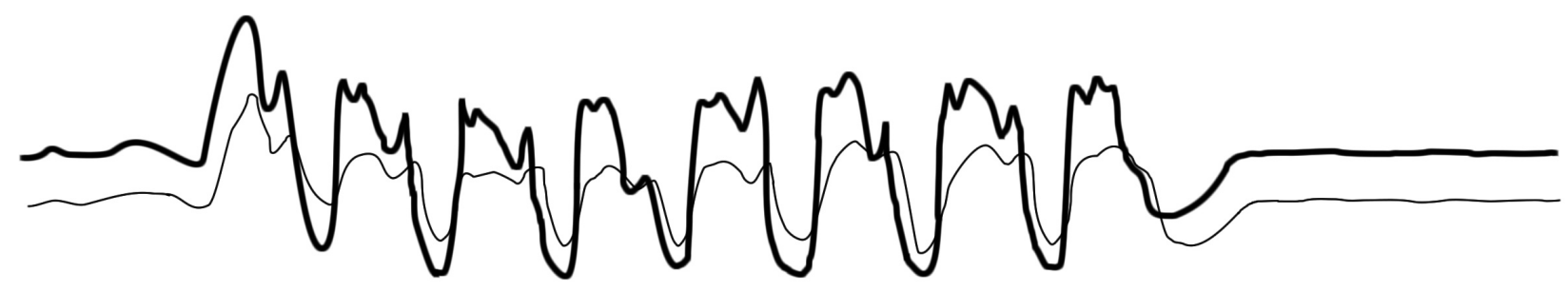

Figure 1 - Simultaneous pressure recordings in the PTV (upper bold curve) and the GSV (lower thin curve) were performed during tiptoe movements in a patient with primary varicose veins and a strong saphenous reflux. The severest hemodynamic disturbance with no decrease in ambulatory venous pressure was registered. Marked systolic and diastolic amplitudes caused by the calf pump are discernible. Little spikes were generated on the descending arms of the pressure curves; they represent the systolic contribution of the foot pump; they do not disturb the decrease in pressure during the calf pump diastole either in the PTV or in the GSV. (Examination was performed by the author himself in the Dept. of Surgery, University Hospital, Hradec Kralove, Czech Rep.).

\section{References}

1) Arnoldi CC. Venous pressure in the legs of healthy human subjects at rest and during muscular exercise in nearly erect position. Acta Chir Scand 1965;130:570-83.

2) Arnoldi CC. Venous pressure in patients with valvular incompetence of the veins of the lower limb. Acta Chir Scand 1966;132: $628-45$.

3) Recek C, Koudelka V. Effet circulatoire du reflux saphénien dans la varicose essentielle. [Impact of saphenous reflux on the venous circulation in varicose vein disease]. Phlébologie 1979;32:407-474.

4) Höjensgard IC, Stürup H. Static and dynamic pressures in superficial and deep veins of the lower extremity in man. Acta Physiol Scand 1952;21:49-61.

5) Recek C, Pojer H. Ambulatory pressure gradient in the veins of the lower extremity. VASA 2000; 29:187-90.
6) Lattimer CR, Azzam M, Kalodiki E, et al. Hemodynamic changes in the femoral vein with increasing outflow resistance. J Vasc Surg Venous Lymphat Disord 2014; 2:26-33.

7) Christopoulos D, Nicolaides AN, Cook A, et al. Pathogenesis of venous ulceration in relation to the calf muscle pump function. Surgery 1989;106:829-35.

8) Recek C: Saphena-Reflux als Ursache der venösen Zirkulationsstörung bei primärer Varikose mit chronischer Veneninsuffizienz. [Saphenous vein reflux is responsible for the venous circulatory disorder in primary varicose veins]. Acta Chir Austriaca 1998;2:76-77.

9) Recek C. Calf pump activity influencing venous hemodynamics in the lower extremity. Int J Angiol 2013;22:23-30.

10) Fitridge RA, Dunlop C, Raptis $S$, et al. A prospective randomized trial evaluating the haemodynamic role of incompetent calf perforating veins. Aust N Z J Surg 1999;69: 214-6. 
C Recek - Contribution of the calf pump and foot pump to the return of venous blood from the lower extremity

11) Padberg FT Jr, Pappas PJ, Araki CT, et al. Hemodynamic and clinical improvement after superficial vein ablation in primary combined venous insufficiency with ulceration. J Vasc Surg $1996 ; 24: 711-8$

12) Binns M, Pho RWH. Anatomy of the 'venous foot pump'. Injury 1988;19:443-5.
13) White JV, Katz ML, Cisek P, et al. Venous outflow of the leg: anatomy and physiologic mechanism of the plantar venous plexus. J Vasc Surg 1996;24:819-24.

14) Broderick BJ, Corley GJ, Quondamatteo F, et al. Venous emptying from the foot: influences of weight bearing, toe curls, electrical stimulation, passive compression, and posture. J Applied Physiol 2010;109:1045-52. 



\section{Surgical prevention of Lymphedema following lymph node dissection: LY.M.P.H.A. technique.}

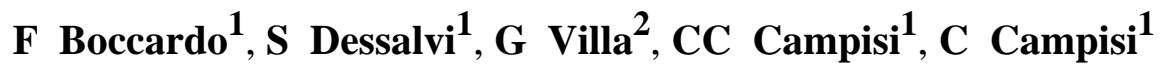

${ }^{1}$ IRCCS Ospedale Policlinico San Martino. Department of Surgery - Unit of Lymphatic Surgery. University of Genoa, Largo R. Benzi 10, 16132, Genoa, Italy.

2 IRCCS Ospedale Policlinico San Martino. Unit of Nuclear Medicine, Largo R. Benzi 10, 16132, Genoa, Italy.

submitted: Feb 23, 2018, accepted: Mar 19, 2018, EPub Ahead of Print: Mar 28, 2018, published: Jun 30, 2018

Conflict of interest: None

DOI: 10.24019/jtavr.41 - Corresponding author: Prof. Francesco Boccardo, francesco.boccardo@ unige.it

() 2017 Fondazione Vasculab impresa sociale ONLUS. All rights reserved.

\begin{abstract}
Background

A side-effect of axillary lymph node excision and radiotherapy for breast cancer is arm lymphedema in about $25 \%$ patients (ranging from 13 to $52 \%$ ). Sentinel lymph node (SLN) biopsy has reduced the severity of swelling to nearly $6 \%$ patients (from 2 to $7 \%$ ) and, in case of positive SLN, complete axillary dissection (AD) is still required. That is why Axillary Reverse Mapping method (ARM) was developed aiming at identifying and preserve lymphatics draining the arm. Leaving in place lymph nodes related to arm lymphatic drainage would decrease the risk of arm lymphedema, but not retrieving all nodes, the main risk is to leave metastatic disease in the axilla. Based on long term experience in lymphatic-venous anastomoses (LVA) for lymphedema treatment, Authors conceived and carried out preventive LVA during nodal dissection (Lymphatic Microsurgical Preventing Healing Approach - LY.M.P.H.A. technique).

Methods

78 patients underwent axillary nodal dissection for breast cancer treatment and in 74 of them LY.M.P.H.A. procedure was performed. Indications to LY.M.P.H.A. technique were based on clinical and lymphoscintigraphic parameters. All blue nodes were resected and 2 to 4 main afferent lymphatics from the arm could be prepared and used for anastomoses. Lymphatics were introduced inside the vein cut-end by a U-shaped stitch. Volumetry was performed
\end{abstract}

preoperatively in all patients and after 1, 6, 12 months and once a year. Lymphoscintigraphy was performed in 45 patients preoperatively and in 30 also postoperatively after at least over 1 year.

Results

Seventy-one patients had no sign of lymphedema. In 3 patients, lymphedema occurred after 8-12 months postoperatively. The incidence of secondary arm lymphedema after LY.M.P.H.A. technique was therefore $4.05 \%$.

\section{Conclusion}

LVA proved not only to prevent lymphedema but also to reduce early lymphatic complications (i.e. lymphorrhea, lymphocele). LY.M.P.H.A. technique is also useful in patients with melanoma of the trunk and vulvar cancer, in whom it is possible to perform preventive LVA simultaneously with inguinal lymphadenectomy. Lymphedema is a consequence of cancer treatment. The use of the blue dye and of LVA helps to solve the problem of preventing secondary arm and leg lymphedema. LY.M.P.H.A. represents a rational approach to the prevention of lymphedema following axillary and groin surgery in the therapy of breast cancer, melanoma, vulvar cancer and other tumors.

Keywords Lymphedema, lymph node dissection, prevention, LY.M.P.H.A. technique, lymphatic-venous anastomosis. 

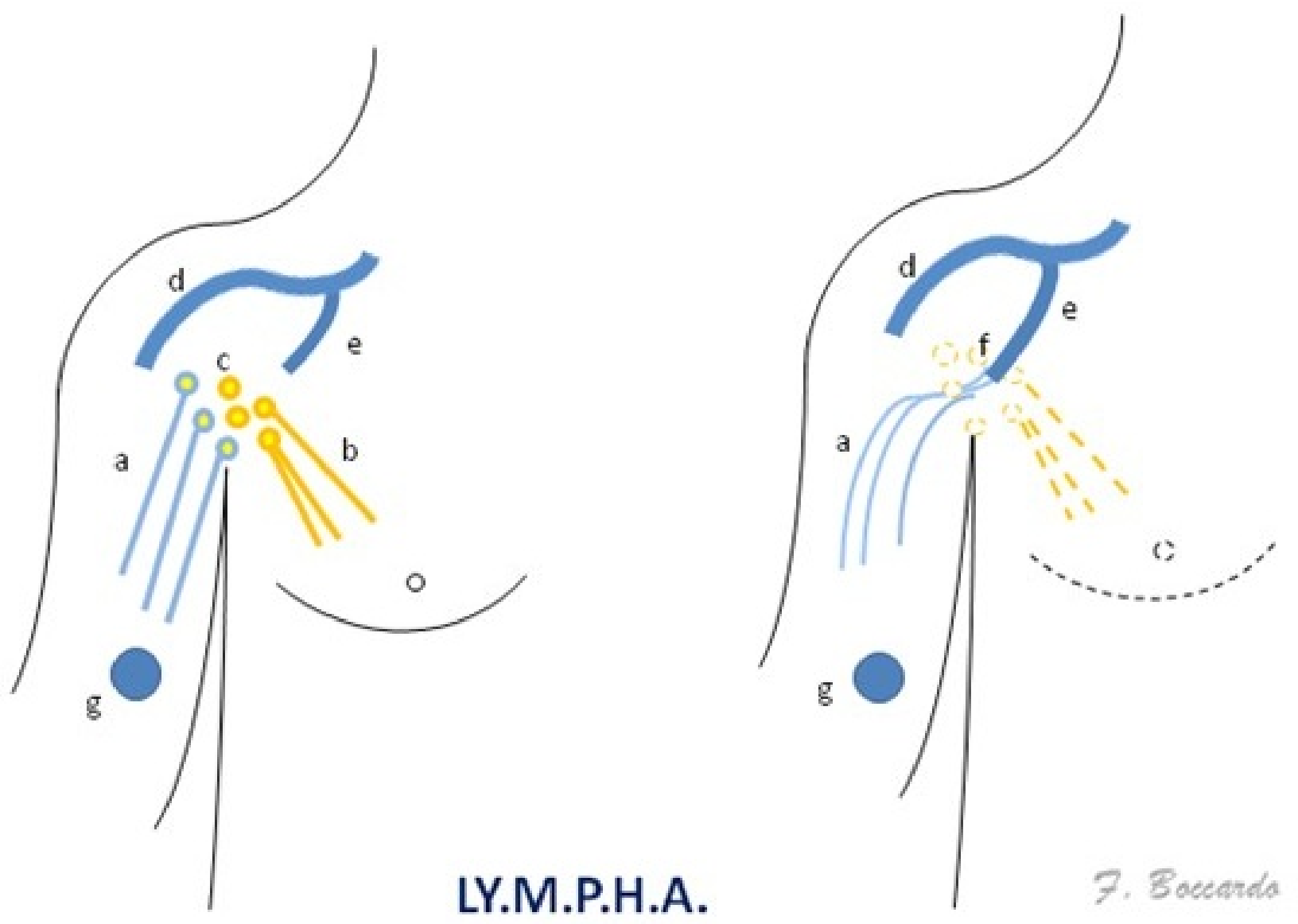

Figure 1 - Schematic drawing of LY.M.P.H.A. procedure at the axilla. a) Arm lymphatics. b) Breast lymphatics. c) Axillary nodes. d) Axillary vein. e) Tributary vein. f) Lymphatic venous anastomosys. g) Blue dye.

\section{Introduction}

A side-effect of axillary lymph node excision and radiotherapy for breast cancer is arm lymphedema in about 25\% patients (ranging from 13 to 52\%). Sentinel lymph node (SLN) biopsy has reduced the severity of swelling to nearly $6 \%$ patients (from 2 to $7 \%$ ) and, in case of positive SLN, complete axillary dissection (AD) is still required. That is why Axillary Reverse Mapping method (ARM) ${ }^{1,2}$ was developed aiming at identifying and preserve lymphatics draining the arm. It consists in injecting intradermally and subcutaneously a small quantity (1-2 $\mathrm{ml}$ ) of blue dye at the medial surface of the arm which helps in locating the draining arm lymphatic pathways. ARM technique allowed to find variable clinical anatomical conditions from what was already generally known, that is the most common location of arm lymphatics below and around the axillary vein. In about one-third of the cases, blue lymphatics can be found till $3-4 \mathrm{~cm}$ below the vein, site where SLN can easily be located, justifying the occurrence of lymphedema after only SLN biopsy ${ }^{3}$. ARM procedure showed that blue nodes were almost always placed at the lateral part of the axilla, under the vein and above the second intercostal brachial nerve ${ }^{4}$. Leaving in place lymph nodes related to arm lymphatic drainage would decrease the risk of arm lymphedema, but not retrieving all nodes, the main risk is to leave metastatic disease in the axilla. Conversely, arm lymphatic pathways when they enter the axilla, cannot be site of breast tumoral disease and their preservation would certainly bring about a significant decrease of lymphedema occurrence rate. Based on long term experience in lymphaticvenous anastomoses (LVA) ${ }^{5,6}$ for lymphedema treatment, Authors conceived and carried out preventive LVA during nodal dissection. Patients candidate to the preventive procedure were selected by body mass index (BMI) and lymphoscintigraphy transport Index (TI): indications were represented by $>30 \mathrm{BMI}$ and $>10 \mathrm{TI}$. Authors report long term outcome of their experience in the prevention of breast cancer related lymphedema using 
Lymphatic Microsurgical Preventing Healing Approach (LY.M.P.H.A.), which consists in anastomosing arm lymphatics to a tributary branch of axillary vein ${ }^{7}$.

\section{Patients and Methods}

From July 2008 to December 2012, 78 patients underwent axillary nodal dissection for breast cancer treatment and in 74 of them LY.M.P.H.A. procedure was performed (Table I). In 4 patients LY.M.P.H.A. could not be carried out because no afferent lymphatics could be found ( 3 patients) and because of massive metastatic disease (1 patient). Indications to LY.M.P.H.A. technique were based on clinical and lymphoscintigraphic parameters. It is well known that obesity predispose to lymphedema and therefore patients with BMI higher than 30 are considered at high risk for lymphedema and are candidates for LY.M.P.H.A.. Patients with normal BMI could be studied with lymphoscintigraphy which was able to point out latent lymphatic impairment ( $\mathrm{TI}>10)$, still not evident clinically.

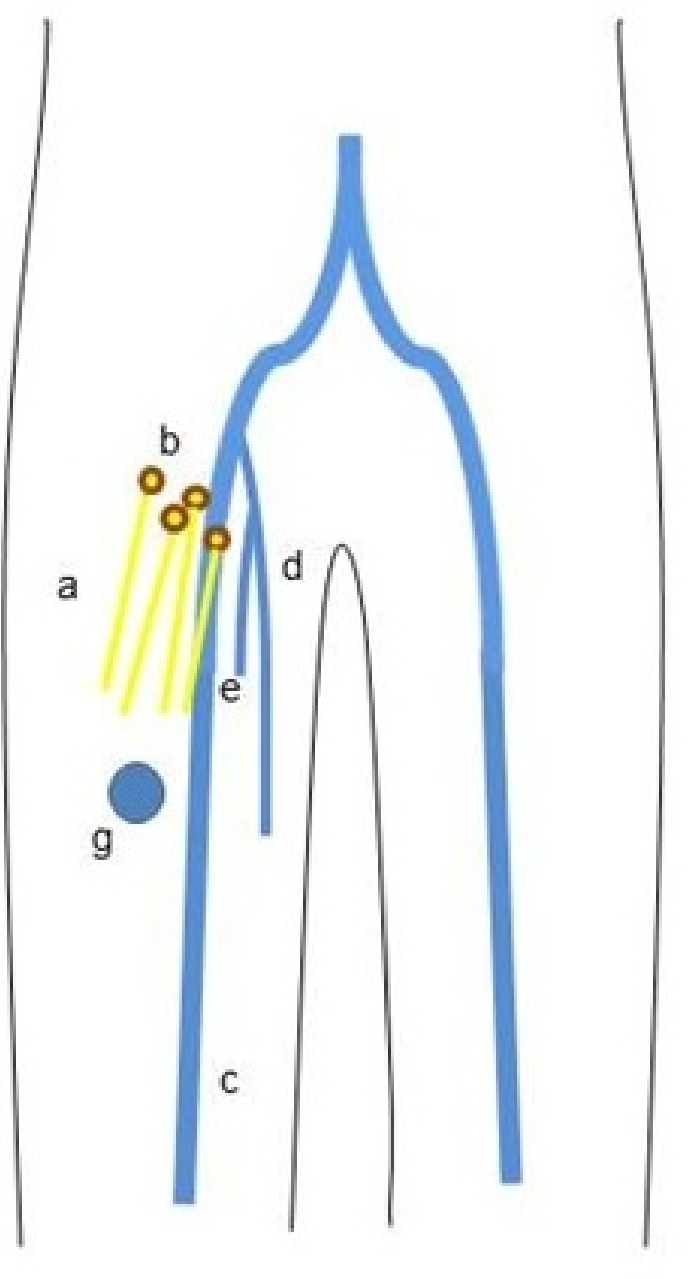

LY.M.P.H.A.

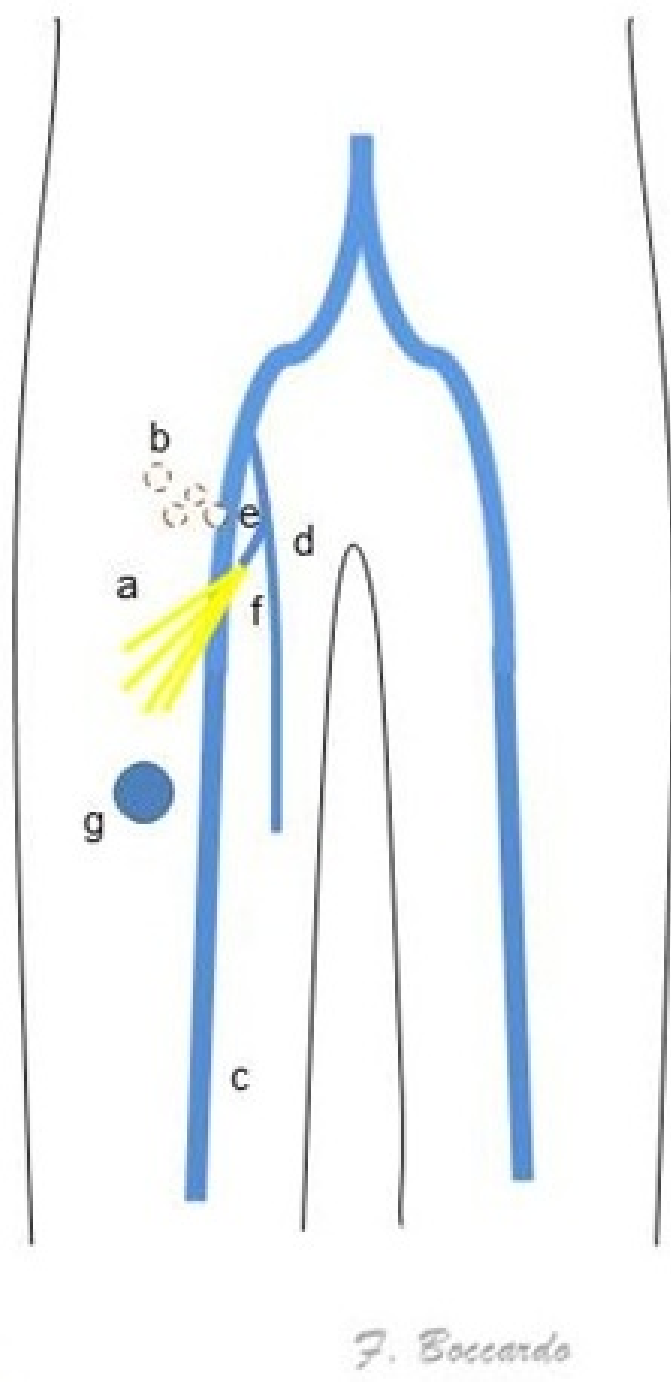

Figure 2 - Schematic drawing of LY.M.P.H.A. procedure at the groin. a) Leg lymphatics. b) Groin nodes. c) Femoral vein. d) Great saphenous vein. e) Tributary vein. f) Lymphatic venous anastomosys. g) Blue dye.

Blue nodes in relation to lymphatic arm drainage could be therefore identified in almost all patients after blue dye injection at the arm. All blue nodes were resected and 2 to 4 main afferent lymphatics from the arm could 
be prepared and used for anastomoses. Lymphatics were introduced inside the vein cut-end by a U-shaped stitch. Other few stitches were given to fix the lymphatic adventitia to the vein wall (Figs.1-4). The operation usually takes only 20 minutes averagely, since both lymphatics and the vein are prepared during nodal dissection. Drain tubes were removed after about 10 days (7-12 days). No bandages at the arm are necessary and patients do not wear any elastic garment.

Volumetry was performed preoperatively in all patients and after 1, 3, 6, 12 months and once per year. Lymphoscintigraphy was performed in 45 patients preoperatively and in 30 also postoperatively after at least over 1 year, comparing pre-op and post-op lymph $\mathrm{TI}^{8}$. Statistical analysis was performed by Fisher's exact test $(\mathrm{P}$ value $<0.05)$.

\section{Results}

Seventy-one patients had no sign of lymphedema and volumetry was coincident to preoperative condition (Table II). In 3 patients belonging to the initial clinical experience lymphedema occurred after 8-12 months postoperatively, usually with the appearance of lymphangitic attacks. Radiotherapy caused temporary edema of the arm in 8 patients and in 3 of them edema became permanent. The incidence of secondary arm lymphedema after LY.M.P.H.A. technique was therefore almost $4 \%$.

Lymphoscintigraphy showed the patency of lymphatic-venous anastomoses at 1-4 years after operation. Comparing lymphatic Transport Index to preoperative conditions, results showed a significant improvement in all patients with early liver tracer uptake. Lymphoscintigraphy was always done in the same department, studying superficial lymphatic circulation, by injecting the tracer at the dorsum of the hand.

\section{Discussion}

LVA proved not only to prevent lymphedema but also to reduce early lymphatic complications (i.e. lymphorrhea, lymphocele - no cases compared with the percentage reported in the literature: $4-89 \%$ ) thanks to the normal regional lymphatic flow.

An important aspect to point out is that, in the axilla, new lymphatic vessel formation (lymphangiogenesis) occurs in response to the ligation of lymphatic vessels involved in lymph node retrievement. Lymphangiogenesis and lymphatic hypertension were demonstrated experimentally in case of lymphatic drainage obstruction. And, in response to lymphatic hypertension, lympho-venous shunts open and provide alternative lymphatic pathways when the main ones are obstructed.

These mechanisms represent an adaptive response to lymphatic hypertension but are not enough to restore normal flow parameters. Furthermore, chronic obstruction to lymph flow progressively leads to a reduced lymphatic contractility, lymphatic thrombosis and fibrotic changes, at a different degree according to variable constitutional predisposition 12,13 .

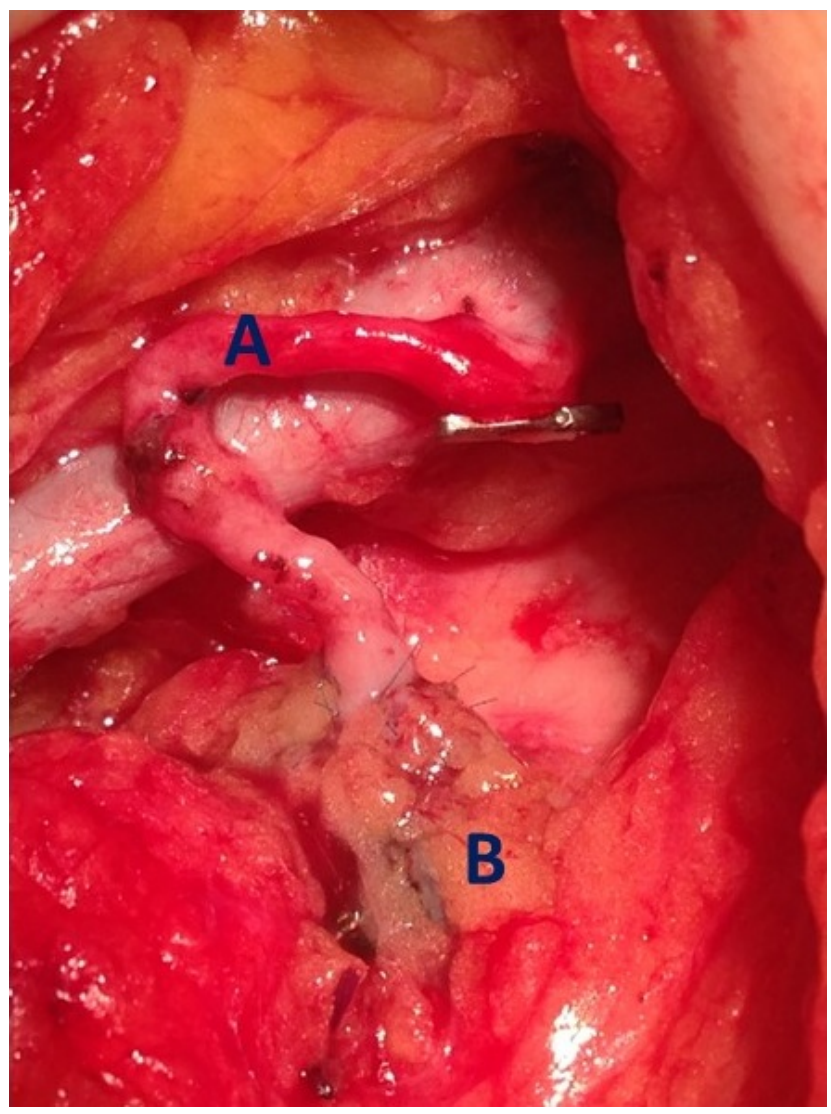

Figure 3 - LY.M.P.H.A. technique at the axilla. A Tributary of the axillary vein. B - Brachial lymphatics colored in blue.

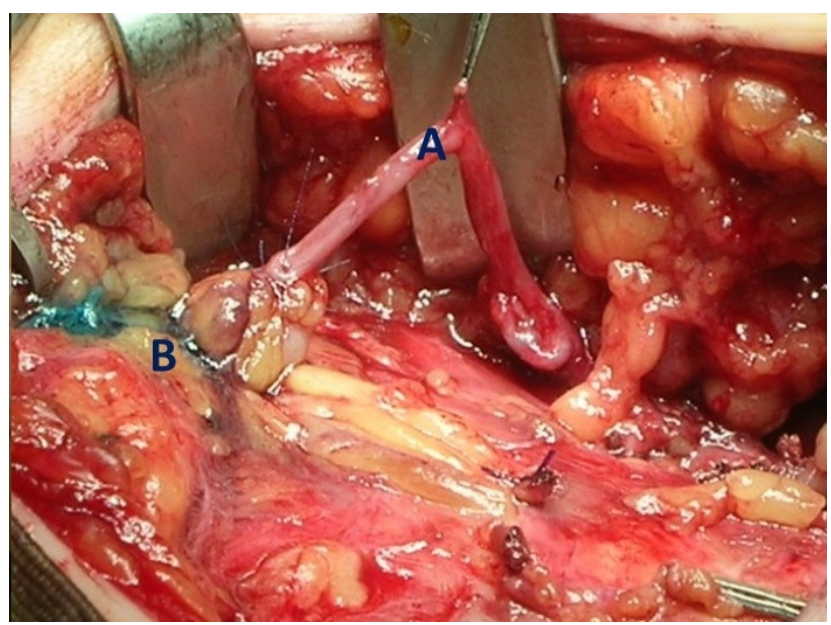

Figure 4 - LY.M.P.H.A. technique at the groin. A - Tributary of the great saphenous vein. B - Lower limb lymphatics colored in blue. 


\begin{tabular}{|lc}
\hline Variable & Mean (range) \\
Age (Years) & $57(42-69)$ \\
Body Mass Index & $24(21-33)$ \\
Variable & \#cases (range) \\
& \\
Lymph Nodes Retrieved & $19(12-21)$ \\
Metastatics Lymph Nodes & $3(0-4)$ \\
Type of surgery (mastectomy/tumorectomy, cases) & $34 / 40$ \\
Radiotherapy (yes/no, cases) & $35 / 39$ \\
Cellulitis (yes/no, cases) & $14 / 60$ \\
Table I - Patients characteristics & \\
\hline
\end{tabular}

\begin{tabular}{|c|c|c|c|c|c|c|}
\hline \multirow[t]{3}{*}{ \# cases } & \multicolumn{3}{|c|}{ Volumetry - Mean $(\sigma)$} & \multicolumn{3}{|c|}{ Lymphoscintigraphy TI - Mean $(\sigma)$} \\
\hline & \multirow{2}{*}{ Pre-Op } & \multicolumn{2}{|c|}{ Post-Op } & \multirow[t]{2}{*}{ Pre-Op } & \multicolumn{2}{|c|}{ Post-Op } \\
\hline & & 1 year & 4 years & & 1 year & 4 years \\
\hline 71 & $760(90)$ & $760(100)$ & $760(90)$ & $12(4)$ & $9(4)$ & $8(4)$ \\
\hline 3 & $770(120)$ & $104(2)$ & I & $14(4)$ & $16(4)$ & l \\
\hline \multicolumn{7}{|l|}{74 total } \\
\hline \multicolumn{7}{|c|}{ Table II - Clinical and instrumental assessment of results after LY.M.P.H.A procedure. } \\
\hline \multicolumn{7}{|c|}{$\begin{array}{l}\sigma \text { standard deviation. P value }<0.05 \text { (Pre-Op and Post-Op volumetric measurements in } 71 \text { patients). TI: Transport } \\
\text { Index. }\end{array}$} \\
\hline
\end{tabular}

Recent advances in the treatment of breast cancer, specifically as concerns the prevention of lymphatic complications following sentinel lymph node biopsy and axillary dissection brought to the proposal of a new technique to primarily prevent lymphedema by microsurgical lymphatic-venous anastomoses (LY.M.P.H.A.). L-V shunts have been chosen for LY.M.P.H.A. technique instead of lymph node or lymph vessels transplantation because it is a faster technique and does not require lymph node or lymph vessels harvesting ${ }^{14}$, 15. ARM technique allows to identify arm lymphatics and lymph nodes which can therefore be preserved even though there is the risk to leave undetected metastatic disease in the axilla. ARM is effective for sentinel lymph node biopsy because it allows to preserve brachial nodes when they are not involved in the procedure. But, it is almost impossible to preserve efferent lymphatics from the blue nodes because they join the common axillary nodal basin draining the breast. Thus, not preserving efferent lymphatics makes practically impossible to preserve arm lymphatic flow. So, on the basis of our wide experience in the treatment of lymphedema by microsurgical lymphaticvenous anastomoses (LVA), we thought to perform LVA immediately after finishing nodal axillary excision. The surgical technique proposed for patients with operable breast cancer requiring an axillary dissection consisted in carrying out LVA between arm lymphatics identified by injecting blue dye in the arm and an axillary vein branch simultaneously. It is almost always possible to find blue lymphatics and also to find a vein branch long enough to be connected to arm lymphatics which are usually locate very laterally.

Disruption of the axillary nodes and closure of arm lymphatics can explain the significantly high risk of early and late lymphatic complications after axillary dissection, especially the most serious complication, that is arm lymphedema ${ }^{16}$. Patients candidate to the preventive procedure were selected by BMI and lymphoscintigraphy TI: indications were represented by $>30 \mathrm{BMI}$ and > 10 TI. TI is a semi quantitative parameter that derives from the measurements of the tracer clearance from the injection point, lymph node uptake and pattern of the drainage along the limb. The incidence of secondary arm lymphedema after LY.M.P.H.A. technique was therefore $4.05 \%$, compared to the incidence rate after only complete 
axillary dissection reported in the literature which ranges from 13 to $65 \%$, depending on the criteria used and means of assessment. Finally, it is important to underline that all three patients who developed lymphedema notwithstanding LY.M.P.H.A. technique belonged to the preliminary clinical experience.

Based on our experience and of the experience of other groups, we can say that the learning curve for LY.M.P.H.A. is of about 20-30 cases. There is no particular method on which we have based to say that but this suggestion derives from the direct clinical experience. LY.M.P.H.A. technique is also useful in patients with melanoma of the trunk, in whom it is possible to perform preventive lymphatic- venous anastomosis (LVA) simultaneously with inguinal lymphadenectomy. The blue dye is injected at the medium third of the medial surface of the thigh. Blue lymphatics afferent to the groin are isolated and anastomosed to a tributary of the great saphenous vein. In most cases, the medial accessory saphenous vein is used and all blue afferent lymphatics are anastomosed to the same vein segment (multiple LVA). A shirtsleeve-shape technique is used. This procedure permits the lymph coming from the main lymphatic pathways of the limb to flow into the bloodstream.

This preventive surgical approach can only be carried out in patients with melanoma localized at the trunk.

In case of melanoma of the extremities, this preventive approach cannot be used for oncological reasons and lymphedema development can be limited with accurate post-operative management. Immediate postoperative elastic wraps have proved their efficacy when placed from the foot to above the knee with multiple layers, replaced afterwards by compression stockings. Leg elevation is useful as well when the patient is still lying on the bed.

After an accurate oncological assessment and the absence of any sign of relapse of the pathology, lymphedema can be treated afterwards by lymphatic

\section{References}

1) Thompson $M$, Korourian S, Henry-Tillman R, Adkins L, Mumford S, Westbrook KC, Klimberg VS. Axillary Reverse Mapping (ARM): A New Concept to Identify and Enhance Lymphatic Preservation. Ann Surg Oncol, 2007; 14(6):1890-1895.

2) Sakorafas GH, Perosa G, Cataliotti L, Vlastos G. Lymphedema Following Axillary Lymph Node Dissection For Breast Cancer. Surg Oncol, 2006; 15(3):153-165.

3) Nos C, Lesieur B, Clough KB, Lecuru F: Blue Dye Injection in the Arm in Order to Conserve the Lymphatic Drainage of the Arm in Breast Cancer Patients Requiring an Axillary Dissection. Annals of Surgical Oncology 14(9):2490-2496 microsurgery, in order to bypass the obstacle to lymph flow by derivative multiple LVA at the groin. In these patients, lymphoscintigraphy represents the gold standard to assess lymphatic transport capacity preoperatively and afterwards to evaluate long term results.

Venous ultrasonography is performed in all patients to study vein circulation. LVA proved to be successful above all in lymphedema at early stages, due to the absence of fibrotic changes of tissues and lymphatic wall.

A correctly performed completion lymphadenectomy with careful attention to surgical details can help to minimize wound complications, decrease the time of closed-suction drains and decrease venous thromboembolism. As concern lymphedema conversely, there is always a congenital predisposition even though it appears to be a real secondary lymphedema in terms of anatomical-functional predisposition. Risk patients may be assessed preoperatively with lymphoscintigraphy and be addressed to preventive measures ${ }^{17,18}$.

Similar experiences have been reported in the literature, confirming the efficacy of LY.M.P.H.A. procedure in the prevention of secondary arm lymphedema and LY.M.P.H.A. technique was included among the surgical procedures to prevent breast cancer related lymphedema ${ }^{19-22}$.

\section{Conclusion}

Lymphedema is a consequence of cancer treatment and patients should be informed of the signs, symptoms and possibilities of prevention for lymphedema. The use of the blue dye and of LVA helps to solve the problem of preventing secondary arm and leg lymphedema even maintaining the oncological radicality. LY.M.P.H.A., therefore, might represent a rational approach to the prevention of lymphedema and reduce other lymphatic complications after axillary and groin surgery in the therapy of breast cancer, melanoma and other tumors.

4) Ponzone R, Mininanni P, Cassina E, Sismondi P. Axillary Reverse Mapping in Breast Cancer: Can we Spare what we Find? Ann Surg Oncol, 2007.

5) Campisi C, Bellini C, Campisi CC, Accogli S, Bonioli E, Boccardo F. Microsurgery for lymphedema: clinical research and longterm results. Microsurgery. 2010 May;30(4):256-60.

6) Auba C, Marre D, Rodriguez-Losada G, Hontanilla B. Lymphaticovenular anastomoses for lymphedema treatment: 18 months postoperative outcomes. Microsurgery 2012 May; 32 (4):261-8.

7) Boccardo F, Casabona F, De Cian F, Friedman D, Villa G, Bogliolo S, Ferrero S, Murelli F, Campisi C. Lymphedema Microsurgical Preventive Healing Approach: A New Technique For 
Primary Prevention Of Arm Lymphedema After Mastectomy. Ann Surg Oncol 2009;16:703-708.

8) E. Kleinhans, R.G.Baumeister, D.Hahn, S.Siuda, U.Bull, E.Moser. Evaluation of transport kinetics in lymphoscintigraphy: follow up study in patients with translplanted lymphatic vessels. Eur J Nucl Med, 1985

9) Boccardo F, Fulcheri E, Villa G, Molinari L, Campisi C, Dessalvi S, Murdaca G, Campisi C, Santi PL, Parodi A, Puppo F, Campisi C. Lymphatic microsurgery to treat lympedema: techniques and indication for better results. Ann Plast Surg, 2013; Mar 28 (Epub).

10) Deutsch M, Land S, Begovic M, Sharif S. The Incidence Of Arm Edema In Women With Breast Cancer Randomized On The National Surgical Adjuvant Breast And Bowel Projet Study B-04 To Radical Mastectomy Versus Total Mastectomy And Radiotherapy Versus Total Mastectomy Alone. Int J Radiat Oncol Biol Phys, 2008; 70:1020-1024.

11) Kwan ML, Darbinian J, Schmitz KH, Citron R, Partee P, Kutner SE, Kushi LH. Risk Factors For Lymphedema In A Prospective Breast Cancer Survivorship Study: The Pathways Study. Arch Surg, 2010; 145:1055-1063.

12) Gartner R, Jensen MB, Kronborg L, Ewertz M, Kehlet H, Kroman N. Self-Reported Arm-Lymphedema And Functional Impairment After Breast Cancer Treatment: A Nationwide Study Of Prevalence And Associated Factors. Breast, 2010; 19:506-515.

13) Jila A, Kim H, Nguyen VP, Dumont DJ, Semple J, Armstrong D, Seto E, Johnston M. Lymphangiogenesis Following Obstruction Of Large Postnodal Lymphatics In Sheep. Microvasc Res 2007; 73:214-223.

14) Modi S, Stanton AWB, Svensson WE, Peters AM, Mortimer PS, Levick JR. Human Lymphatic Pumping Measured In Healthy And Lymphoedematous Arms By Lymphatic Congestion Lymphoscintigraphy. J Physiol 2007; 583.1:271-285.

15) Felmerer G, Sattler T, Lohrmann C, Tobbia D. Treatment of various secondary lymphedemas by microsurgical lymph vessel transplantation. Microsurgery 2012 Mar; 32 (3):171-7.
16) Francissen CMTP, Dings PJM, Van Dalen T, Strobbe LJA, Van Laarhoven HWM, De Wilt JHW: Axillary Recurrence After A Tumor-Positive Sentinel Lymph Node Biopsy Without Axillary Treatment: A Review Of The Literature. Ann Surg Oncol, 2012; 19:4140-4149.

17) Paskett ED, Dean JA, Oliveri JM, Harrop P. Cancer-Related Lymphedema Risk Factors, Diagnosis, Treatment, And Impact: A Review. J Clin Onc 2012; 30 (30):3726-3733.

18) Witte MH, Dellinger MT, Papendieck CM, Boccardo F. Overlapping biomarkers, pathways, processes and syndromes in lymphatic development, growth and neoplasia. Clin Exp Metastasis. 2012 Oct; 29(7):707-27.

19) Feldman S, Bansil H, Ascherman J, Grant R, Borden B, Henderson P, Ojo A, Taback B, Chen M, Ananthakrishnan P, Vaz A, Balci F, Divgi CR, Leung D, Rohde C. Single Institution Experience with Lymphatic Microsurgical Preventive Healing Approach (LYMPHA) for the Primary Prevention of Lymphedema. Ann Surg Oncol. 2015 Oct;22(10):3296-301.

20) Hahamoff M, Gupta N, Munoz D, Lee BT, Clevenger P, Shaw C, Spiguel L, Singhal D. A lymphedema surveillance program for breast cancer patients reveals the promise of surgical prevention. J Surg Res. 2018 Feb 1. pii:S0022-4804(17)30662-5.

21) McLaughlin SA, Staley AC, Vicini F, Thiruchelvam P, Hutchison NA, Mendez J, MacNeill F, Rockson SG, DeSnyder SM, Klimberg S, Alatriste M, Boccardo F, Smith ML, Feldman SM. Considerations for Clinicians in the Diagnosis, Prevention, and Treatment of Breast Cancer-Related Lymphedema: Recommendations from a Multidisciplinary Expert ASBrS Panel : Part 1: Definitions, Assessments, Education, and Future Directions. Ann Surg Oncol. 2017 Oct;24(10):2818-2826.

22) McLaughlin SA, DeSnyder SM, Klimberg S, Alatriste M, Boccardo F, Smith ML, Staley AC, Thiruchelvam PTR, Hutchison NA, Mendez J, MacNeill F, Vicini F, Rockson SG, Feldman SM. Considerations for Clinicians in the Diagnosis, Prevention, and Treatment of Breast Cancer-Related Lymphedema, Recommendations from an Expert Panel: Part 2: Preventive and Therapeutic Options. Ann Surg Oncol. 2017 Oct;24(10):2827-2835. 



\title{
Does Rivaroxaban have a fibrinolytic effect?
}

\author{
PL Antignani ${ }^{1}, \mathrm{C}$ Allegra $^{2}$ \\ ${ }^{1}$ Director, Vascular Center, Nuova Villa Claudia, Rome, Italy \\ ${ }^{1}$ Founding President, Central European Vascular Forum
}

submitted: Mar 25, 2018, accepted: Mar 26, 2018, EPub Ahead of Print: Mar 28, 2018, published: Jun 30, 2018 Conflict of interest: None

DOI: 10.24019/jtavr.46 - Corresponding author: Prof. Pier Luigi Antignani, antignanipl@ gmail.com

C 2017 Fondazione Vasculab impresa sociale ONLUS. All rights reserved.

\begin{abstract}
Aim

The study started from the observation of complete recanalization of thrombus in subjects with DVT treated with rivaroxaban after 1-2 weeks. Aim of this clinicalinstrumental observational retrospective research is to evaluate clinically and by means of Echo color Duplex the fibrinolytic effect of Rivaroxaban in patients with recent and previous DVT.

Methods

We evaluated two populations of patients:

$1^{\text {st }}$ group: 27 patients males (range of age 50-73 years) with popliteal-femoral DVT (12 months before) treated with standard anticoagulant therapy. In this patients we found a complete superficial femoral recanalization and partial recanalization of the popliteal vein $(30 \%$ of residual thrombus). The patients had normal creatinine clearance and liver function. The patients switched from warfarin to rivaroxaban for no compliance to warfarin.

$2^{\text {nd }}$ group: 19 patients (range of age 65-85 years) with previous popliteal-femoral DVT and complete common femoral veins recanalization (already know or
\end{abstract}

\section{Introduction}

The objectives of anti-coagulation are prevention of extension of the thrombus, avoidance of pulmonary embolism (PE), prevention of recurrence of VTE and ultimately the avoidance of post-thrombotic syndrome (PTS). Considerable progress in the treatment of deep-vein thrombosis (DVT) of the lower extremities was achieved with the development of direct non-vitamin $\mathrm{K}$ antagonists (DOACs) and fibrinolytic therapies. Rivaroxaban is an oral, direct factor $\mathrm{Xa}$ inhibitor that inhibits free and clot-bound documented). The patients presented recent superficial femoral vein re-thrombosis (1 week before). The patients had normal creatinine clearance and liver function.

Results

$1^{\text {st }}$ group: we observed in all patients the complete recanalization of the popliteal veins.

$2^{\text {nd }}$ group: we observed in all patients the complete recanalization of the superficial femoral veins after 2 weeks of the therapy of Rivaroxaban and complete recanalization of the popliteal veins after 4 weeks. No adverse events for both groups were observed.

Conclusion

According to our results, we consider that Rivaroxaban could have a fibrinolytic effect not only on recent thrombus but also on organized thrombus with, as result, a complete recanalization of affected veins and consequent reduction of incidence of post-thrombotic syndrome saving the valves structure.

Keywords Acute venous thrombosis, re-thrombosis, DOACs, post-thrombotic syndrome, fibrinolysis

factor $\mathrm{Xa}$ and factor $\mathrm{Xa}$ in the prothrombinase complex. Preclinical studies demonstrated a potent anticoagulant effect of rivaroxaban in plasma as well as the ability of this agent to prevent and treat venous and arterial thrombosis in animal models. These studies led to an extensive phase I clinical development program that investigated the pharmacological properties of rivaroxaban in humans ${ }^{1,2,3}$.

The pharmacodynamic effects of rivaroxaban (for example, inhibition of factor $\mathrm{Xa}$ and prolongation of 
prothrombin time) were closely correlated with rivaroxaban concentrations in plasma ${ }^{4}$.

Rivaroxaban is indicated for the treatment of deep vein thrombosis (DVT), and prevention of recurrent DVT and pulmonary embolism (PE) following an acute DVT in adults. For the initial treatment of acute deep vein thrombosis, the recommended dosage of rivaroxaban is $15 \mathrm{mg}$ twice daily for the first 21 days followed by 20 $\mathrm{mg}$ once daily for continued treatment and prevention of recurrence $^{5-8}$.

During the treatment of the patients with DVT we observed the complete recanalization of thrombus after 1-2 weeks. We presented these results during some congresses and other authors reported the same observation.

Aim of this clinical-instrumental observational retrospective research is to evaluate clinically the fibrinolytic effect of Rivaroxaban in patients with recent and previous DVT, i.e.with re-thrombosis or organized thrombus.

\section{Material and methods}

We evaluated two populations of patients (see table I)

$1^{\text {st }}$ group: 27 patients (mean age $50-73$ years) with previous popliteal-femoral DVT (max 12 months before) treated with standard anticoagulant therapy at long time for different reasons.

The patients switched from warfarin to rivaroxaban for no compliance to warfarin (frequent long distance travel with important jet-lag, no observation for the food, continuous change of INR values, no correct observance of dosages).

At the first observation (time 0) by means of echo duplex we found a complete superficial femoral recanalization and partial recanalization of the popliteal vein (with $30 \%$ of residual thrombus).

$2^{\text {nd }}$ group: 19 patients (mean age 65-85 years) with the same presentation of $1^{\text {st }}$ group (previous poplitealfemoral DVT with the complete common femoral veins recanalization and partial popliteal recanalization and residual thrombosis of $30 \%$, already know or documented) but with recent superficial femoral vein re-thrombosis (onset 1 week before).

In these patients we started with the treatment with rivaroxaban due to intolerance to low molecular weight heparin (L.M.W.H.) and no compliance to warfarin.

We treated all patients with $15 \mathrm{mg}$ BID for 21 days followed by $20 \mathrm{mg}$ OD of Rivaroxaban for 3 months. All patients had normal creatinine clearance and liver function.
Both groups were submitted to the clinical and echo duplex examination at time 0 and at 1,2,3,4 weeks and after 3 months during the DOACs treatment.

\section{Results}

$1^{\text {st }}$ group: we observed in all patients after 2 weeks the complete recanalization of the popliteal veins (previous thrombosis with $30 \%$ of residual thrombus).

$2^{\text {nd }}$ group: in the same way, we observed in all patients the complete recanalization of the popliteal veins (previous thrombosis) after 4 weeks.and the complete recanalization of the recent thrombosis of the superficial femoral veins after 2 weeks of the therapy of Rivaroxaban.

No adverse events for both groups were observed.

\section{Conclusions}

Factor $\mathrm{X}$ has long been known to have a key role in hemostasis, and its activated form, factor Xa, has a significant function in the blood coagulation pathway because it catalyzes the production of thrombin, which leads to clot formation. Activation of factor $\mathrm{X}$ to factor $\mathrm{Xa}$ occurs through both the intrinsic and extrinsic pathways of the coagulation cascade. Factor $\mathrm{Xa}$ initiates the final, common pathway that results in thrombin activation via the prothrombinase complex. Early studies of naturally occurring factor Xa inhibitors indicated that targeting factor Xa could provide effective anticoagulation ${ }^{8}$. Selective inhibition of factor Xa produces antithrombotic effects by decreasing the generation of thrombin, thus diminishing thrombin-mediated activation of both coagulation and platelets without affecting the activity of existing thrombin 9,10 .

In the paper of Garabon ${ }^{11}$ Rivaroxaban was shown to decrease the rate of coagulation, which was decreased further at higher concentrations of thrombomodulin (TM). The presence of either thrombin activatable fibrinolysis inhibitor (TAFI) variant also seemed to decrease clot formation rate at higher levels of rivaroxaban and TM. At all concentrations of TM, TAFI-dependent resistance to fibrinolysis was attenuated by rivaroxaban. The effect of rivaroxaban was, however, greater for wild-type TAFI than for the T325I variant. In conclusion, rivaroxaban exhibits TAFI-dependent profibrinolytic effects that are influenced by the levels of TM and the by intrinsic stability of TAFIa. TM also affected the dynamics of coagulation. These findings suggest a role for the anatomical location of a procoagulant stimulus and plasma TM-altering disease phenotypes in the pharmacodynamics and a role for the T325I polymorphism in the pharmacogenomics of rivaroxaban. 
$1^{\text {st }}$ group

Patients

Mean age

Range

Males/females

Onset of previous thrombosis

Onset of acute thrombosis

Complications

Adverse effects by rivaroxaban
27

61,5 years

50-73 years

$9 / 18$

max 12 months

...

none

none $2^{\text {nd }}$ group

19

66,8 years

65-85 years

$8 / 11$

$\max 12$ months

1 week

none

none

Table I - Patients data subdivided by groups. Treatment: rivaroxaban $15 \mathrm{mg}$ BID for 21 days followed by $20 \mathrm{mg}$ OD for 3 months. BID - bis in die. OD - once a day.

Álvarez ${ }^{12}$ also showed that Rivaroxaban also altered ( $>2$ fold change) the expression of matrix metallopeptidase 2 and urokinase plasminogen activator (u-PA), but counteracted the FXa $(9 \mathrm{nM})$-induced up-regulation of several pro-inflammatory genes $(\mathrm{P}<0.05)$ and FXaenhanced platelet adhesion over human umbilical vein endothelial cells (HUVEC). Rivaroxaban increased u-PA protein expression in HUVEC supernatants and enhanced u-PA activity (up to $4 \mathrm{IU} \mathrm{ng}^{-1}$ of u-PA). Rivaroxaban ( $1 \mathrm{nM}-$ $1 \mu \mathrm{M})$ showed a significant and dose-dependent positive effect on HUVEC growth that was inhibited by BC-11hydroxibromide, an inhibitor of u-PA. Healing properties after a wound on HUVEC cultures, and fibrinolytic properties were also shown by rivaroxaban. Both effects were reversed by BC-11-hydroxibromide. Rivaroxaban enhanced viability, growth and migration of HUVEC, mainly by u-PA activation and upregulation, which also participate in the rivaroxaban-induced fibrinolytic activity at endothelial level. Rivaroxaban also protected from the pro-inflammatory effects of FXa on HUVEC. Altogether may improve endothelial functionality and could contribute to the cardiovascular benefits of rivaroxaban.

From the clinical point of view, the EINSTEIN investigators ${ }^{13,14}$ conducted a post-hoc subgroup analysis of the Einstein DVT trial $(\mathrm{N}=3449)$ to assess the impact of rivaroxaban therapy on the development of PTS. KaplanMeier survival analysis was performed to compare the cumulative incidence of PTS between the rivaroxaban and enoxaparin/VKAgroups. They included 336 patients, $162(48 \%)$ treated with rivaroxaban and $174(52 \%)$ with enoxaparin/VKA. The cumulative PTS incidence at 60 months was $29 \%$ in the rivaroxaban group and $40 \%$ in the enoxaparin/VKAgroup. After adjusting for age, gender, body mass index, previous VTE, ipsilateral recurrent DVT, extent of DVT, idiopathic DVT, duration of anticoagulant treatment, compliance to assigned study medication, elastic compression stocking use and active malignancy, the HR of PTS development for rivaroxaban was 0.76 (95\% CI: 0.51-1.13). The investigators concluded that treatment of acute DVT with rivaroxaban was associated with a numerically lower but statistically non-significant reduction in risk of PTS compared with enoxaparin/ VKAtreatment.

Van Es ${ }^{15}$ confirms early clot regression in acute PE following 21 days of rivaroxaban in the $88 \%$ of patients with PE.

Many of the pharmacological effects of Rivaroxaban and other DOACs on cardiovascular system remain unexplored at this time. Since novel mechanisms might be involved in venous recanalization during rivaroxaban treatment, we might have to return from bedside to the bench (basic science) to understand these mechanisms. Additional data with the DOACs will emerge from basic science as well as prospective clinical trials, ultimately helping cardiovascular patients prevail over such severe diseases.

We consider that our results showed that Rivaroxaban could have a fibrinolytic effect not only on recent thrombus, as demonstrated from several trials, but also on organized thrombus with, as result, a complete recanalization of the previous residual thrombus. This action probably is due to the effect on remodeling of endothelium, considering that the organization of thrombus begins after adherence of the clot to the vessel wall, with formation of a thin lining of endothelial cells over its surface, followed by ingrowth of cells from the intima media and capillary buds into the thrombus. 
Our data allow us to consider rivaroxaban as useful drug for reducing the incidence of post-thrombotic syndrome saving the valves structure.

It may be clinically relevant to identify the speed of clot resolution during anticoagulant treatment. As in patients with a suspected recurrent DVT, it is often unclear whether thrombi reflect a recurrence or an old thrombus. Consequently, knowledge about the time to clot resolution

\section{References}

1) McRae SJ, Ginsberg JS Initial treatment of venous thromboembolism. Circulation 2004; 110: I3-I9.

2) Ageno W, Gallus AS, Wittkowsky A, Crowther M, Hylek EM, Palareti G. Oral anticoagulant therapy: antithrombotic therapy and prevention of thrombosis. 9th ed: American College of Chest Physicians evidence-based clinical practice guidelines. Chest 2012; 141: e44S-e88S

3) Brummel-Ziedins KE, Orfeo T, Gissel M, Mann KG, Rosendaal FR. Factor Xa generation by computational modeling: an additional discriminator to thrombin generation evaluation. PLoSONE 2012: 7:e29178. doi: 10.1371/journal.pone.0029178

4) Bauer KA. Pros and cons of new oral anticoagulants. Hematology 2013; 7: 465-70.56.

5) Allegra C, Antignani PL, Kalodiki E. News in Phlebology. Minerva Medica Ed. Torino 2013.

6) Garcia DA, Baglin TP, Weitz JI, Samama MM. Parenteral anticoagulants: antithrombotic therapy and prevention of thrombosis, 9thed: American College of Chest Physicians evidence-based clinical practice guide lines. Chest 2012; 141: e24S-e43S.

7) Einstein Investigators, Bauersachs R, Berkowitz SD, et al. Oral rivaroxaban for symptomatic venous thromboembolism. N Engl J Med. 2012;363(26):2499-2510.

8) Einstein-PE Investigators, Büller HR, Prins MH, et al. Oral rivaroxaban for the treatment of symptomatic pulmonary embolism. N Engl J Med. 2012;366(14):1287-1297. might be helpful in the diagnostic work-up of patients with recurrent DVT. In our case reports, we observed the complete resolution of acute thombi after 2 weeks and the complete recanalization of old thrombi after 4 weeks.

Of course, it is necessary more observation to confirm these hypotheses and to establish the correct dosage of drug but probably the single drug approach (20 mg OD) at long time could be the correct treatment.

9) Rodriguez RA, Carrier M, Wells PS. Non-adherence to new oral anticoagulants: a reason for concern during long-term anticoagulation? J Thromb Haemost. 2013;11(2):390-394.

10) Weitz JI, Gross PL. New oral anticoagulants: which one should my patient use? Hematology Am Soc Hematol Educ Program. 2012;2012:536-540.

11) Garabon JJ, Boffa MB. Impact of Thrombomodulin and Thrombin-activatable Fibrinolysis Inhibitor on the Anti-coagulant and Pro-fibrinolytic Effects of Rivaroxaban Arteriosclerosis, Thrombosis, and Vascular Biology. 2016;36:A34.

12) Álvarez E, Paradela-Dobarro B, Raposeiras-Roubín S, González-Juanatey JR Protective, repairing and fibrinolytic effects of rivaroxaban on vascular endothelium. Br J Clin Pharmacol 2018; 84: 280-291.

13) Cheung YW, Middeldorp S, Prins MH, Pap AF, Lensing AW, Ten Cate-Hoek AJ, et al. Post-thrombotic syndrome in patients treated with rivaroxaban or enoxaparin/vitamin $\mathrm{K}$ antagonists for acute deep-vein thrombosis. Apost-hoc analysis. Thromb Haemost 2016;116:733-8.

14) EINSTEIN-PE Investigators, Büller HR, Prins MH, Lensin AW, Decousus H, Jacobson BF, et al. Oral rivaroxaban for the treatment of symptomatic pulmonary embolism. N Engl J Med 2012;366:1287-97.

15) van Es J et al, Clot resolution after 3 weeks of anticoagulant treatment for pulmonary embolism: comparison of computed tomography and perfusion scintigraphy $\mathbf{J}$ Thromb Haemost 2013;11:679-685 


\section{Hemodynamics in Klippel-Trenaunay Syndrome}

\section{R Mattassi ${ }^{1}$, W Pozzoli ${ }^{1}$}

${ }^{1}$ Center for Vascular Malformation "Stefan Belov". Clinical Institute Humanitas "Mater Domini”. Castellanza (Varese), Italy Invited presentation to the Venous Hemodynamic Session of the XVIII World Congress of the International Union of Phlebology (UIP), Melbourne Feb 4-8, 2018 submitted: Apr 6, 2018, accepted: Apr 16, 2018, EPub Ahead of Print: Apr 20, 2018, published: Jun 30, 2018 Conflict of interest: None

DOI: 10.24019/jtavr.48 - Corresponding author: Prof. Raul Mattassi, raulmattassi@gmail.com

() 2017 Fondazione Vasculab impresa sociale ONLUS. All rights reserved.

Abstract Klippel-Trenaunay syndrome (KTS) is a complex vascular malformation that involves extensively the lower limb and may be combined with lymphatic and capillary defects. Very little has been published about hemodynamic of this disease. In this paper, we studied with duplex scan the hemodynamics in a group of 52 patients affected by KTS. In a former study, we recognized the following vascular venous defects: dysplastic venous areas infiltrating tissues, dysplastic superficial veins, hypoplasia and aplasia of deep veins, presence of marginal vein and presence of sciatic vein. The study demonstrates several hemodynamic defects, like venostasis and reflux in superficial dysplastic veins, blood stasis in infiltrating, mainly intramuscular, venous malformations, reflux and venostasis in large marginal veins, no main reflux in sciatic vein and dilatation of calf veins with some stasis but no reflux. Duplex scan study is mandatory in KTS but need to be an oriented exam in order to find out main defects existing in KTS. Standard examination, like in varicose veins, is not a correct study as it may ignore some main defects.

Keywords Klippel-Trenaunay syndrome, vein aplasia, marginal vein, venous malformations, intramuscular venous malformations

\section{Introduction}

Klippel Trenaunay Syndrome (KTS) has been described in 1900 as a congenital vascular disease of the lower limbs characterized by a triad of clinical signs: cutaneous nevus, limb hypertrophy and superficial abnormal veins ${ }^{1}$. At that time, only clinical descriptions were possible, as no diagnostic tools were available. In more recent times, several publications about the disease were available but a great majority regards single case descriptions $^{2,3}$. Systematic analysis of hemodynamics in a series of patients affected by KTS has rarely been performed. A recent review of the literature shows that very often diagnosis is performed by MR and venography rather than by duplex scan ${ }^{4}$. However, a recent single study demonstrates the diagnostic efficacy of color Doppler in KTS $^{5}$
Hemodynamic of a dysplastic venous system depends on the anatomical anomalies of veins. Knowledge of the possible anomalies that may exist is necessary for a correct hemodynamic analysis of KTS. In a former study we got that data on 46 cases $^{6}$. Based on that knowledge, we analyzed with duplex scan a group of patients affected by KTS in order to find out flow anomalies. A main problem in studies about KTS is that the definition is controversial, as the role in the combination of venous and lymphatic and even AVM is not clearly indicated in many papers. Even the name of the defect is still today unclear, as the wrong term of Klippel-Trenaunay-Weber (a type of "combination" of Klippel-Trenaunay and Parkes Weber syndrome, which is meaningless) is often used. For that reason, strict selection criteria of patients to include in this study has been adopted, according to a consensus of experts ${ }^{7}$ 


\section{Material and methods}

A group of 52 patients, observed between 2011 and 2017 were included in this study. Inclusion criteria were:

- diffuse vascular disease of the whole limb: limited defects only of the thigh or of the calf were excluded as they do not meet the criteria of a diffuse, extended defect

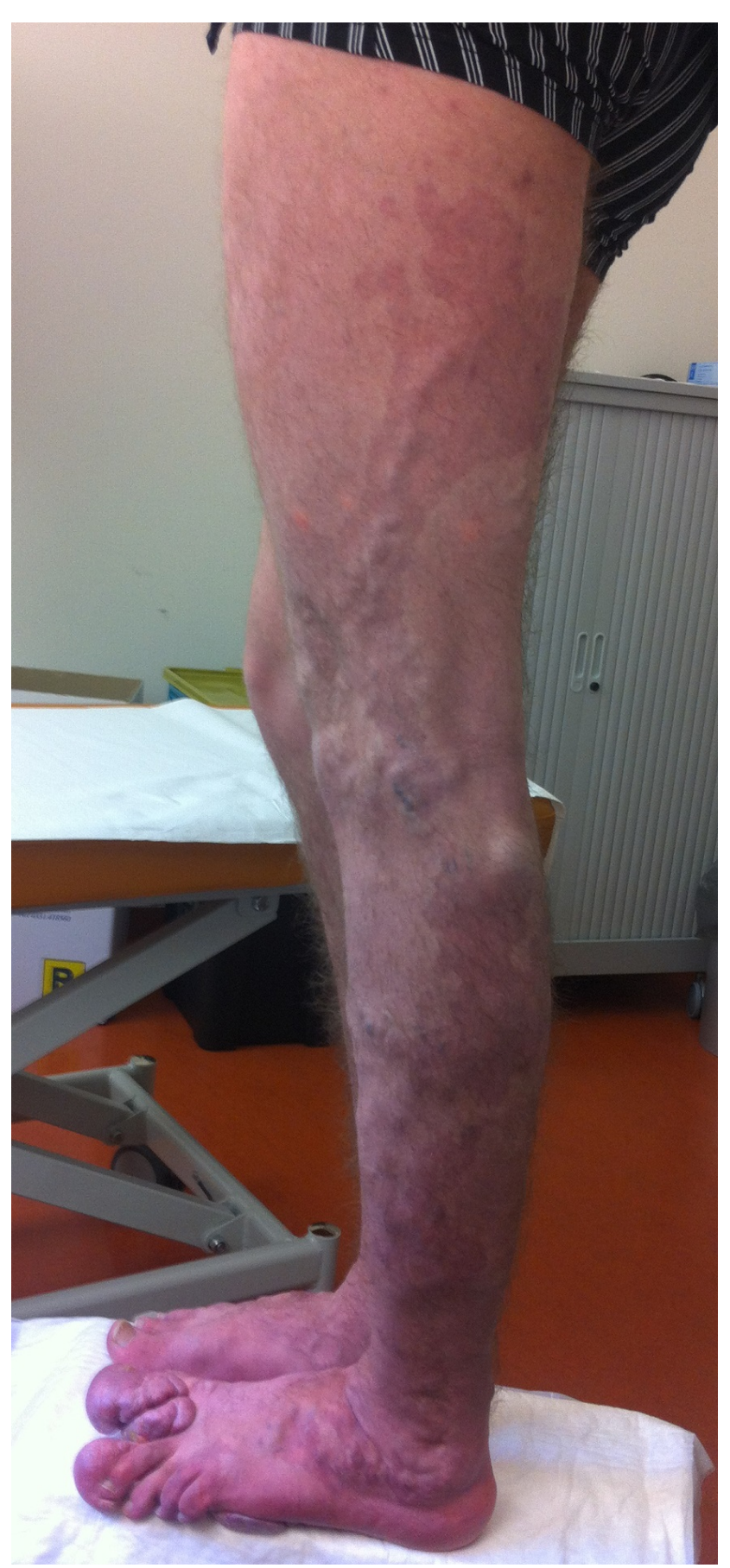

Figure 1 - Dilated abnormal superficial lateral veins in KTS absence of artero-venous defects. First selection was done by clinical criteria; a duplex scan that rule out AVM was then also performed

presence of venous anomalies. Patients without that criteria, like pure lymphatic dysplasia were excluded from that study

Types of vascular defects were recorded by duplex scan and MR. Hemodynamic defects in each case were studied by duplex scan.

\section{Result}

In a former study on vascular anomalies in KTS, the following anatomic defects in 46 cases were recognized ${ }^{6}$ :

- $\quad$ superficial dysplastic veins, like varicose veins

but with a dysplastic wall (100\%)

- deep infiltrating dysplastic veins (41\%)

- $\quad$ marginal vein $(30 \%)$

- $\quad$ deep vein aplasia $(19 \%)$

- $\quad$ deep vein hypoplasia $(19 \%)$

- $\quad$ sciatic vein (7\%)

Based on that list of anomalies, we analyzed our cases of KTS by duplex scan study, looking for those defects and trying to find out hemodynamic anomalies.

The following hemodynamic anomalies were observed:

1) Reflux in deep main veins (femoral and popliteal vein): 22 cases of 52 (42\%).

2) Venostasis (blood stagnation in standing position) in superficial abnormal veins. These veins were often placed on the lateral edge of the limb, extending in some cases proximally until gluteus. Wide or extremely wide (up to $1 \mathrm{~cm}$ diameter) lateral perforating veins were sometimes recognizable. Locations were variable; lateral side of the calf (in several cases a huge, lateral perforating vein were sited just below the peroneal epiphysis), lateral side of the thigh and gluteus laterally but also on the posterior surface. These veins were not considered part of a marginal vein because there were no main longitudinal lateral located vessel that drain blood from distally to proximal, but only varicose like vessels with an oblique or transversal course. Significant reflux were recognized through these perforating veins with stasis on superficial dilated veins. All cases had dysplastic superficial veins with reflux (fig 1).

3) Stasis in deep infiltrating intramuscular venous malformations. Areas of sponge-like, dysplastic venous areas infiltrating muscles were common in these cases. The hemodynamic study demonstrates venous stasis in these areas, mainly in standing position, in which these defects filled with blood and enlarged, compressing the tissues and provoking discomfort. 23 cases (44\%) (fig. 2). 


\section{Anatomic defect}

Dysplastic superficial veins Intramuscular dysplastic veins Marginal vein

Sciatic vein

Normal deep veins

Dilated calf veins

\section{$\mathbf{n}^{\circ}(\%)$}

$52(100 \%)$
$23(44 \%)$
$15(29 \%)$
$4(8 \%)$
$40(78 \%)$
$8(16 \%)$

Hemodynamic defect $\mathbf{n}^{\circ}(\%)$

Table I - Vein anomalies and hemodynamic defects in 52 cases of Klippel-Trenaunay syndrome

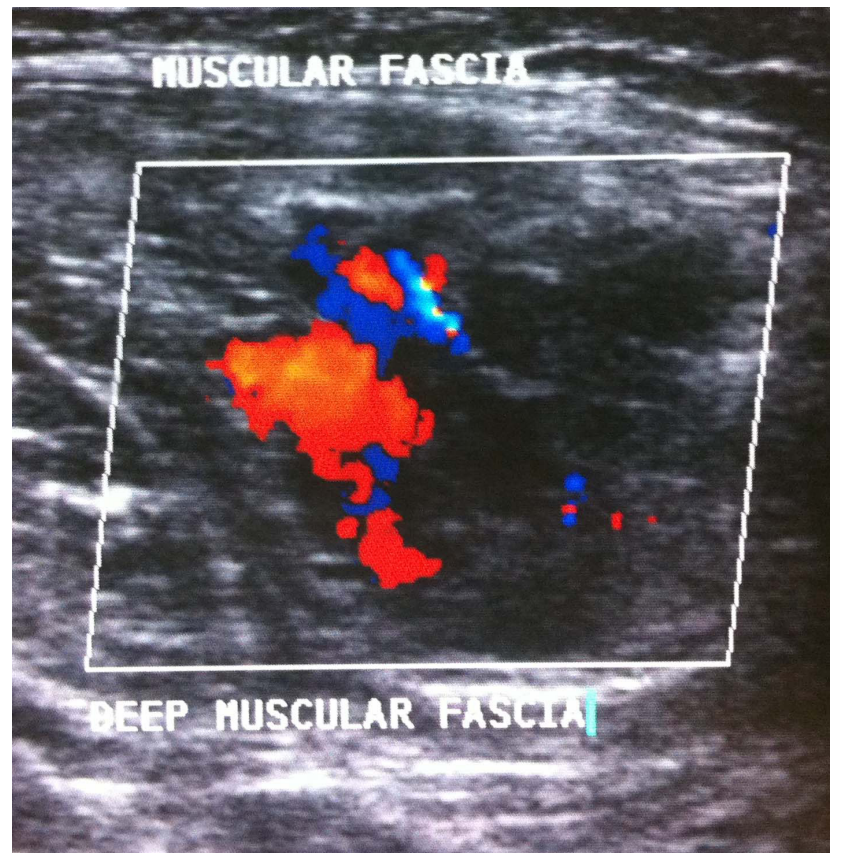

Figure 2 - Duplex scan picture of area of dysplastic veins inside muscle

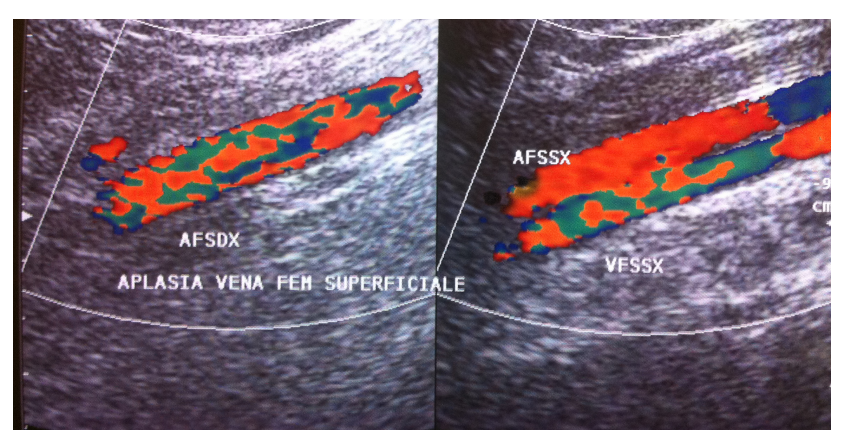

Figure 3 - Duplex scan of femoral vessels demonstrating aplasia of right femoral vein: only the artery is visible (on the left in the picture). Compare with the contralateral side (on the right of the picture) where both vessels are clearly visible.

4) Reflux in marginal vein. These abnormal, lateral veins, always demonstrate reflux. We couldn't find valves in all cases analyzed. In some small marginal veins, reflux was less evident, but always existed. All 4 four types described by Weber were recognized ${ }^{8}$.

- 5) A sciatic vein was found in 4 cases. This was a large, deep, intramuscular, posterior thigh vein connecting with popliteal vein through several branches which ends proximally in several smaller veins, sometimes connecting with branches of deep femoral vein. In all 4 cases no marginal vein, which is located superficially, was found. Even if this vein was large in all cases, no reflux could be demonstrated but only relative flow stasis.

6) Calf veins were dilated in several cases; no reflux but only stasis were noticed.

- 7) Deep vein aplasia and hypoplasia had hemodynamic anomalies related to the adjunctive defects, like superficial dysplastic veins, marginal vein and deep infiltrating intramuscular malformations (fig. 3)

Venous anomalies and hemodynamic defects recognized in this study are summarized in Table I:

\section{Discussion}

KTS is a combination of venous defects (sometimes also of lymphatic anomalies) in different forms, originating different hemodynamic anomalies. That means that there is not a "standard" hemodynamic condition in KTS but it varies according to the anomalies existing. These flow anomalies explain symptoms.

Recognition of the defects by duplex scan is required for a correct, symptoms oriented, treatment strategy. However, for a complete duplex study in KTS, knowledge of the different types of anomalies that may exist is required. The standard study of deep reflux and of condition of 
the saphenous veins, commonly performed, is absolutely incomplete. Search of marginal vein, abnormal perforating veins, hypoplasia or aplasia of deep veins, flow in abnormal

The different types of anatomical and hemodynamic defects explains symptoms. Main discomforts were due to superficial dysplastic veins, especially if these were extremely large and with reflux through huge perforating veins, sited mainly laterally on the limb. These veins, which are different from marginal vein because of their course (not vertical on the lateral edge of the limb by variable and often transversal), represent a truncular defect because of their primitive vascular structure (thin walls with a high tendency to bleed during surgery).

Another cause of severe discomfort with pain was the infiltrating dysplastic venous malformations, sited mainly inside muscles. These sponge like vascular areas are cause of pain due to blood stasis and compression on surrounding tissues and also because of chronic thrombosis inside. These mechanism is demonstrated by permanent increased D-dimer. In case of extended malformation a local intravascular coagulopathy (LIC) may develop with consumption of coagulation factors and lowering of fibrinogen (fig 1).

Marginal vein may be also a cause of discomfort due to stasis distally, especially if the vessel is of large size; small marginal veins may have less stasis and can be also symptom free.

Sciatic vein may be even very large; however, no sciatic vein related symptoms were noticed in our cases.

\section{References}

1) Klippel M, Trénaunay P. Memoires originaux : du naevus variqueux ostéo-hypertrophique. Archives générales de médecine, Paris, 1900;3:641-672.

2) Dogan R, Dogan OF, Oç $M$ et al. A rare vascular malformation, Klippel - Trenaunay syndrome. Report of a case with deep vein agenesis and review of the literature. J Cardiovasc Surg 2003;44(1):95-100.

3) Islam MN, Hossain MA, Rahman MS, Tazmin T, Ali MA, Sultana F, Haque SA. Klippel Trenaunay Syndrome: A Case Report. Mymensingh Med J. 2016;Oct;25(4):776-779.

4) Wang SK, Drucker NA, Gupta AK, Marshalleck FE, Dalsing MC. Diagnosis and management of the venous malformations of Klippel-Trénaunay syndrome. J Vasc Surg Venous Lymphat Disord. 2017 Jul;5(4):587-595. lateral veins (which are different from marginal vein - see above), study of soleal veins and search of sciatic vein are necessary for a complete hemodynamic study o KTS.

Probably the fact that in all our cases no main reflux were noticed because these veins had no main high connections with reflux. However, cases with a main, direct connection to main pelvic venous system has been described; these cases may be symptomatic ${ }^{9}$.

Some sense of heaviness could be related with cases with abnormal dilated calf veins. However, coexistence of other cause of stasis, like superficial abnormal veins, intramuscular malformations and marginal vein made it difficult to distinguish origin of symptoms.

\section{Conclusion}

KTS is a complex, mainly venous, vascular malformation that may create significant discomfort due to hemodynamic anomalies. Duplex scan is the first, most important, diagnostic tool. To study KTS with duplex scan it is mandatory to know which anomalies may exist in this disease in order to perform a specific exam searching for the possible venous defects described before. That means also to study, for example, the muscles and to look for abnormal vessels inside, as also to search marginal vein on the lateral edge of the limb and of sciatic vein in the posterior thigh. A standard venous duplex scan is not sufficient to study hemodynamics of KTS.

5) Qi HT, Wang XM, Zhang XD, Zhang MH, Li CM, Bao SG, Yuan H. The role of colour Doppler sonography in the diagnosis of lower limb Klippel-Trénaunay syndrome. Clin Radiol. $2013 \mathrm{Jul} ; 68(7): 716-20$.

6) Mattassi R. Management of combined venous and lymphatic malformations. Phlebology 2016;23(2):112-119.

7) Markovic JN, Lee BB, Passariello F. The Klippel Trenaunay syndrome. JTAVR 2017;1(2):112-118. DOI: https://doi.org/10.24019/ jtavr.11

8) Weber J, Dafflinger N. Congenital vascular malformations: the persistence of marginal and embryonal veins. VASA 2008;35:67-77.

9) Kenneth J, Cherry KJ Jr, Gloviczki P, Stanson W. Persistent sciatic vein: diagnosis and treatment of a rare condition. J Vasc Surg 1996;23(3):490-497. 


\section{Invited commentaries}

(C) 2017 Fondazione Vasculab impresa sociale ONLUS. All rights reserved.

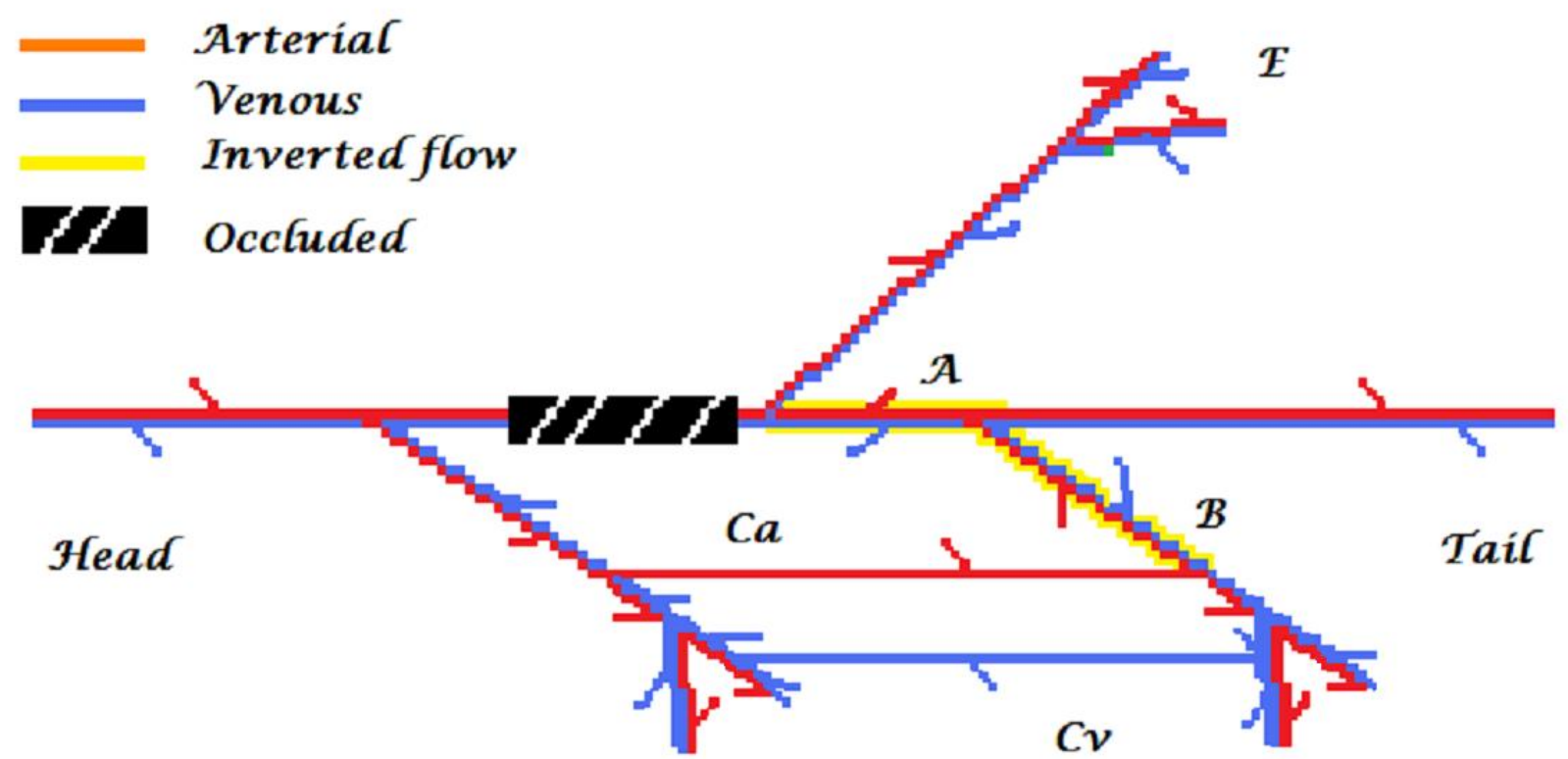

Figure 1 - Collateral circulation by-passing an obstruction in an arterial and venous schematic example. Half arrows point to the direction offlow, red for arteries, blue for veins. Yellow for inverted flow. Black for occlusion. A, inverted main trunk. B, inverted collateral path. E, excluded region. Ca, arterial anastomosis. $C v$, venous anastomosis (from Passariello F. JTAVR 2017;2(1):33-35).

Invited commentary on 'The hypothesis of the toxic effects of the venous collateral circulation' by F Passariello. The venous collateral circulation.

\section{BB Lee ${ }^{1}$}

${ }^{1}$ Professor of Surgery and Director, Center for the Lymphedema and Vascular Malformations, George Washington University, Washington DC, USA. Adjunct Professor of Surgery, Uniformed Services University of the Health Sciences, Bethesda, MD, USA. Visiting Professor of Surgery, Johns Hopkins University School of Medicine, USA. Emeritus Professor of Surgery, Georgetown University, Washington DC, USA. submitted: Nov 9, 2017, accepted: Nov 9, 2017, EPub Ahead of Print: Apr 01, 2018, published: Jun 30, 2018

DOI: 10.24019/jtavr.39 - Corresponding author: Prof. Byung Boong Lee, bblee38@ comcast.net

(C) 2017 Fondazione Vasculab impresa sociale ONLUS. All rights reserved.

The author formulated quite challenging hypothesis of the 'toxic' effects of the venous collateral circulation (TEVCC) based on the fact that the venous collateral circulation is generally spread in more peripheral vessels than in arteries, i.e. in veins, the collateral circulation can be intraparenchymal. Hence, a low concentration oxygen and high concentration carbon dioxide will exert a detrimental effect on downstream tissues around the collateral vessel ${ }^{1}$. 
Indeed, 'abundant intraparenchymal collateral circulation' reminds me of well-known collateral condition among three hepatic veins which seems to be quite vulnerable to its chronic outlet obstruction/stenosis with limited/insufficient compensation despite excellent response to allow a partial -mostly for the living- liver transplantation with minimum morbidity.

Besides, the author drew further bold (?) conclusion for the TEVCC, claiming "the greater the volume of compensation, the greater the toxic damage" based on two different scenarios, one with the post-thrombotic syndrome (PTS) and another with the chronic cerebrovascular insufficiency (CCSVI) ${ }^{1}$.

Interestingly, for the CCSVI, the author cautioned that a venous surcharge inside the brain and the spinal cord system caused by the stenosis/occlusion in the venous cerebrospinal system could have an effect only when a valid collateral circulation giving same clinical impact to the tissue/ brain like PTS.

However, even if CVI/PTS would block normal/ efficient venous drainage to worsen the venous stagnation at the tissue level, it is hard to explain 'well developed' venous collaterals would cause/precipitate the venous stagnation to spread such 'toxic' effect to the tissue, which is odd with the definition/mission of the collaterals. After all, the collaterals are one of fool-proof life lines the nature created to compensate unseen jeopardy.

Although various components of the waste product/ metabolites would exert negative impact to tissue/cellular level to deter normal cellular metabolism when it failed to be evacuated properly (e.g. indolent venous stasis ulcer by CVI/PTS), 'deoxygenated' blood per se can hardly cause/ precipitate 'hypoxic' damage to the tissue. After all, 'low concentration oxygen and high concentration carbon dioxide' in the venous blood is not equivalent to the 'hypoxic' arterial blood.

Indeed, if TEVCC should be based on its/retrograde dissipation at the capillary level, its mechanism should be able to verify based on current Starling's law, and explain this phenomenon of 'retrograde seeping' of the deoxygenated blood from venous capillary into the tissue to cause such direct damage to the tissue/cellular level.

I also wonder how much pressure (gradient) will be needed to overcome the competent (vein) valves along the segment of A \& B to allow retrograde flow to serve as a collateral(?) for segment E! We know substantial number of 'smaller' vein tributaries can remain resisting to the arterialized flow with a good valve competency when we do 'in situ' distal bypass for the critical limb ischemia. Another word, we stop doing the ligation of small twigs/branches routinely when we establish arterial flow following the valve resection along the GSV for the 'in situ' bypass because only a few branches remain as AV shunting route but the majority does not by such unexpectedly strong valve competency against back flow.

Nevertheless, the natural collaterals to warrant sufficient venous drainage are essential not only for surviving through critical period of embryogenesis to complete complicated process of vasculogenesis/ angiogenesis, but also after the birth especially when the defective development should occur to interfere normal venous drainage (e.g. iliac vein aplasia; femoral vein hypoplasia) $^{2}$.

When this natural compensatory mechanism through the collaterals (e.g. marginal/lateral embryonic vein) should fail, deranged venous drainage will cause back fire throughout its target organ/tissues; suprahepatic inferior vena cava (IVC) occlusive disease, also known as primary Budd-Chiari Syndrome (BCS), is the best example of inadequate compensation by natural collaterals to relieve hepatic vein outlet obstruction as the outcome of defective development to resulting in portal hypertension and chronic venous insufficiency ${ }^{3}$.

CCSVI is also well accepted condition of same nature/pathogenesis as a mirror image of primary BCS, caused by defective development along the extracranial venous drainage system: jugular-vertebral-superior vena cava (SVC)-azygos system. But actual impact/clinical outcome in its target/tissue level will be certainly different depending upon the degree and extent of the collaterals to compensate 4 .

Hence, 'maintaining enough collateral/compensatory circulation' route is crucial for the brain circulation system in particular so that it will go through rigorous fool-proof embryological development process till it is fully matured. But, when a defective development should occur during a long delicate evolution/involutional process and a valid collateral circulation is not sufficient to compensate, such unique condition of CCSVI will develop.

Indeed, by the beginning of the fourth week, primitive blood vessels develop from some clusters of angiogenetic cells -Pander's Island- and an extensive network of blood vessels starts as a complex capillary/reticular form of vascular plexuses first before proceeding to the next stage of the axial/truncal venous system development based on four pairs of embryonic cardinal veins ${ }^{5}$.

A pair of anterior cardinal/pre-cardinal veins leads the formation of matured extracranial venous system and complete 'jugular-vertebral-superior vena cava (SVC)' system as well as azygos/hemiazygos vein system together with two other pairs of posterior/post-cardinal and supracardinal veins. And three pairs of posterior cardinal, supracardinal, and subcardinal veins will also have to go 
through much more complicated process to form IVC and further distal limb venous system ${ }^{5}$.

Naturally, the risk of defective development through such long-complicated evolution-involution process among four different pairs of cardinal veins to form one single matured vein system of SVC and IVC is quite high to resulting in unique condition of stenosis/obstruction to hamper the venous drainage from the target organ/tissue.

But in reality, the nature remains more generous(?) to allow a good portion of the embryonic/ cardinal veins

\section{References}

1) Passariello F. The hypothesis of the toxic effects of the venous collateral circulation. (Journal of Theoretical and Applied Vascular Research JTAVR 2017;2(1):33-35. DOI: https://doi.org/10.24019/ jtavr.34

2) Lee BB, Baumgartner I, Berlien P, Bianchini G, Burrows P, Gloviczki P, Huang Y, Laredo J, Loose DA, Markovic J, Mattassi R, Parsi K, Rabe E, Rosenblatt M, Shortell C, Stillo F, Vaghi M, Villavicencio L, Zamboni P. Diagnosis and Treatment of Venous Malformations Consensus Document of the International Union of Phlebology (IUP): updated 2013. Int Angiol 2015;34(2): 97-149.

3) Lee BB, Villavicencio L, Kim YW, Do YS, Koh KC, Lim HK, Lim JH, Ahn KW: Primary Budd-Chiari Syndrome: Outcome of

\section{Invited commentary on 'The hypothesis of the toxic effects of the venous collateral circulation' by F Passariello. PTS, CCSVI-MS: Do intraparenchymal venous detours turn the blood toxic?}

\section{F Schelling 1}

${ }^{1}$ Department of Radiology, Landeskrankenhaus Feldkirch submitted: Nov 8, 2017, accepted: Nov 8, 2017, EPub Ahead of Print: Apr 01, 2018, published: Jun 30, 2018 Conflict of interest: None

DOI: 10.24019/jtavr.40 - Corresponding author: Dr. Franz Schelling, dr.franz.schelling@gmail.com

C 2017 Fondazione Vasculab impresa sociale ONLUS. All rights reserved.

Keywords Venous obstruction, compensatory collateral venous outflow, postthrombotic syndrome, to become a natural escape route to relieve the obstruction as potential collaterals even though they already involuted after normal vena cava formation.

And such collaterals are able to provide reasonable compensation to abort clinical condition in majority (e.g. marginal vein to compensate iliac-femoral vein aplasia/ hypoplasia) ${ }^{6}$. But if it should fail, we do see such clinical condition of CCSVI or primary BCS.

Endovascular Management for Suprahepatic Venous Obstruction . J Vasc Surg. 2006 Jan;43(1):101-108.

4) Lee BB, Laredo J, Neville R: Embryological background of truncular venous malformation in the extracranial venous pathways as the cause of chronic cerebrospinal venous insufficiency. International Angiology 2010 April;29(2):95-108.

5) Lee BB. Venous embryology: the key to understanding anomalous venous conditions. Phlebolymphology. 2012;19(4):170-181.

6) Lee BB. Marginal vein is not a varicose vein; it is a venous malformation. Veins and Lymphatics 2014;3:4050:64-70. DOI: https:// doi.org/10.4081/v1.2014.4050

chronic cerebrospinal venous insufficiency, multiple sclerosis

\section{Sir,}

The literature confronts us with ever new attempts made at explaining the clinical manifestations of puzzling hemodynamic affections by immunological, genetic or other biochemically determined processes.

The idea the intraparenchymal diversion of major compensatory venous outflow volumes might become pathogenic in overtaxing the transport capacity of the blood opens up a new perspective.

The postthrombotic syndromes of the lower limbs and the instances of multiple sclerosis relating to obstructions of major venous drainages of brain and spine show no doubt an intensified collateral venous drainage.

The lesions of neither can yet be said to emerge typically along and via the most overburdened collateral venous pathways of the affected limbs, spinal cords, and brains.

Already in legs affected by posthrombotic syndromes, the ever new forms of interaction of recurrent abrupt with protracted or even continuous flow inversions that present in as variable locations can hardly be explained by certain biochemical circumstances. 
As little as the latter can be said to shed light on the ways in which the hemodynamic deviations clinically manifest.

In multiple sclerosis (MS) and chronic cerebrospinal venous insufficiency (CCSVI), the compensatory collateral venous flow patterns can no more be said to reflect either the ways in which MS lesions spread or to relate to the ways in which CCSVI is diagnosed.

The central vein sign, recently proposed for facilitating earlier and more reliable MS diagnoses, might possibly be adduced for buttressing your hypothesis.

If it is looked at more carefully, the pertinent postmortem evidence can yet again hardly be said to

Answers to the invited commentaries on 'The hypothesis of the toxic effects of the venous collateral circulation' by $\mathrm{F}$ Passariello.

\section{F Passariello 1}

${ }^{1}$ Fondazione Vasculab ONLUS, via Francesco Cilea 280 80127 Naples, Italy submitted: Mar 27, 2018, accepted: Mar 27, 2018, EPub Ahead of Print: Apr 01, 2018, published: Jun 30, 2018 Conflict of interest: None

DOI: 10.24019/jtavr.45 - Corresponding author: Dr. Fausto Passariello, afunzionale@ tiscalinet.it

(C) 2017 Fondazione Vasculab impresa sociale ONLUS. All rights reserved.

I have to thank the Authors for their commentaries to the paper on the toxic effect of the venous collateral circulation (TEVCC) ${ }^{1-3}$, as they were able to discover several points which deserve a thorough discussion.

\section{A common premise}

The TEVCC hypothesis subdivided into 3 parts, almost totally independent on each other: 1) the TEVCC itself; 2) the more peripheral positioning of venous collateral circulation (CC) compared to the arterial one; 3 ) its intra-parenchymal placement. indicate a compensatory collateral venous flow determined lesion spread.

Rather than focusing on MR spectroscopic evaluations of the blood of the lesion veins, focusing on the behavior of the MS lesions relative to their veins might hold the promise of coming closer to the biomechanical and hemodynamic factors which are here brought into play.

\section{References}

1) Passariello F. The hypothesis of the toxic effects of the venous collateral circulation. (Journal of Theoretical and Applied Vascular Research JTAVR 2017;2(1):33-35. DOI: https://doi.org/10.24019/ jtavr.34

Thus formulated criticism could be sound for instance for one of those points and not for the others.

If the venous compensating circulation is more peripheral than the arterial one, it could be just an interesting hypothesis, however not essential to TEVCC. Looking at the similar arterial/venous obstruction in Fig 1, it is easily seen that the arterial collateral circulation is always cephalad compared to the caudal venous one. Even if the previous remark could have no practical meaning, the arterial $\mathrm{CC}$ has generally a greater pressure than the venous $\mathrm{CC}$ and the higher pressure could select more direct arterial paths to destination than the lower venous pressure which could fill a wider and more peripheral venous bed.

\section{Answers to the commentary of Prof. BB Lee}

Prof. BB Lee provided a lot of very interesting remarks which are worth answering in details.

It is hard to explain 'well developed' venous collaterals would cause/precipitate the venous stagnation to spread such 'toxic' effect to the tissue.

The TEVCC hypothesis could be better understood following the following analogy: drugs generally have several beneficial effects as well as they provide too several secondary adverse effects. In the same way, well-developed venous collaterals (see $\mathrm{Cv}$ in Fig. 1) would ease the drainage from territories excluded by the obstruction/stenosis, with an undoubted beneficial effect ( $E$ in Fig. 1). In the same time they could overcharge the territory they traverse (B and $\mathrm{Cv}$ in Fig. 1), increasing carbon dioxide concentration and catabolite content. As it can be easily seen, the two effects occur in different and separate parts of the venous bed: beneficial in $\mathrm{E}$, overcharging in $\mathrm{B}$ and $\mathrm{Cv}$.

'low concentration oxygen and high concentration carbon dioxide' in the venous blood is not equivalent to the 'hypoxic' arterial blood. 
I agree that a decreased $\mathrm{O}_{2}$ and an increased $\mathrm{CO}_{2}$ are somewhat physiological in the venous system, but of course it depends on the range of gas pressures and on the threshold values over which effective gas exchanges are insured from and towards tissues.

'retrograde seeping' of the deoxygenated blood from venous capillary into the tissue to cause such direct damage to the tissuel cellular level.

This is a very interesting criticism about the mechanism by which TEVCC could exert its effect according to the well-known Starling principle ${ }^{4}$. Even if we accept this old pathophysiologic mechanism, the increased venular (and by consequence arteriolar) pressure causes the loss of the reabsorption phase along all the capillary.

Filtration and absorption are generally referred to the balance between capillaries and tissue, separated by a thin semipermeable capillary wall, under the mechanism described by the Starling principle. Starling stated the hypothesis that two gradients oppose across the semipermeable capillary membrane: the hydraulic pressure gradient and the osmotic pressure gradient.

The semipermeable membrane allows the transport of water and smal molecules in both directions, while big molecules (like proteins) cannot traverse it. The difference in proteins concentration in the tissue and in the capillary generate a gradient of osmotic pressure, directed towards the capillary, while the pressure gradient is directed towards the tissue.

As the intra-capillary pressure falls down going from the arteriolar to the venular capillary terminal, while the osmotic pressure gradient and the tissue pressure are constant, the resulting net flow provokes the filtration and absorption of water and cristalloids, respectively at the arteriolar and the venular terminals.

This well-known hypothesis was later better defined ${ }^{5,6}$ and then taken for an undoubted fact by many following researchers. The hypothesis justifies filtration and absorption of water and electrolytes in the extreme tissue territories and is generally presented in this way in almost all medical schools.

However, I would like to remind the interesting discussion we had on Vasculab in 2016 about the revised Starling principle $^{7-9}$. The essential conclusion was that the old Staling's capillary exchange is nowadays obsolete and should be substituted by a three compartments mechanism, where the capillary is in a filtration phase along almost its length and fluid is almost completely absorbed by lymphatics, i.e. the old mechanism of capillary reabsorption at the capillary venous end should be considered just a myth and not true.

The main driving variable is then the venular pressure, which causes the entity of filtration. According to this interpretation context, the system is highly conditioned by the venular pressure. Consequently, the increased venous pressure in the non-draining territories reflects itself on the venous extremity of the capillary, conditioning the direction (towards the tissue) and the intensity of filtration.

How much pressure gradient will be needed to overcome the competent (vein valves) along the segments $A \& B$

High pressure is able to force venous valves to cause inverted flow segments (A \& B in Fig. 1), where however the obstruction does not involve the same segments, at least completely, as they must be completely or partially patent to insure the collateral flow. Thus valves can be forced directly by pressure or by venous dilatation. As regards the inversion of several venous tributaries in the "in-situ bypass", it's worth noting that once the first A$\mathrm{V}$ anastomoses are realized, a competitive flow occurs so that additional branches could also not be recruited. An additional remark deals with the level of pressure needed to force or disrupt the valve at the onset of the incompetence, while once the retrograde flow is established the exerted pressure can be much lower. Furthermore, an "in-situ bypass" is generally performed on an almost healthy greater saphenous vein (GSV), where valves can have a strong resistance to high pressure, while after a deep venous thrombosis (DVT) wall changes can extend also to nearby veins, which could exhibit altered elastic properties.

An increased pressure regimen is commonly detected in post-thrombotic syndrome (PTS) or in acute thrombotic events in lower limbs. Venous pressure can be easily measured non-invasively using the Bartolo's method ${ }^{10-12}$, using a pressure cuff and detecting the level of venous pressure when a wind-like noise appears. According to Franceschi ${ }^{13}$ venous pressure must be measured in the supine position. Analogous experimental results were reported in the past following invasive phlebodynamometry $^{14}$

Venous collaterals in embryogenesis and defective development...the nature remains more generous...reasonable compensation to abort clinical condition in majority...

Venous collaterals have of course a beneficial effect in several phases of vascular development as well as in chronic cerebro-spinal venous insufficiency (CCSVI) compensation. However, compensating veins can be classified at least into 2 groups:

1) Deep veins, generally with almost the same caliber of the occluded or non-well-developed vein. They generally pre-exist and convey almost the same amount of blood (cardinal veins, IVC, Open vicarious Path, Flat 1, all inside the N1 network) ${ }^{15-18}$;

2) Diversion to veins of the superficial network, i.e. saphenous or extra-saphenian segments in the lower limb, where generally the caliber as well as the amount of blood can be much lower (GSV, SSV, marginal vein). (Open vicarious Path, Type I or III according to the Graph Classification ${ }^{18}$.

These 2 types can have a completely different hemodynamic effect. In the $1^{\text {st }}$ case the compensatory vascular bed is generally adequate and it extends almost totally inside big conducting veins but out of tissues. In the latter instead, the vascular bed extends towards non-conducting superficial veins, which are generally of inadequate caliber. These venous diversions could 
influence in a greater extent the capillary circulation. Occasionally, these veins can convey on the contrary a great flow.

\section{Answers to the commentary of Dr. F Schelling}

Dr. F Schelling commentary essentially is focused on the claimed venous $\mathrm{CC}$ positioning more in periphery and its devised consequences. inversions...

...recurrent abrupt with protracted or even continuous flow

This Multiple Sclerosis (MS) observation matches the common idea that in PTS more relevant clinical pictures are seen when mixed remnants of obstruction coexist with incompetent segments (valve destruction) of deep veins. In addition, it is clear that any acute or chronic obstruction always shows one or more inverted flow segments (A \& $\mathrm{B}$ in Fig. 1), which are essential to the development of the compensation.

...the compensatory collateral venous flow patterns can no more be said to reflect...MS lesions spread...central vein sign...focusing on the behavior of the MS lesions relative to their veins...

I have not Dr Schelling's long-lasting wide experience in MRI and post-mortem investigations in MS nor his clinical insight in this disease to catch with competence the association between MS lesions and the patterns of venous compensation.

I agree with his proposal of a deeper study about the spatial relationship between MS lesions and their nearby veins.

I would like just to underline that the hemodynamical effects of a hampered drainage impinge also at distance from the excluded territory and in tissues around but also far from the compensating flow.

They are due indeed to the greater venular-arteriolar pressure, which cause the prevalence of the filtration over the reabsorption at the capillary level. Thus in search for a hemodynamic effect, upstream for excluded territories and just around the compensatory veins for the traversed territories, a much greater range should be considered.

\section{References}

1) Passariello $F$. The hypothesis of the toxic effects of the venous collateral circulation. (Journal of Theoretical and Applied Vascular Research JTAVR 2017;2(1):33-35. DOI: https://doi.org/10.24019/ jtavr.34

2) Lee BB. Invited commentary on 'The hypothesis of the toxic effects of the venous collateral circulation' by F Passariello. The venous collateral circulation. JTAVR 2017;2(3):EPub Ahead of Print. DOI: http://doi.org/10.24019/jtavr.39

3) Schelling F. Invited commentary on 'The hypothesis of the toxic effects of the venous collateral circulation' by F Passariello. PTS,
CCSVI-MS: Do intraparenchymal venous detours turn the blood toxic? JTAVR 2017;2(3):EPub Ahead of Print. DOI: http://doi.org/10.24019/ jtavr.40

4) Starling EH. On the absorption of fluids from the connective tissue spaces. J Physiol 1896;19:312-326.

5) Landis EM. Micro-injection studies of capillary permeability. II. The relation between capillary pressure and the rate at which fluid passes through the walls of single capillaries. Am J Physiol 1927;82:217-238.

6) Pappenheimer JR, Soto-Rivera A. Effective osmotic pressure of the plasma proteins and other quantities associated with the capillary circulation in the hind-limbs of cats and dogs. Am J Physiol 1948;152:471-491.

7)The revised Starling principle. Vasculab Message Archive. DOI: 10.24019/2016.RevisedStarlingPrinciple - Msgs - , , 2016. https:// it.groups.yahoo.com/neo/groups/vasculab/conversations/messages/ - , Mar, 2016. Accessed on line on Apr 1, 2018. A (free) subscription is required.

8) Levick JR, Michel CC. Microvascular fluid exchange and the revised Starling principle. Cardiovascular Research 2010;87:198-210. doi:10.1093/cvr/cvq062

9) Bates DO, Levick JR and Mortimer PS. Starling pressures in the human arm and their alteration in postmastectomy oedema. Journal of Physiology 1994;477(2):355-63.

10) Bartolo M, PhleboDopplertensiometry, a noninvasive method for measuring venous pressure. Folia Angiol. 1977;25:199-202.

11) Bartolo M, Nicosia PM, Antignani PL, Raffi S, Ricci S, Marchetti M, Pittorino L. Noninvasive venous pressure measurements in different venous diseases. A new case collection. Angiology. 1983;34(11):717-23.

12) Bartolo M. Antignani PL, Nicosia PM, Todini AR. Noninvasive venous pressure measurement and its validation. Int Angiol 1988;7:182-89.

13) Franceschi C, Cappelli M, Ermini S, Gianesini S, Mendoza E, Passariello F, Zamboni P. CHIVA: Hemodynamic concept, strategy and results. International angiology $2016 \mathrm{Feb} ; 35(1): 8-30$.

14) Lee BB et al. Venous hemodynamic changes in lower limb venous disease: the UIP consensus according to scientific evidence. International Angiology 2016 June;35 (3):236-352.

15) Passariello F. VNET (RETE VENOSA). Software di disegno assistito e valutazione diagnostica della mappa venosa ecografica degli arti inferiori. [VNET (VENOUS NET). Computer aided design software and diagnostic evaluation of ultrasound venous mapping of the lower limbs.]. Min. Angiol. 1991; 16:373-4.

16) Passariello F. La Mappa Venosa Ecografica degli Arti Inferiori. Rilevazione, Teoria e Realizzazione Informatica. [The ultrasound venous map of the lower limbs. Detection, theory and implementation.]. Min. Angiol. 1991; 16; Suppl. 1 al N. 2, 299.

17) Passariello F. Il modello VNet per la simulazione chirurgica venosa. [The VNet Model for the venous surgical simulation.]. Minerva Cardioangiol 2006;54(Suppl. 1):132-3.

18) Passariello F. The Graph Classification for the venous system of the lower limb. Poster to the XVI world meeting of the Union Internationale de Phlebologie (UIP50, Monaco Principate, 2009). DOI: https://doi.org/10.24019/2009.UIP50GRAPH 


\section{Memorial pages}

(C) 2017 Fondazione Vasculab impresa sociale ONLUS. All rights reserved.

\section{In memory of Prof. Marco Apperti}

\section{G Quarto $^{1}$, A Sellitti ${ }^{2}$}

${ }^{1}$ Professor of General Surgery - University of Naples

Federico II, Napoli, Italy

${ }^{2}$ Angiology and surgical phlebology Unit, Department of onchologic surgery, Ospedale di Pagani, Salerno, Italy submitted: Mar 24, 2018, accepted: Mar 24, 2018, EPub Ahead of Print: Mar 28, 2018, published: Jun 30, 2018

DOI: 10.24019/jtavr.44 - Corresponding author: Prof. Gennaro Quarto, gquarto@unina.it

() 2017 Fondazione Vasculab impresa sociale ONLUS. All rights reserved.

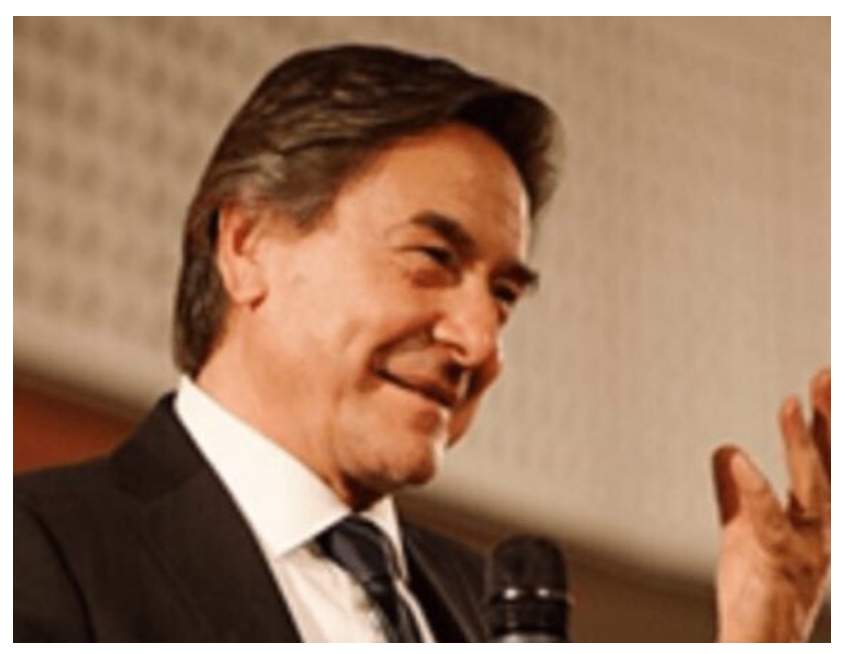

Figure 1 - Prof. Marco Apperti

Prof. Marco Apperti passed away in the evening of Mar 8 2018, while visiting his daughter, leaving his beloved family and his friends and colleagues.

Marco Apperti was born in Maddaloni (Italy) on Aug $31,1947$.

After the high school diploma at the Giordano Bruno High School of Maddaloni, he enrolled at the Faculty of
Medicine and Surgery at the University of Naples Federico II, graduating in 1974 and earning at the same University the specialization degree in Vascular Surgery in 1977 and then in General and Emergency Surgery at the Second University of Naples (SUN).

He was Professor of General Surgery at the department of Medicine and Surgery of the SUN, in the Degree Course in Medicine and Surgery in Caserta, and Professor of Surgical Semeiotics at the School of Specialization in General and Emergency Surgery of the SUN until 2011.

In his career as a lecturer and researcher, he always showed a great passion for venous and lymphatic diseases and for the treatment of ulcerative lesions, teaching Phlebology at Advanced Courses, Masters and Research Doctorates not only at Campania Universities, but also at University of Perugia and University of Camerino.

The passion for phlebology made Prof. Apperti one of the pillars of the Italian Society of Phlebology, one of the oldest and most representative Italian Phlebology scientific societies, of which he was President in the biennium 2014-15, Past-President in the 2016-17 and currently a member of the Executive Board.

His passion for teaching led him to create the Italian School of Phlebology, which he was Director of, with the aim of providing an adequate training-professional curriculum to those who, young and old, decided to devote themselves to the treatment of veins and lymphatics.

With his studies and his researches, he developed phlebology both in the diagnostics, with the transillumination of the superficial venous system, but also in the therapeutic field, with his studies about hemodynamics of telangiectasiae and the treatment of lower legs ulcers.

Among his prestigious professional positions we would like to remind his scientific direction of CoRe Med Phlebology and his membership to the Scientific Board of the Inter-University Research and Education Center in Phlebology of the University of Perugia and to the Board of the international scientific journal "Annali Italiani di Chirurgia", directed by prof. Nicola Picardi.

Prof. Apperti combined his competences of teacher, researcher and scientist with uncommon human and cultural gifts, cultivating a sincere friendship with his colleagues 
and behaving in every occasion with elegance, which was inherent to him.

With his demise, the world of phlebology and the scientific community lose one of their pillars, but his human and scientific teaching will continue to live among his many students and among the many friends in the SIF and in the academic world; in this way they want to remember him, a gentleman who practiced medical arts with passion, in the constant search for "Why", quality that distinguishes the simple teacher from the scientist and researcher, who not only knows, but knows how to do, knows how to teach and keeps his mind continuously looking for "why" and as of natural phenomena.

Goodbye, Prof. Apperti, YOU do not leave a gap in the Italian Society of Phlebology, because your many

\section{In memory of Prof. Dino De Anna}

\section{Gasbarro ${ }^{1}$}

${ }^{1}$ Vascular and Endovascular Surgery Unit. S. Anna University Hospital, Ferrara, Italy submitted: Apr 6, 2018, accepted: Apr 6, 2018, EPub Ahead of Print: Apr 6, 2018, published: Jun 30, 2018

DOI: 10.24019/jtavr.47 - Corresponding author: Prof. Vincenzo Gasbarro,gsv@unife.it

(C) 2017 Fondazione Vasculab impresa sociale ONLUS. All rights reserved.

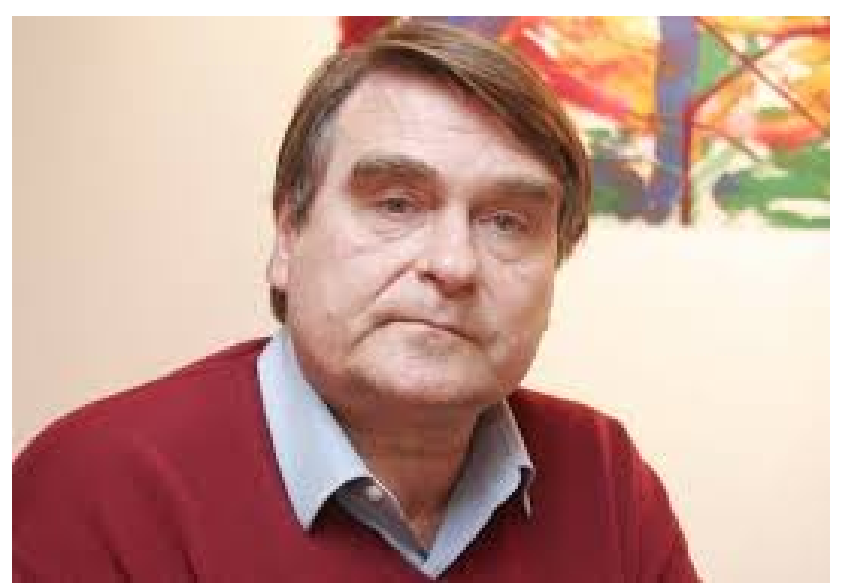

Figure 1 - Prof. Dino De Anna friends who guide it today, will always ask, in the moments of difficult choices, as rightly said our common friend Antonio Sellitti, "Marco, in this situation, what would you do?"

Goodbye, Marco, from all of your friends!

\section{Gennaro Quarto \\ SIF President}

Antonio Sellitti

SIF Treasurer

On behalf of the Executive Board of the Italian Society of Phlebology (SIF)

How can I try to tell about the life of Dino?

It's not easy to express the sense of pain, anger, grief, and void which feels right now someone who owes Him a lot, not to mention everything?

How not to be overwhelmed by emotions and give readers a clear and honest image of Dino De Anna?

With this emotional turmoil I'm about to tell who He was and what Dino De Anna did for italian and international phlebology.

Born in Cordenons, Pordenone, 72 years ago, He graduates from School of Medicine at University of Ferrara, thus he continues to cultivate his passion for rugby, who plays at the highest level, both with Petrarca Padova and Sanson Rovigo, winning two major series, in 1976 and 1977.

As a young resident he meets Mirella, Prof. Donini's trusty secretary, who will become his wife.

The Master, keen of the physical prowess of the young rugby player and knowing him interested in surgery, after a quick interrogatory, typical of his style, offers Him to become a scholar at Department of Surgery at University of Ferrara.

And so begins the university career of Dino De Anna.

In that years he completes the fellowship in general surgery, pediatric surgery and vascular surgery.

Always been passionate of venous and lymphatic pathology, picks up and widens the knowledges of his Masters in this specific field. We owes to Him the intuition to approach phlebology to aesthetical medicine, thanks to the relationship of affection and respect that was born 
between our School and Carlo Alberto Bartoletti, pioneer of aesthetical medicine in Italy.

Under the push of our Teacher, Prof. Donini, in November 1986 He founded in Ferrara the Italian Society of Phlebolymphology, becoming then its President from 2000 to the 2003 .

He also makes himself mediator in the process of approach of the greatest Italian Phlebologic Societies, that will culminate with the birth of the Italian College of Phlebology (CIF) in July of 1996.

The international conferences of phlebolymphology he wanted and organized in the second halves of the eighties are still remembered and they saw the presence of the gotha of the world of phlebology from Stemmer to Van deer Stricht, from Simkin to Altman Canestri, from Cockett to Hobbs, from Partsch to Ouvry.

He has directed later the institute of Surgical Pathology at the University of Sassari in the half of nineties and the Institute of General Surgery at the University of Udine a few years later.

Eclectic and dynamic man as He was, He alternated the university career to politics, covering the position of Senator of the Italian Republic from 1996 to 2001.
In phlebolymphology his studies are remembered on the the surgical therapy of the venous ulcer and the external valvuloplasty of the saphenous - femoral junction.

Mention should also be made of his numerous scientific contributions in diagnosis and treatment of lymphoedema. President of Honor of the Italian College of Phlebology from 2011.

He left us on last March 29. I am certain that these few lines don't describe in an exhaustive way the personality and the sensibility of a Man that in every circumstance has always shown his honesty and good sense.

We remember his clear and direct speech. Of the so many memories that I will bring with me inside, selfmockery and modesty are certainly the most characterizing notes of the strong personality of Dino.

Who has had the fortune as me, to know Him and to frequent Him, will have of Him a strong and indelible memory of Man and Teacher.

Vincenzo Gasbarro M.D.

Professor and Chief

Vascular and Endovascular Surgery Unit

S. Anna University Hospital. Ferrara, Italy 
Index of Authors 2017

Lee BB …............................................... 153

Allegra C

145 Lun B

Antignani PL

117,145

Marhl M

Boccardo F

Botta $\mathrm{G}$

Mattassi R

Campisi CC

Nettuno A

Campisi C

Cappelli M

Quarto G

Celentano M

Passariello F

$9,33,59,97,119,123,156$

Coscia V

11

Peruzzi G

Dessalvi S

21,83

Pozzoli W

Ermini $\mathrm{S}$

Rastel D

Recek C

Franceschi C

27,97 Schelling F

Gasbarro V

$21,83,160$

Sellitti A ....

Grenier E

77 Tonetti L

Izzo M

Villa $\mathrm{G}$

\section{Index of Reviewers 2017}

We thanks the Reviewers for their volunteer support to the Journal:

\section{History and philosophy of Biology}

Maurizio Balistreri, Maria Conforti, Umberto di Porzio, Maël Montevil.

\section{Biology and Medicine}

Pier Luigi Antignani, Serge Chanchole, Vincenzo Coscia, Giovanni Criscuolo, Stefano Ermini, José Maria Escribano, Francesco Ferrara, Byung Boong Lee, Fabrizio Mariani, Mark Malouf, Michele Papa, Fausto Passariello, Franz Schelling, Massimo Vaghi. 
Fondazione Vasculab impresa sociale ontus

\section{www.vasculab.eu}

\section{DONA IL TUO 5 PER MILLE}

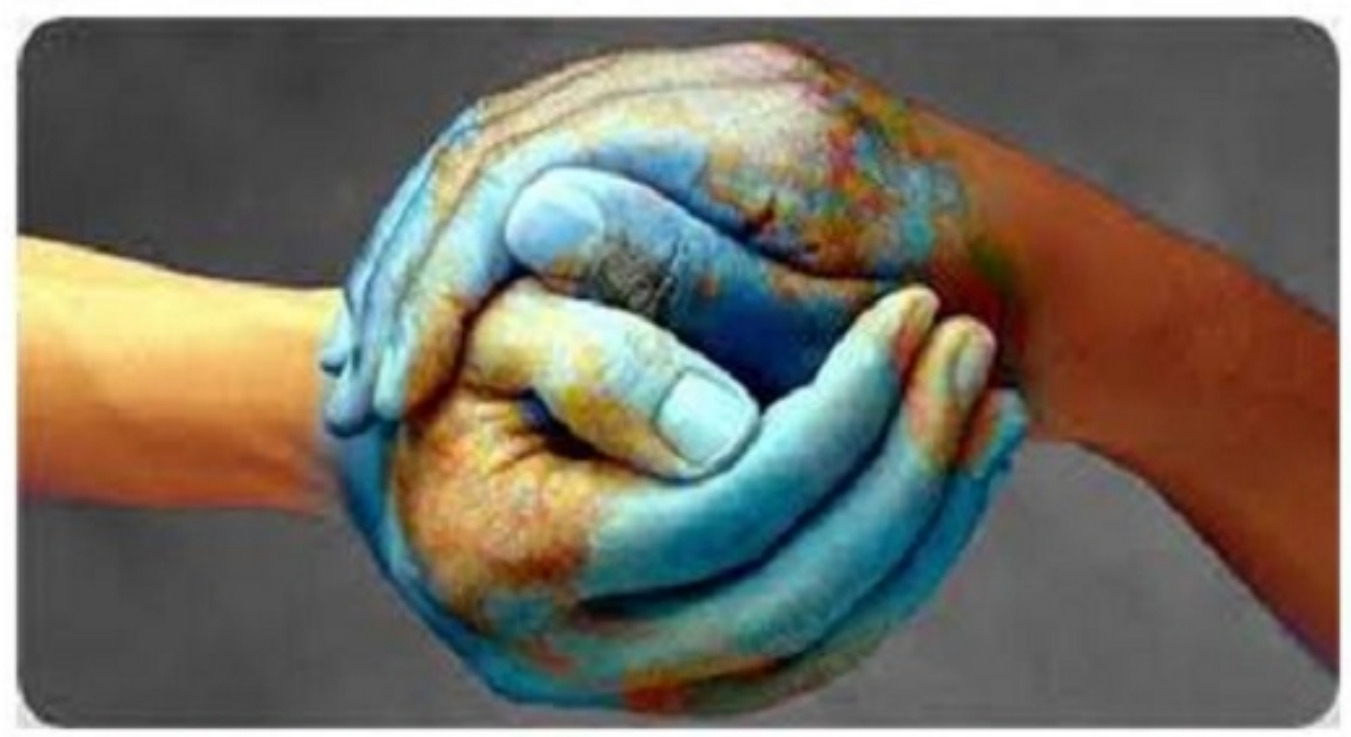

Sostieni le iniziative della Fondazione Vasculab ONLUS

- Ricerca scientifica e divulgazione in Medicina

- Metodi alternativi alla sperimentazione animale

- Missioni mediche umanitarie all'estero

Inserisci il Codice Fiscale della Fondazione

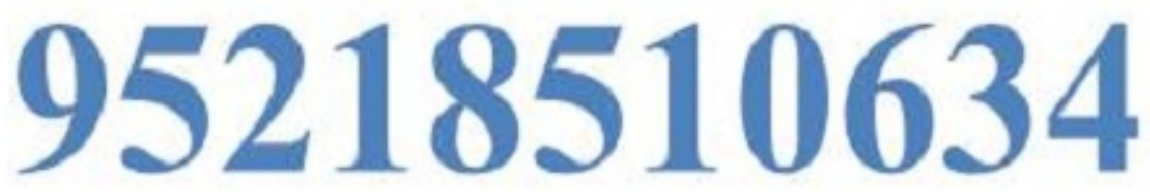

nella dichiarazione dei redditi (Unico o 730)

nella sezione del 5 per mille

Fondazione Vasculab impresa sociale (ONLUS)

Email fondazione@vasculab.it

tel/fax: +390817144110 cell +393356250756

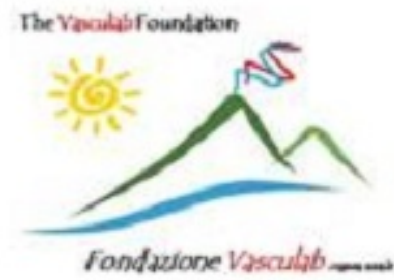




$$
\text { ber }
$$




\section{Fondazione Vasculab}

impresa sociale ONLUS. CF 95218510634. The Vasculab Foundation is a non-profit organization aimed to scientific research and to social solidarity.

\section{Donations}

You can donate using several methods: cash or bank check during a Vasculab associated event - by credit card - by bank transfer See at the page http://www.vasculab.it/ common/donate.htm

\section{Supporting membership}

Even a minimal donation gives you the status of Supporting membership. Send by email your name and complete address and additional info about the type of help offered with your donation. By default, contributes are given generically to all the institutional activities of the Foundation.

But if you want, you can choose to give your contribute to support: - scientific research - a young researcher - a specific and already active scientific research of Vasculab (specify which one by email) - the organization of a specific educational/scientific event (specify which one by email) - alternate methods to animal experiments in scientific research - solidarity and health missions in low income countries

\section{Ask for a receipt}

Add other data in order to emit a correct receipt:

name of donating people or company, address, VAT number or any other info, according to your country fiscal laws.

\section{VASCULAB, The Vascular List}

Vasculab is a free-access non-profit vascular mailing list on Internet

VASCULAB was born in 1990.

Since August 2015 VASCULAB is the official mailing list of the "Fondazione Vasculab impresa sociale ONLUS".

\section{TOPICS}

Vascular Diseases Discussion List, Vascular Ultrasound Diagnosis, Vascular Biomechanics, Chiva Discussion List (Chirurgie Hemodynamique de l'Insuffisance Veineuse en Ambulatoire), Haemodynamic Venous Map (MEV), Minimal MEV, V N e t, the Model of the Venous Circulation, Micro-Circulatory Disorders,
Lymphatic Diseases, Lasers in Vascular Diseases, Foam and Sclerotherapy, Vascular Malformations.

\section{VASCULAB RULES}

1) VASCULAB is a restricted Yahoo! Message List, open only to members

2) Active participation to this List is subjected to approvation of the Moderator.

3) Accepted members, mainly people of several professions involved in the management of vascular diseases, must respect generic "Netiquette" rules (Net Etiquette), as also the specific rules and the discussion topics listed in the first message they receive from the List.

4) Topics are many, but they all are scientific ones.

5) Direct consultation with patients is not allowed.

6) Drugs or medical devices promotion is forbidden inside the messages (as also hidden in messages, e.g. mail address of companies and their web sites).

7) Outside of the messages and clearly separated from them, commercial information can be given, though generally subjected to a fee.

If these rules do not comply with you, it's better to unsubscribe. Participating actively to the discussions automatically implies the Vasculab Policy agreement.

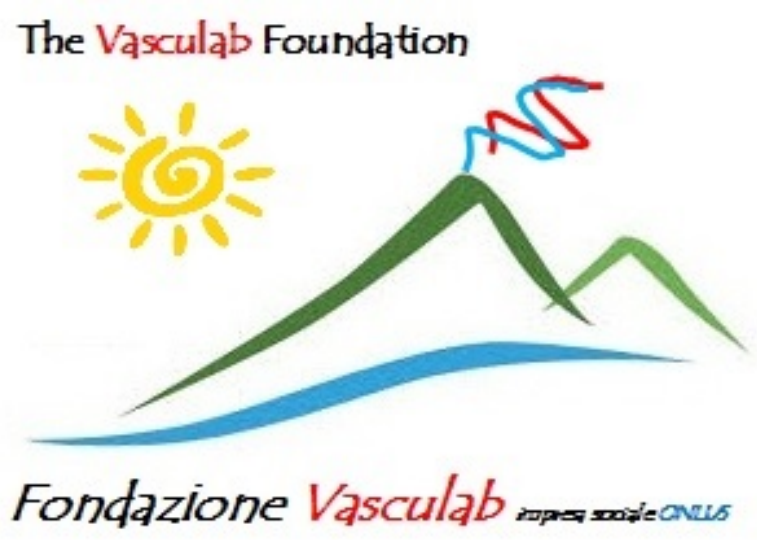

The Vasculab Foundation 


\section{Journal of Theoretical and Applied Vascular Research The Official Journal of the Vasculab Foundation}

\section{Volume 2 Nov 2017 Issue 3}

Editorial Board

Vascular News

Chronic venous disorders: from macrocirculation to microcirculation

PL Antignani

Non-animal ultrasound phantoms for device testing and training

F Passariello

Dimensional analysis in the venous system

F Passariello

Contribution of the calf pump and foot pump to the return of venous blood from the lower extremity C Recek

Surgical prevention of Lymphedema following lymph node dissection: LY.M.P.H.A. technique.

F Boccardo, S Dessalvi, G Villa, CC Campisi, C Campisi

Does Rivaroxaban have a fibrinolytic effect?

PL Antignani, C Allegra

Hemodynamics in Klippel-Trenaunay Syndrome

R Mattassi, W Pozzoli

Invited commentaries

Invited commentary on 'The hypothesis of the toxic effects of the venous collateral circulation' by F Passariello.

The venous collateral circulation. BB Lee

Invited commentary on 'The hypothesis of the toxic effects of the venous collateral circulation' by F Passariello.

PTS, CCSVI-MS: Do intraparenchymal venous detours turn the blood toxic? F Schelling

Answers to the invited commentaries on 'The hypothesis of the toxic effects of the venous collateral circulation' by F Passariello. F Passariello

Memorial pages

In memory of Prof. Marco Apperti G Quarto, A Sellitti

In memory of Prof. Dino De Anna V Gasbarro

Index of Authors and Reviewers 2017

Table of contents 